\title{
Income-Generating Products for People with Disabilities in the Majority World: Understanding the Complexities of Participatory Design in Rural Uganda
}

\author{
by \\ Amanda Cox
}

\begin{abstract}
A thesis submitted to
the Faculty of Graduate and Postdoctoral Affairs in partial fulfillment of the requirements for the degree of
\end{abstract}

Master of Design

in

Industrial Design

Carleton University

Ottawa, Ontario

(C) 2014, Amanda Cox 


\begin{abstract}
This thesis is based on examining income-generating devices for people with disabilities in Uganda. The project involved having solar-charging kiosks manufactured in the Kasese region. These devices were given to people with disabilities in the area by a local organization so that they could start a business charging mobile phones and generate an income for their family. The researcher looked for insights in multiple areas, such as if they could generate an adequate income, whether it created independence or dependency, if the design of the device was appropriate for the context, and gaining a better understanding of the complexities of this type of project. The research was conducted using questionnaires filled out by volunteers of the local organization, as well as observations and in-person interviews during two weeks of field-work in Uganda. The findings show that these types of projects are complex, and that more case studies would help to shed light on this emerging design field. The researcher also discovered many insights related to the device itself, including: people would bring it inside at night to light their homes; people had differing abilities to generate income; and recipients needed multiple revenue sources to earn a living.
\end{abstract}

Keywords: Design for the Other 90\%, Design with the Majority, Kasese, Uganda, Africa, Developing Countries, Underserved Communities, Extreme Poverty, International Development, People with Disabilities, Assistive Devices, Income-Generation, Participatory Design 


\section{ACKNOWLEDGMENTS}

Over the past two years, many people have helped and supported me to finish my master's degree (especially during the final stages writing of this thesis).

My Peers - Anne, Laura and Kim - I know we don't get to see each other as often as we would like, but I'm glad we stayed in touch since we finished our undergrad. Your lives and careers have all been an inspiration to me as a designer. Thank you to everyone in the MDes program, you were a great source of knowledge, and the venting that we shared over our individual and group troubles was immeasurable in its contribution to my sanity. Thanks Jessie, Mike, Jay, Abeer, Weiwen, Neda, Neil, Maya, Anthony, and Dea. Jenna, I'm glad you stayed in Ottawa so we could hang out, you're the best baker I know!

My Family - Thanks Mom! You're my rock... I couldn't have got through any of this without you (or our good friends, Ben and Jerry!). Shanni, even though you were far away, our conversations were always lovely, and you always made me feel understood, you're a great sister!

My Friends - Jenn, Jessy and Katie - I feel like I've known you my whole life (and I pretty much have), and I don't know what I would do without you guys (and a few cocktails!). Thank you for giving me the down-time that I so desperately needed at times when everyone was just a bit stressed. Steve - You put up with me, even at the worst of moments. You helped read through all of my chapters, multiple times, and picked me up when I was down. You always made me feel that I could do anything, and that my dream to work in Africa (or whatever I wanted to do) was possible. Thanks!

My Supervisors - Bjarki Hallgrimsson, thank you for all of your guidance and support. I wouldn't have done as well without all of the late-night emails, long sit-downs and random hallway questions that I asked you between classes. Thank you for always being there to answer my questions or guide me in the right direction. Blair Rutherford, thank you for sharing your wisdom about everything related to Africa and international development, your insights helped to shape my thesis. I also appreciate your quick replies to emails and detailed editing, very helpful!

CanUgan and KADUPEDI - Navin Parekh, thank you for all of your guidance, your vast knowledge of Ugandan culture was invaluable to my research. A huge thank you to Baluku Peter and Bwambale Robert (and everyone else at KADUPEDI), without all of your time and effort, none of this would have been possible.

Fourth Year Industrial Design Students - I would like to thank last year's students for their hard work on this project: Ruby Hadley, Alyssa Wongkee, Carmen Liu and Andrew Theobald. I would especially like to thank Carmen and Andrew, for designing the income-generating devices (the grinding attachment and the solar-charging attachment, respectively) used in my research. Also, thanks to Jennifer Vandermeer, Zoe Krug, Charles Williams and Luis Garcia, for working with me throughout the year on this project, and spending a terrific two weeks together with me in Uganda. 


\section{TABLE OF CONTENTS}

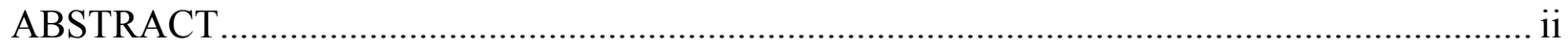

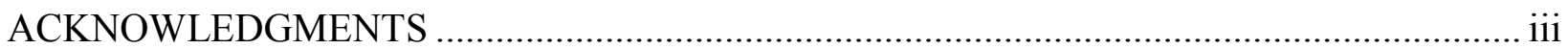

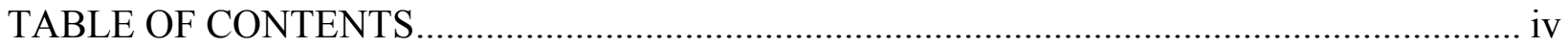

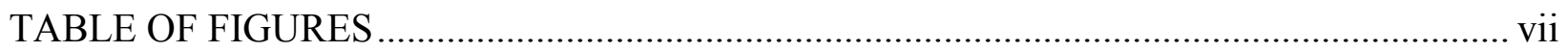

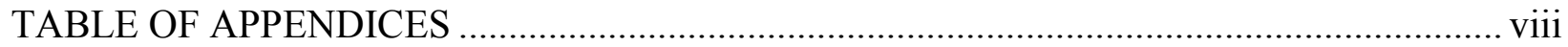

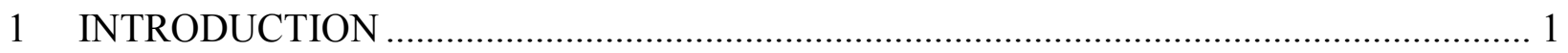

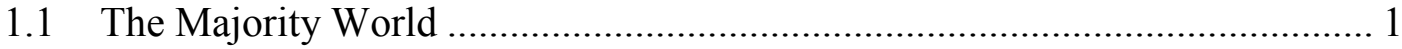

1.2 The Design Innovation for Disability in Kasese Project.............................. 2

1.2.1 Project Origins and Key Collaborators .......................................... 2

1.2.2 Last Year's Projects (September 2012 - April 2013) ......................... 3

1.2.3 This Year's Projects (September 2013 - April 2014) ........................ 5

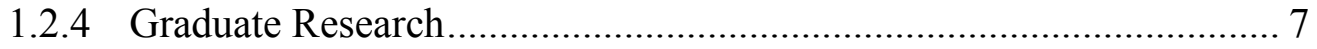

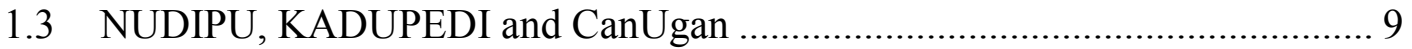

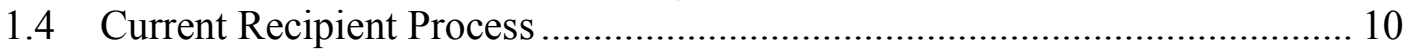

1.5 Scope of the Study ................................................................................ 12

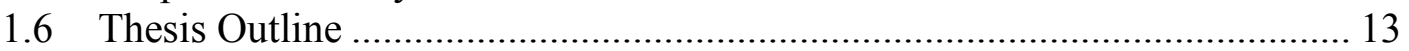

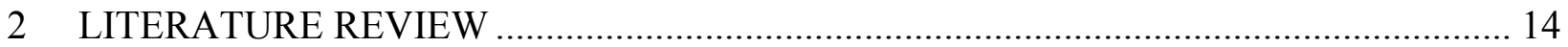

2.1 Extreme Poverty and International Development ................................... 14

2.1.1 Extreme Poverty ...................................................................... 14

2.1.2 International Development and Foreign Aid .................................. 14

2.1.3 How Disability and Poverty Affect Access to Human Rights ........... 16

2.1.3.1 Millennium Development Goals ..................................... 16

2.2 Design with the Majority and Participatory Design................................... 17

2.2.1 The History of Design with the Majority ...................................... 17

2.2.2 Recent Trends and Case Studies ................................................. 18

2.2.2.1 Jaipur Foot .................................................................. 19

2.2.2.2 One Laptop per Child .................................................. 20

2.2.2.3 Drip Irrigation System ............................................... 21

2.2.3 Methods for Participatory Design ............................................... 21

2.3 Poverty and Disability in sub-Saharan Africa and Uganda ........................ 26

2.3.1 Assistive Devices for People with Disabilities in Uganda ................ 29

2.3.2 Telecommunications and Infrastructure in Uganda ....................... 31

2.3.3 The Informal Sector and the African Artisan ................................. 32

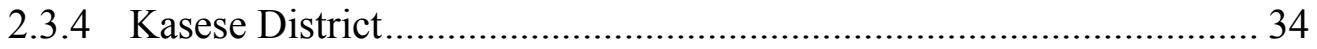

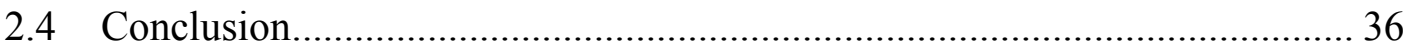




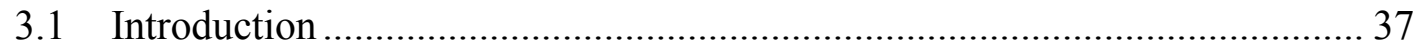

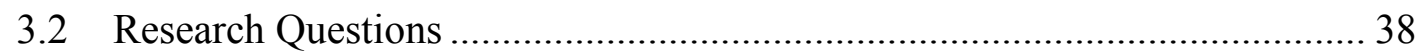

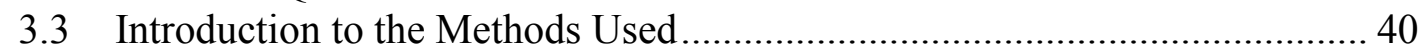

3.4 Initial Questionnaire (Before Recipient Selection) ....................................... 45

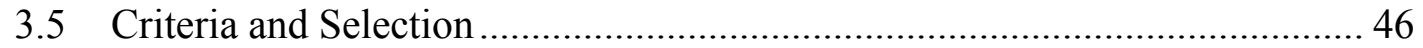

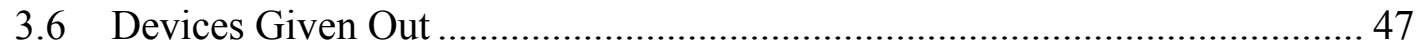

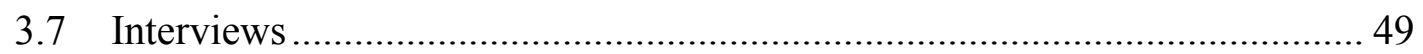

3.7.1 Meeting with Device Recipients ....................................................... 49

3.7.2 Meetings with Other Stakeholders ……………….......................... 51

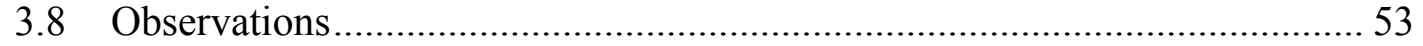

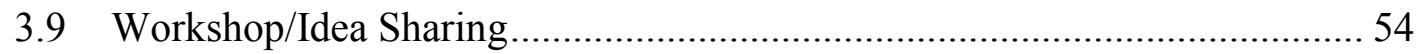

3.10 Secondary Questionnaires (After the Devices Were Given Out) .................. 55

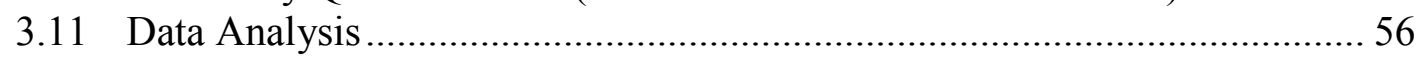

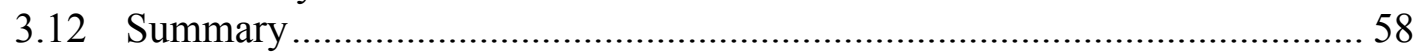

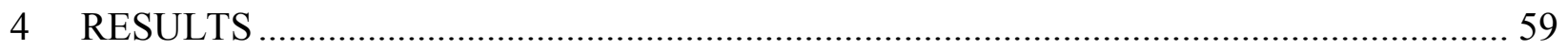

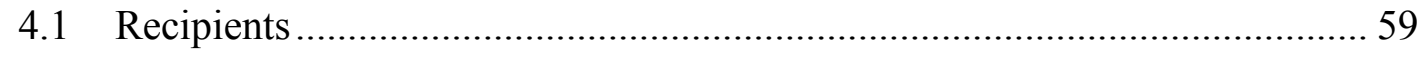

4.1.1 Environment and Context............................................................... 59

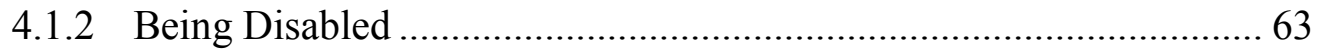

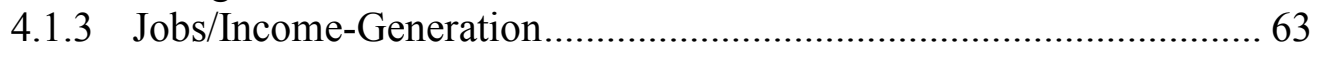

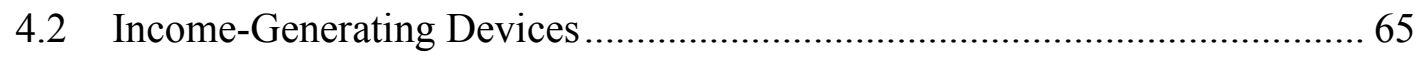

4.2.1 Income Generating Attachments ....................................................... 65

4.2.1.1 Solar-Charging Device ...................................................... 65

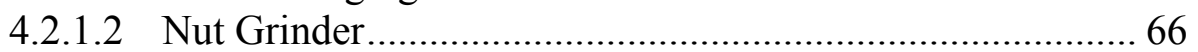

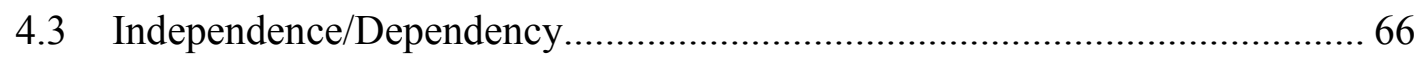

4.3.1 Possible Income Uses (Before and After) ………................................ 66

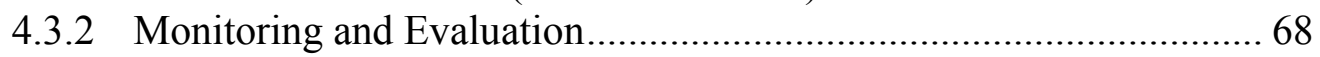

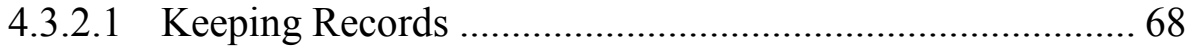

4.3.3 Payment for the Attachments ............................................................. 69

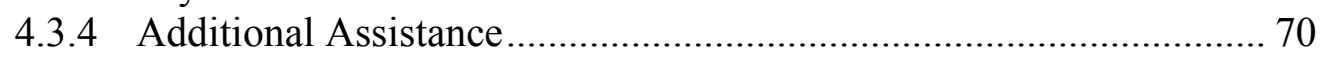

4.4 Design Efficacy ...................................................................................... 71

4.4.1 Hand-Powered Tricycle...................................................................... 71

4.5 Complexities of "Design for the Majority" Projects ........................................ 72

4.5.1 Working with Other Organizations .................................................. 72

4.5.1.1 KADUPEDI................................................................... 72

4.5.1.1.1 Recipient Selection .............................................. 73

4.5.1.2 CanUgan ......................................................................... 74

4.5.2 Knowledge Transfer and Capacity Building ....................................... 75

4.5.2.1 Universities in Uganda .................................................... 75

4.5.2.1.1 Makerere University ............................................ 75

4.5.2.1.2 Kyambogo University ......................................... 76

4.5.2.2 Local Manufacturer ............................................................. 77

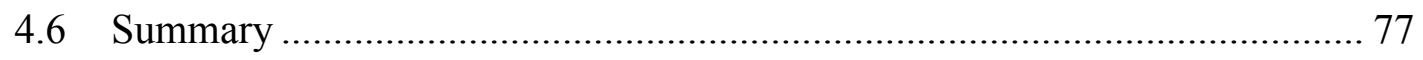




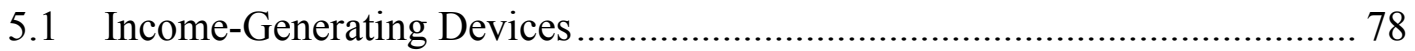

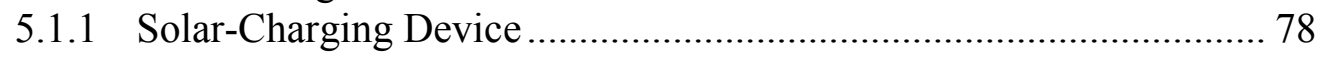

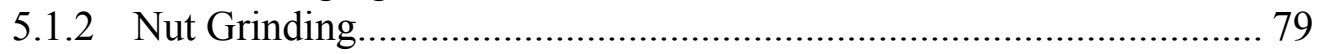

5.1.3 Payment for the Tricycle (and attachments)...................................... 80

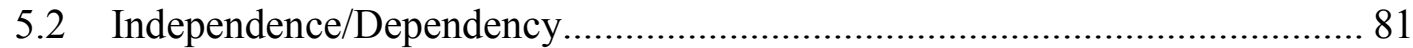

5.2.1 Social Dependency Relationships ……………............................. 82

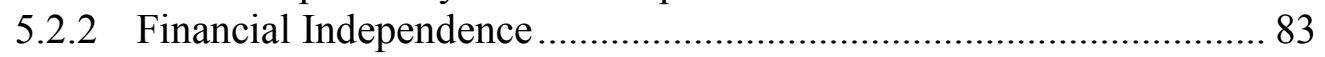

5.2.2.1 Monitoring and Evaluation............................................... 83

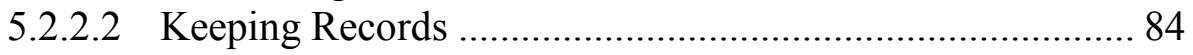

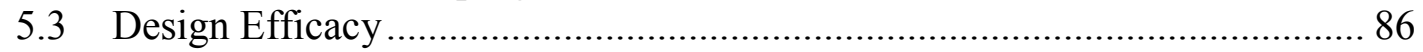

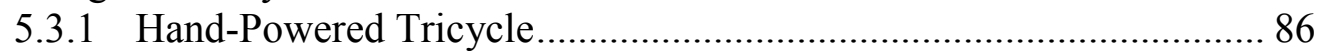

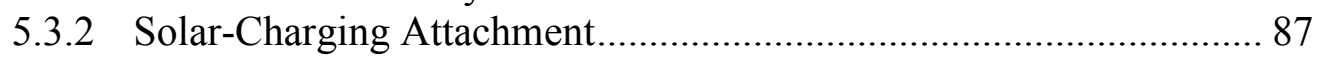

5.4 Complexities of "Design for the Majority" Projects ........................................ 90

5.4.1 Logistic Challenges of Fieldwork ……………................................. 90

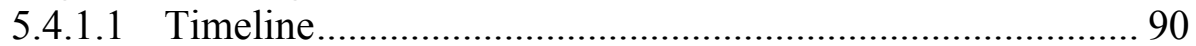

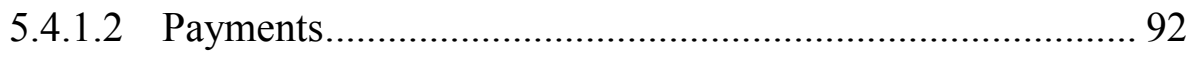

5.4.2 Lessons Learned from the Methodology ............................................. 92

5.4.2.1 Questionnaires ................................................................ 92

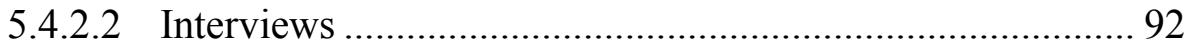

5.4.3 Discrepancies............................................................................. 94

5.4.4 Knowledge Transfer and Capacity Building ………………............... 95

5.4.4.1 Engineering at Makerere University …………................... 95

5.4.4.2 Disability Studies at Kyambogo University ………….......... 96

5.4.4.3 Local Manufacturer .............................................................. 97

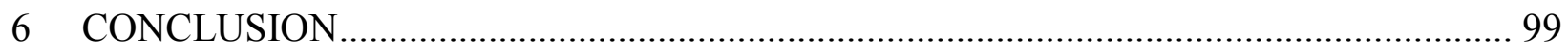

6.1 Factors that Influence Income-Generating Products ....................................... 99

6.2 Limitations of the Study ……………………......................................... 100

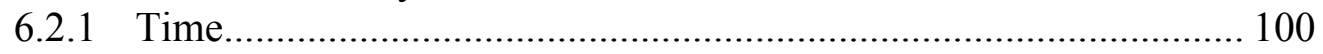

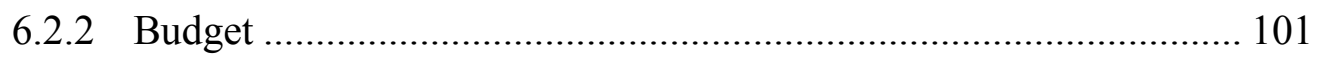

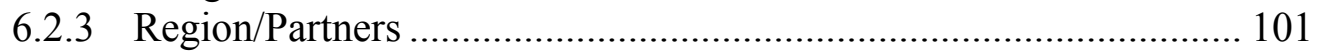

6.2.4 Assumptions and Results.............................................................. 102

6.3 Recommendations for KADUPEDI/CanUgan ............................................ 103

6.4 Recommendations for "Design with the Majority" Projects......................... 106

6.5 Potential Future Research .......................................................................... 112

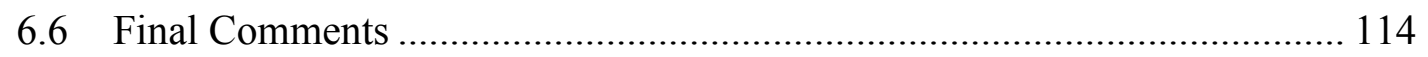

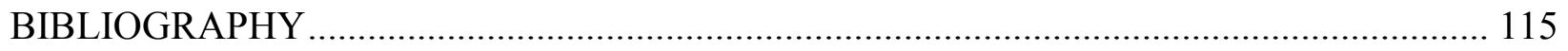

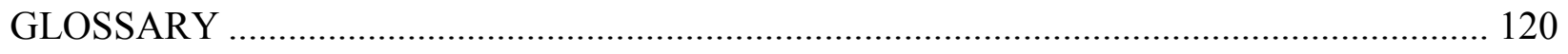

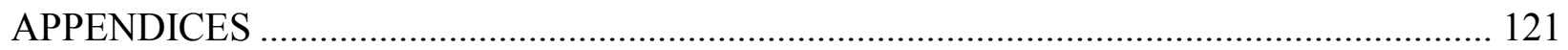




\section{TABLE OF FIGURES}

Figure 1: A summary of the fourth-year student projects from last year (2012/2013)............... 5

Figure 2: A Skype call that was held between Carleton University and KADUPEDI .................. 6

Figure 3: The Industrial Design students from the Uganda Project at the year-end show ............ 7

Figure 4: A doctor fitting a boy with a Jaipur foot below-knee prosthesis................................ 19

Figure 5: One Laptop Per Child - production model. ............................................................. 19

Figure 6: A drip-irrigation system, run along a row of crops ............................................... 19

Figure 7: A simple depiction of the difference between classical design and co-design ............ 22

Figure 8: The Australian Centre for Social Innovation co-design approach diagram................ 23

Figure 9: Co-creation has been known by many names ................................................. 24

Figure 10: A diagram showing some of the methods that can be used during co-design............ 25

Figure 11: A simplified map of Africa, highlighting Uganda, which is in East Africa............... 27

Figure 12: A simplified map of Uganda, highlighting Kasese District and Kampala. ................ 27

Figure 13: Used hospital wheelchairs are often donated (Toledano, 2014). ........................... 30

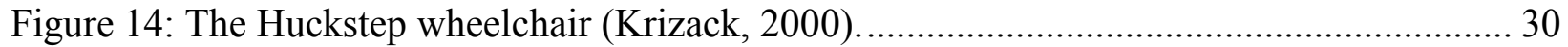

Figure 15: Hand-powered tricycles being produced in Uganda. ............................................ 30

Figure 16: A photo of Kio (the manufacturer) grinding a sheet of steel a................................ 33

Figure 17: A photo of Charles Williams working with Kio (the manufacturer). ...................... 33

Figure 18: Original version of the nut grinding attachment from last year in Uganda............... 43

Figure 19: Original version of the solar-charging attachment from last year in Uganda. .......... 43

Figure 20: A Venn diagram showing the three methods of collecting data used in the research. 57

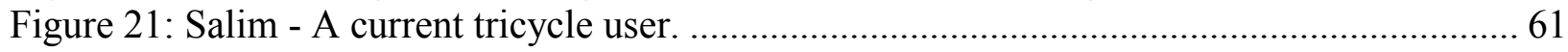

Figure 22: Maria - A potential tricycle user....................................................................... 61

Figure 23: Fauza - A current tricycle user with a solar-charging attachment.......................... 62

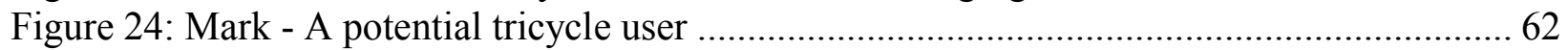

Figure 25: Doreen - A potential tricycle user ................................................................ 62

Figure 26: Margaret - A current tricycle user with a solar-charging attachment....................... 62

Figure 27: Mark and his son (right) sit in front of the building (with hand-painted sign).......... 64

Figure 28: One page of accounting from Margaret's notebook (October/November 2013)....... 69

Figure 29: One page of accounting from Fauza's notebook (January 2014). ........................... 69

Figure 30: The Executive Committee of KADUPEDI in 2012 .............................................. 73

Figure 31: A photo of Navin Parekh (CanUgan) and Amanda Cox (Carleton University)......... 74

Figure 32: A photo taken during an interview .................................................................. 74

Figure 33: A group photo of the board meeting which took place at Makerere University ......... 76

Figure 34: A view of the front of the building at Makerere University................................... 76

Figure 35: Perez Magoola, a 4th year Engineering student at Makerere University................... 76

Figure 36: The two closest tricycles are almost complete ................................................ 87

Figure 37: Kio and Bjarki talking about the tricycle with solar-charging attachment................. 88

Figure 38: A back-view of the tricycle with solar-charging attachment. ................................ 88

Figure 39: A close-up view of the underside of the tricycle with solar-charging attachment. .... 89

Figure 40: A close-up of the inverter on the tricycle with solar-charging attachment. .............. 89 


\section{TABLE OF APPENDICES}

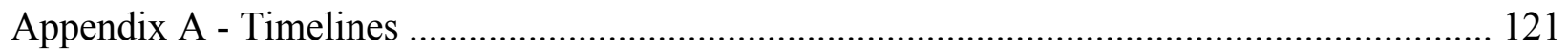

A.1 Timeline for Project ………................................................................... 122

A.2 Timeline for Field-Work ………………….................................................... 122

Appendix B - First Questionnaire - Blank (Before Being Given the Device) ............................. 124

Appendix C - Second Questionnaire - Blank (After Being Given the Device) .......................... 127

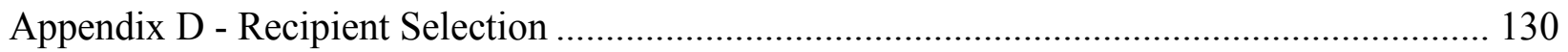

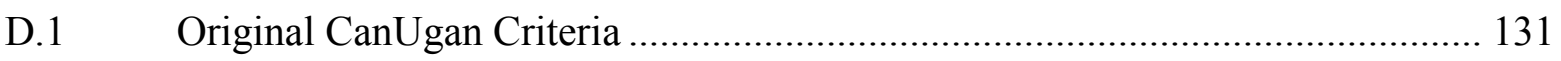

D.2 Revised Criteria (for Solar-Charging Devices) ................................................ 131

Appendix E - Interview Guide (Sample Questions) ………….............................................. 132

E.1 Questions for Recipients of a Tricycle and Solar-Charging Device (2 people).. 133

E.2 Questions for Recipients with a Tricycle (2 people)......................................... 134

E.3 Questions for Potential Recipients (4 people).................................................. 134

E.4 Questions for CanUgan (1 person) …………............................................ 135

E.5 Questions for KADUPEDI (2 people) ......................................................... 136

E.6 Questions for the Manufacturer (1 person) ……………………………........... 136

E.7 Questions for Students (3 people) ..................................................................... 137

Appendix F - Summary of Recipient Information from First Questionnaire ………….............. 138

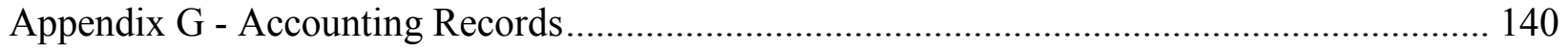

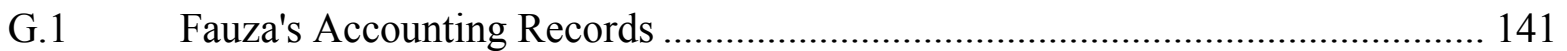

G.2 Margaret's Accounting Records ................................................................... 142 


\section{INTRODUCTION}

This project was completed as part of an interdisciplinary graduate degree in Industrial Design with a focus on International Development. It involves a case study in partnership with many collaborators, including universities, local organizations, and NGOs in both Canada and Uganda. The project is based in the Kasese district of Uganda, due to the poverty that can be found in the region. The project looks into mobility devices for people with disabilities (PWD) within this context. The author's specific research looks into the creation of income-generating attachments that can be added to those assistive devices, and explores different issues that relate to their actual success in use for the recipients in the region.

It is often assumed that it is easy to design for those who are not well-off. Designers and other members of society assume that since people in poor regions have so little, any additional help they are getting will improve their quality of life immensely. However, these assumptions do not take into account the vast complexities that are involved in these types of projects.

Designing for people in a different part of the world who have very different lives is incredibly complex, and involves many unique issues that will be explored in this thesis.

\subsection{The Majority World}

Throughout history, there have been many different terms for people who live in poorer areas of the world. These terms have included: newly industrialized countries (NIC), the Third World, low-and-middle-income countries (LMIC), developing countries, and most recently, the Global South (Er, 1997). This author prefers to think of these areas as simply underserved communities, however, this term does not relate specifically to issues faced in poor countries, 
and may confuse some readers. Since the term "developing countries" has negative connotations, the term "majority world" has been suggested, since the vast majority of the world's population lives in these countries (Balaram, 2010). Therefore, the author will be using the term "majority world" throughout the text, except for in instances where it is quoted from another source.

\subsection{The Design Innovation for Disability in Kasese Project}

\subsubsection{Project Origins and Key Collaborators}

The Design Innovation for Disability in Kasese (DIDK) Project started in 2012 through the Research, Education, Accessibility and Design (READ) Initiative at Carleton University. In October 2011, READ hosted a Town Hall and Tribute to Rick Hansen, which brought the School of Industrial Design at Carleton University together with the CanUgan Disability Support Project (CanUgan). CanUgan is an NGO based in Ottawa, Canada, which raises funds to support assistive devices for people with disabilities in the Kasese District of Western Uganda. CanUgan works through a local organization in Kasese that is made up of people with disabilities, and tries to provide devices, training, and advocacy to their members. This organization is the Kasese District Union of People with Disabilities (KADUPEDI), which represents over 50,000 people with disabilities in the region (Hallgrimsson, Liu, \& Hadley, 2013). The School of Industrial Design at Carleton University has a long history of working with people with disabilities, and was interested in helping CanUgan improve their assistive device designs and create new ones. This work was funded through a generous grant from the International Development Research Centre (IDRC) in Ottawa, Canada. Although this grant was only meant to cover the first year of the project, the school was granted an extension in order for this researcher to continue the 
project for a second year. This year there was a continued focus on sustainability, capacity building, and fostering collaborative relationships with our international partners.

\subsubsection{Last Year's Projects (September 2012 - April 2013)}

During the last school year, four undergraduate Industrial Design students chose to work on a project related to devices for people with mobility impairments in Uganda. The students did the work as part of a fourth year major project that involved starting with a problem, researching it, creating concepts and finally making a complete working prototype that could be used. The student projects were all based around the idea of mobility, and centred on the design of a handpowered tricycle that was currently made on a piece-by-piece basis by Kio Metalworks in Kasese. The fall semester involved learning about Uganda, and creating concepts for products that might be needed by people with disabilities. Leading design experts in the field of disability design and low-income communities in developing countries were also invited to Carleton University for a workshop in November 2012, including Catapult Design and Whirlwind Wheelchairs, both of San Francisco. In addition, students shared ideas and had online discussion with members of KADUPEDI as part of the workshop sessions. This ideation process was also furthered by online email exchanges in order to make sure that end users in Kasese had design input during the early stages of the project.

In January the students started creating rough prototypes in the shops at Carleton, using materials and processes confirmed to be available in Uganda. Since the focus of the project was to design with the users, instead of designing for the users, it was important to actually make a trip to Uganda. During the trip in February 2013, the students worked closely with the local 
manufacturer to create prototypes in an iterative design process, and visited the homes of local device recipients to test their devices. These visits also helped to shed light on what the lives of people in Kasese are really like, including their small homes and lack of access to basic services, like water and electricity. The trip also included visits to Makerere University and Kyambogo University in Kampala, with the aim of generating relationships for future collaboration on this project. Two representatives from KADUPEDI also travelled to Ottawa, Canada in May 2013 to attend a conference on African Studies, which gave them a unique chance to experience our culture as the students had experienced theirs previously.

The four final designs were left in Uganda to be disseminated to willing recipients, while prototypes, posters, reports and final models were made of each design back at Carleton (see Figure 1). Alyssa Wongkee looked at a redesign of the tricycle frame itself, focusing on making it more structurally sound through its configuration, simplifying the production process, and reducing the cost through material reduction. Ruby Hadley designed a rolling walker that could withstand the local terrain and was simplified to be efficiently produced in a Ugandan context. Carmen Liu used the tricycle as a foundation, and took advantage of the power output from the tricycles drivetrain to power other tools, such as a grinder for ground nuts. Andrew Theobald used the tricycle as a platform for a small business of generating income by charging other peoples mobile phones using power from a solar panel. Since my graduate project was meant to focus on income generation, the last two designs were an excellent fit for my research. 


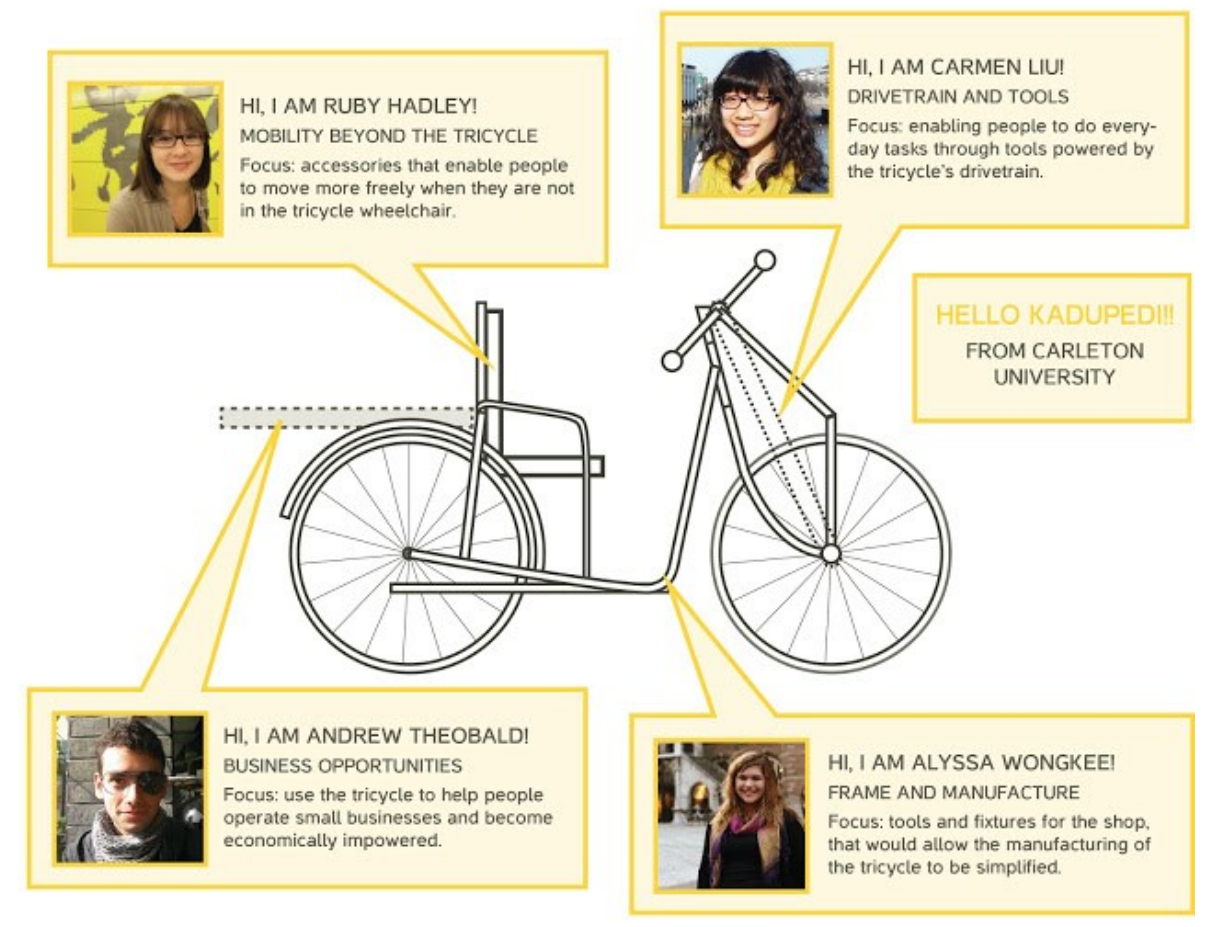

Figure 1: A summary of the fourth-year student projects from last year (2012/2013).

\subsubsection{This Year's Projects (September 2013 - April 2014)}

During the second year of the project another four undergraduate students were selected from the fourth year class, based on their interest in the project. The students looked at secondary research in the fall, as well as communicating to groups in Uganda with questions they had, via email and Skype (see Figure 2). These students had the advantage of understanding the contexts from their experience watching the previous students work on their projects. Based on the findings from the previous year, this year's students understood that mobility was not the ultimate goal, but rather empowerment for people with disabilities. By the end of the first semester, in December 2013, the students had each formulated an idea. Throughout December and January, they created sketches and tested multiple iterations of models in order to prove their ideas could be successful. In February 2014, the four undergraduate students, one graduate 
student (the author) and one professor went to Uganda in order to test their designs. During the two weeks in Uganda, the students met with recipients, co-designed with Kio, the local manufacturer, and met with other stakeholders, such as local organizations and Makerere University in Kampala. After returning from the trip, the students spent their last two months finalizing the design and building finished prototypes.

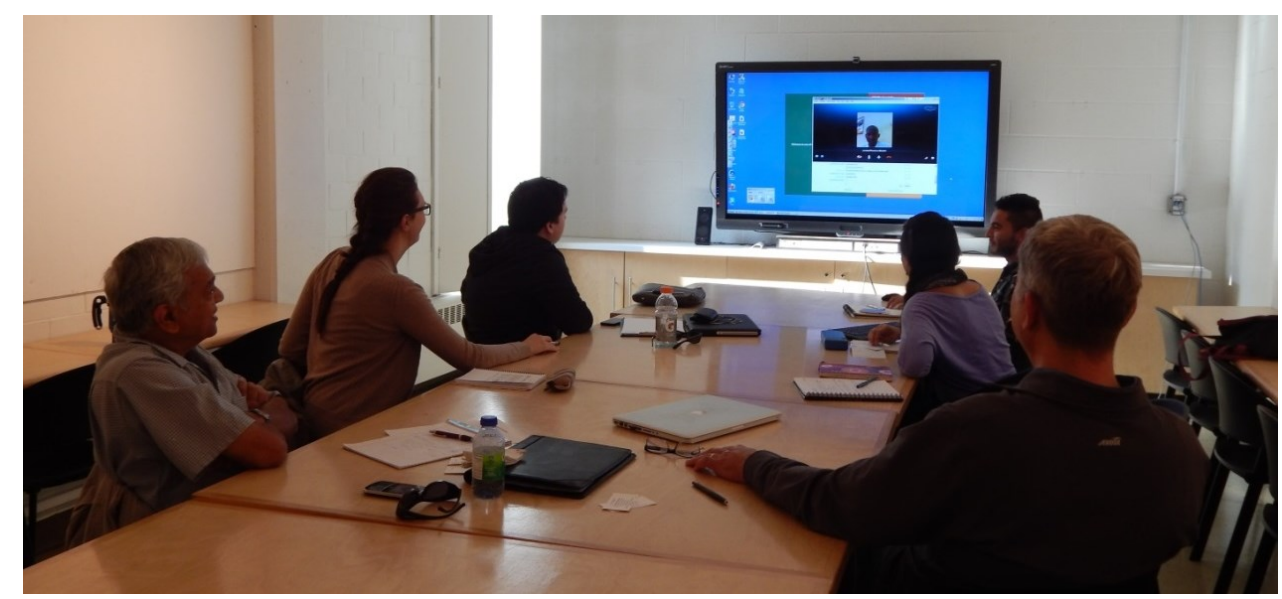

Figure 2: A Skype call that was held between the students at Carleton University (in Ottawa) and KADUPEDI (in Kasese, Uganda) in November 2013. From left to right-Navin Parekh, Jennifer Vandermeer, Charles Williams, Zoe Krug, Luis Garcia, Bjarki Hallgrimsson.

The four designs were all unique, and offered solutions to different groups within the PWD community (see Figure 3). Jennifer Vandermeer originally wanted to design a device that allowed children with disabilities go to school. Her solution ended up being a wheelchair for indoor use, which could be turned into a tricycle for longer distances, and allowed many different types of people to utilize both indoor and outdoor modes of transportation, including students. Luis Garcia focused on the fact that most people in rural Uganda are subsistence farmers. Since many PWD have difficulty tending to their farms, Luis designed a rolling garden chair that allowed them to help their family plant and grow vegetables. Charles Williams looked at the issue of post-harvest processes, which is a key activity in a country that is so dependent on 
agriculture. He designed a device which can be used to shell ground nuts using a hand-crank.

These nuts come out whole, and can either be replanted, eaten, sold, or ground into a paste that is used in a very popular local dish. Zoe Krug originally wanted to focus on a set of attachments for the tricycle that would allow women with disabilities to take their handicrafts to market, which included a crafting tray, display areas, and storage capabilities. However, once in Uganda, she soon realized that going to market was not the main issue, but the concern was about how to take a child with you, since children up to two years of age are kept with the mother at all times. Her design changed into a re-design of the tricycle with a rear-seat for holding a child so that the mother could travel with her child wherever she wanted to go. The projects are quite varied, and the students learned a great deal from this collaborative, participatory design process.

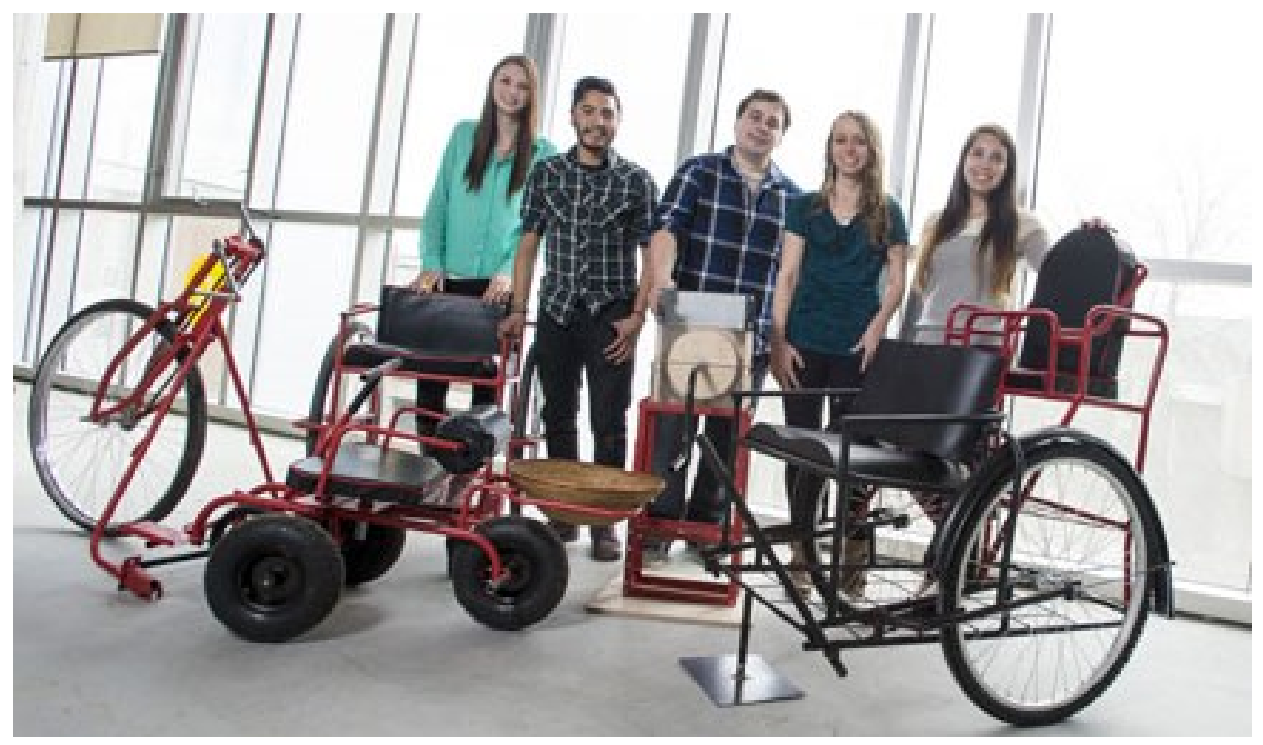

Figure 3: The Industrial Design students from the Uganda Project at the year-end show at Carleton University. From left to right-Jennifer Vandermeer, Luis Garcia, Charles Williams, Amanda Cox and Zoe Krug.

\subsubsection{Graduate Research}

Beginning in the spring of 2013, the researcher got involved with the DIDK project. After reading about different issues in international development and humanitarian aid, the 
researcher decided to focus on products for people in Africa, and already had an interest in working with people with disabilities, so the project fit perfectly. The project team decided that a more comprehensive look at the effect of the project on the recipients was needed. Therefore, the author decided to use two of the projects from the previous year, and investigate them further. More devices were to be distributed, so that the graduate researcher could focus on a more detailed follow-up of what really happens after the devices are given out. Preliminary research sub-questions focused on the efficacy of designing such new products; if they actually create an income; how would it be measured; and if the device could stand up to the physical requirements of the environment.

Two of the devices designed in the previous year seemed like logical choices as they had been co-developed and had been well received by the local end users. The first option was the nut grinder front wheel attachment. During the course of the project it was determined that an appropriate nut grinder could not be found locally, and the only substitute could be a meat grinder. After discussing the issues with KADUPEDI, this did not seem like a viable device for the case study. Hence, the emphasis was placed on the solar-charging device. The device included all of the mobility considerations of a hand-powered tricycle, along with the recipient having the ability to charge mobile phones for a fee using the attached solar panels.

Another focus of the graduate research was capacity building and knowledge transfer. In order to make the project more sustainable, the current project is also in conjunction with the School of Engineering at Makerere University in Kampala. The goal of this collaboration was to share knowledge across the schools, and hopefully help KADUPEDI by partnering them with a 
university in their area. It would be ideal to transfer as much as possible to the students and staff at that school in order for them to continue the project in the future. The complexities of the relationship with them and the future possibilities will be discussed in later sections.

\subsection{NUDIPU, KADUPEDI and CanUgan}

NUDIPU (National Union of Disabled Persons of Uganda) is a national umbrella organization that was created in 1987 as a way for people with disabilities to become involved in the planning and implementation of programs that were meant to benefit them. They are now one of the strongest national advocacy and lobbying organizations in the country for championing the needs of marginalized groups in Uganda, with mantras such as "disability is not inability" and "nothing about us without us" (NUDIPU, 2013b). NUDIPU has various goals, including: mobilizing people with disabilities into social groups for collective action; working to create disability-friendly legislation and policies nationwide; creating economic opportunities for PWDs; working with the government to ensure services are provided to PWDs; creating awareness in society about the needs and rights of PWDs; and removing social and physical barriers towards inclusion of PWDs in mainstream development (NUDIPU, 2013c). The national union also identifies many human rights violations that take place within the disabled community, such as: higher levels of sexual abuse; societal stigma; a lack of access to services (such as healthcare and education); and discriminatory employment practices despite the passing of the Persons with Disabilities Act in 2006 (NUDIPU, 2013a). NUDIPU is composed of district level groups including KADUPEDI (Kasese District Union of Persons with Disabilities), and disability-specific groups, including groups for members of the blind and deaf communities. 
KADUPEDI was founded in 1996 and is run completely by people with disabilities, on a voluntary basis. It is also an umbrella organization, and some of its affiliates run microcredit saving programs, tree planting, and training in skills like using a computer and basket weaving. KADUPEDI also coordinates local activities; collects and manages data about its members; collaborates with other NGOs and organizations in the area; and advocates and lobbies for PWDs, aiming to protect and promote their access to human rights. They run a number of programs, including vocational training, an emergency flood relief program and provide assistive devices to local people with disabilities. They also advocate for the human rights and inclusion of people with disabilities in the district.

CanUgan is an Ottawa-based non-governmental organization (NGO) formed by Navin Parekh. CanUgan was started in 2010 after Navin lived in Kasese, in Western Uganda, and realized there was a need for assistive devices within the region. The organization supports KADUPEDI by holding fundraisers, publishing news and creating partnerships to promote their work (CanUgan, 2014b). Most of the funding goes towards providing assistive devices, such as white canes and hand-powered tricycles. Since KADUPEDI works with a local welder/craftsman (Kio) to make their mobility aids for its constituents, it was a perfect match to work with the School of Industrial Design at Carleton University. They implement the project locally by overseeing manufacturing and procurement of assistive devices and by distributing them to people with disabilities in the region (CanUgan, 2014b).

\subsection{Current Recipient Process}

CanUgan currently provides all of the funding for the assistive devices, and KADUPEDI 
does all of the on-the-ground work related to meeting with recipients and coordinating dissemination of devices. To do this effectively, KADUPEDI has a team that is spread out through Kasese District. The region of Kasese has 23 sub-counties. In each sub-county there are two "mobilizers", who are people with disabilities volunteering for KADUPEDI. Their duties include writing reports on who should be given devices, coming to Kasese town for training, informing recipients if they are to receive a device and monitoring recipients once they go back to their homes. These mobilizers are the ones who originally identify the need for a tricycle from the people in their community, and tell KADUPEDI to add this person to the list of potential recipients.

After these reports are submitted, KADUPEDI meets with the potential recipients to ask them questions and complete a medical evaluation. This information is then brought back to the board of the CanUgan project at KADUPEDI, which consists of three members. Baluku Peter, a local city council person and KADUPEDI Coordinator, is the Team Leader. Bwambale Robert, a healthcare professional, acts as the Treasurer of this board. Joseph Kahyana, who represents children with disabilities, is the Secretary of this board. Mutebi Phestus is the Youth Program Coordinator, and although he is not technically on the board, he tries to help out, and owns a boda-boda which helps for transportation. The board gets a long list of people who might need devices, and narrows these down to a smaller list for each quarter based on the availability of devices and the severity of need for each person. This list is then given to CanUgan for final approval. After CanUgan approves the list, the devices are created by Kio Metalworks. The recipients then come to Kio's shop to test the devices, to ensure they are able to use them, and to receive some training. Once the devices are finished, KADUPEDI calls the recipients to collect 
their devices and sign waivers. The recipients take their devices home, and are periodically monitored by different volunteers from KADUPEDI. This process will also be used in this project, with some minor variations.

\subsection{Scope of the Study}

This study was created as an interdisciplinary design research effort, combining aspects of industrial/product design with international development in a specifically African context. It is critical to understand that many different issues may affect the success of a design project, including, but not limited to socioeconomic statuses, environment, cultural context, psychological factors, and societal influences (Crilly, Moultrie, \& Clarkson, 2004, p. 556). Although these areas are recognized as being very important, most of them are outside the scope of this project. The project looks at one case study of design for people with disabilities in Uganda, and discusses some factors which influence the success or failure of the income generating devices within that context. The author is not an expert in the other fields, and would not like to make assumptions or assertions without that background knowledge. Therefore, these issues will be touched on briefly as possible inferences, but any actual conclusions can be presented by other researchers on the more specific topics areas, some of which are listed in the conclusion. The main question the author was interested in was whether or not incomegenerating products can improve the lives of people with disabilities in the developing world. The author will focus on four specific areas of research (within the larger research scope), as they relate to this case study. The first area looks at the income-generating device itself, and investigates its social and economic impact on the recipients of the device. The second area examines issues of dependency and independence, and how they are influenced by working with 
NGOs, local organizations, and income-generating devices. The third research area concerns design efficacy, and whether the proposed design solution was appropriate for the people and the context for which it was designed. The last research area looks at the complexities involved in projects of this nature, and will offer recommendations to future cross-cultural and interdisciplinary researchers on how to make their project more successful.

\subsection{Thesis Outline}

This section offers a summary of what the reader can expect to find in the following chapters. The second chapter is a literature review, which delves into the existing research related to extreme poverty, international development, design for the other $90 \%$, and participatory design, and then investigates the relationship between poverty and disability in subSaharan Africa and Uganda. The third chapter is the methodology. This section begins with the research questions and their associated hypotheses. The author then describes the methods used and data analysis is discussed. The fourth chapter details the findings from the research. Section 4.1 offers a brief description of living conditions for the recipients in Kasese, in order for the reader to better understand the context of the results. Sections 4.2 to 4.5 , offer the results of the research, as they pertain to the four main research areas. The fifth chapter is a reflection, which goes over the results mentioned in the fourth chapter, while offering the author's insights,

opinions and recommendations. The sixth chapter is the conclusion, which sums up the findings, explains the limitations of the research, provides recommendations for KADUPEDI and CanUgan, gives design researchers a checklist of things to consider in "Design with the Majority" projects, suggests potential areas of future research and offers the author's final comments. 


\section{LITERATURE REVIEW}

Based on the four research areas proposed in the introduction (income-generation, independence/dependency, design efficacy, and project complexities), the author decided to look at the secondary research related to the themes of international development, poverty, human rights, participatory design, design with the majority and specific cultural phenomena within the context of Uganda. This secondary research helped to focus the research areas into more specific questions, as described in Chapter 3.

\subsection{Extreme Poverty and International Development}

\subsubsection{Extreme Poverty}

Extreme poverty is generally defined as living on less than US \$1.25 a day, which represents the minimum food consumption needed to sustain life (World Bank, 2014c). As of 2010, it was estimated that approximately 1.2 billion people live in extreme poverty, primarily in the majority world (World Bank, 2014c). No matter which indicator you use, the number of people living in extreme poverty has been dropping. Most of the people who fall into this category live in sub-Saharan Africa, Asia or Latin America, though the numbers in Asia have been dropping quite quickly over the last decade (World Bank, 2014b). However, throughout the world, it seems that people with disabilities are being left behind, which represents an estimated 1 billion people (World Bank, 2014a).

\subsubsection{International Development and Foreign Aid}

Many different types of groups do development work in impoverished countries around 
the world, including governments, NGOs, multi-national corporations, and international organizations. Each group has a different focus and ways of working with people in poverty. Some of the methods have changed over the years, and some are deemed to be more successful than others. Past efforts have included a focus on large infrastructure projects, privatization of government run services and a focus on good governance (Moyo, 2009) (Woods, 2005). In recent years, there has been a major debate over whether or not donors should continue to give aid and how to make the money have the largest impact on those who are worst off in the world, though most agree many errors have been made in the past. These discussions are often started by the most well-known economists, who mostly happen to be rich white men from developed countries who work at large organizations such as the International Monetary Fund (IMF), the World Bank (WB) or the United Nations (UN), with some exceptions (Collier, 2007) (Easterly, 2006) (Sachs, 2005). Some argue that aid has been completely unsuccessful (and perhaps harmful) in the past and that we should cease giving any in the future (Moyo, 2009) (Easterly, 2006). Others argue the opposite, that the reason aid has failed is because we have not given enough, and we should make an effort to give much more in the future (Singer, 2009) (Sachs, 2005). Since most of these experts have created their own new solution to the problem of poverty in the majority world, it is difficult to know whose solution will actually work, if any, without actually trying them. Most of these changes would require a massive overhaul to the system, buy-in from many countries and organizations and a considerable amount of money (Polak, 2009) (Collier, 2007). The future of foreign aid and development is unclear at the moment, since there are so many different opinions on what should be done. 


\subsubsection{How Disability and Poverty Affect Access to Human Rights}

The United Nations has declared certain aspects of life to be human rights (United Nations, 2014). However, most people living in poverty do not have access to all of their rights, such as democracy, education, and health care. It has been seen that people with disabilities are more at risk of not having access to these fundamental rights (Buchanan, 2001). Although many governments technically have laws stating these rights, they are not always enforced. The perception of the society at large is an important factor in ensuring that people with disabilities are treated fairly in all areas of society.

\subsubsection{Millennium Development Goals}

The Millennium Development Goals (MDGs) were created by the UN in 2000, and were composed of eight basic goals that the world was aiming to achieve by 2015. The goals included reducing extreme poverty, reducing child mortality, improving access to education, and halting the spread of HIV/AIDS (UN Secretary General, 2006). Many of the goals directly translate into human rights, such as the right to education, healthcare, and economic opportunities. Currently, some countries have met or are on track to meet their goals by 2015 , while others will not even be close. According to the 2010 Progress Report, Uganda is on track to meet seven sub-goals including: halving extreme poverty, dealing with international debt, increasing access to clean water and sanitation, and eliminating gender disparity in schools. The country is making little progress on eight other sub-goals, including: slowing habitat loss, creating access to generic drugs, and reducing the child mortality rate, and is doing poorly in halting the spread of AIDS (Ministry of Finance, Planning and Economic Development, 2010). Although not all of the goals are specifically related to people with disabilities, PWD are often the least likely to have 
good access to many government services. Therefore, improving services and standards for the whole country is at least a step in the right direction of making sure that in the future people with disabilities might have access to government programs.

\subsection{Design with the Majority and Participatory Design}

\subsubsection{The History of Design with the Majority}

Design for the other $90 \%$ (or Design for the Majority) looks at the fact that most of the design that has been created in the last hundred years has only gone to the most well-off $10 \%$ of the world (Smith, 2007). People have been starting to think like Dr. Paul Polak, author of Out of Poverty and an advocate of designing for "extreme affordability", when he says "...I keep asking why $90 \%$ of the world's designers work exclusively on products for the richest $10 \%$ of the world's customers" (Stanford University, 2012). This new movement focuses on the $90 \%$ that are living with far less resources. Other synonyms for this include Design for the Majority (recently updated to Design with the Majority), the Bottom of the Pyramid or the Bottom Billion. In 2007, the Cooper-Hewitt National Design Museum held an exhibit (and created a book) focusing solely on projects that catered to Design for the Other $90 \%$, with categories such as access to water, renewable energy, access to technology, transportation and improved agriculture (Smith, 2007). Other design books were published around the same time, such as Design Revolution: 100 Products That Empower People (Pilloton E. , 2009), and Design like You Give a Damn: Architectural Responses to Humanitarian Crises (Architecture for Humanity, 2006), which show that this exhibit was not an isolated phenomenon, and that this is actually a growing movement in the design community. Although these books do not solely focus on the majority world, they do focus on marginalized communities, and the products and structures are created to 
increase their quality of life in an affordable way.

In his influential book, The Fortune at the Bottom of the Pyramid, C. K. Prahalad (2006) explains that those in poverty are not just in need of charity, but are actually in need of products and services for which they can afford to pay. Although each buyer only has a small sum of money, when this is multiplied by the billions of people who live in poverty the profits are considerable. This book changes the focus from only charitable projects to advocating for businesses to become active in products for the majority world. These products often have to come in very small portions, and need to be extremely affordable, as people in poverty do not have the excess money needed to buy in bulk (Prahalad, 2006). Design focused on the majority world addresses people who are marginalized by society and other members of societies who may have less access to the economic marketplace. The ideas are not entirely new, as Papanek mentioned some of the issues with product design in his book, Design for the Real World, in 1971. The difference between the movement now and what Papanek discussed then, is that he mainly wanted to shift the user group, to create "appropriate technology" for those who were marginalized, such as people living in poor areas, the disabled, and the elderly (1971). The current movement additionally looks at trying to better understand and work with end-users during the process, as described in section 2.2.3.

\subsubsection{Recent Trends and Case Studies}

This section will look at case studies in order to determine what types of products have been created and how much of a success they are in actual use. Often the motivation behind a product is good, but key factors were not considered so the design becomes problematic. There 
is often also a problem of follow-up and maintenance that is not addressed in many of these projects. In 2012, an audit done by the European Union of their own development assistance showed that only half of their projects in sub-Saharan Africa were successful and the World Bank declared that 39\% of its projects failed in 2010 (Dracup, 2013). Therefore, it is useful to look at why certain companies or products are more successful than others, so that they can be used to create more successful projects in the future (Prahalad, 2006) (Pilloton E. , 2009) (Smith, 2007).

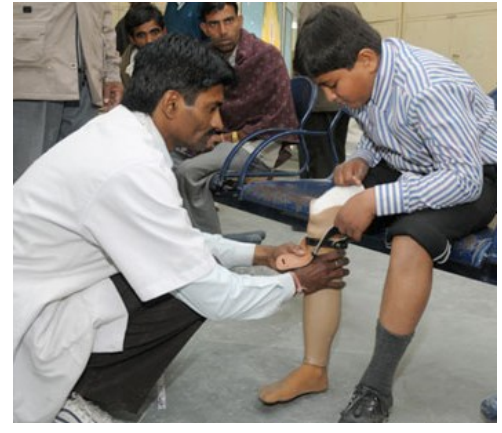

Figure 4: A doctor fitting a boy with a Jaipur foot below-knee prosthesis (Jaipurfoot, 2013).

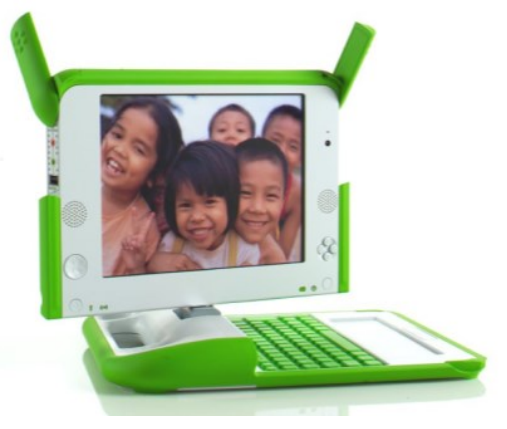

Figure 5: One Laptop Per Child-production model (Fuse-Project, 2006).

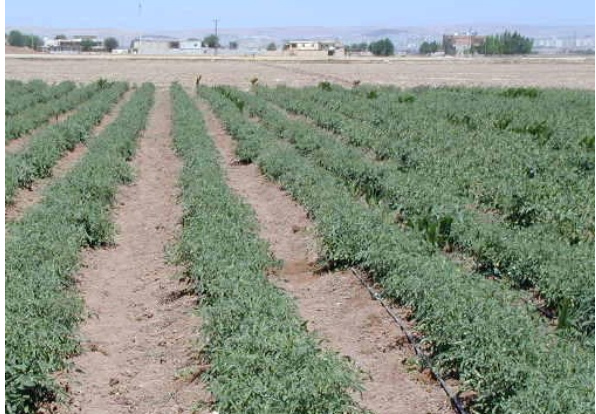

Figure 6: A drip-irrigation system, run along a row of crops (United States Department of Agriculture, 2005).

\subsubsection{Jaipur Foot (Charitable Model - Successful)}

The Jaipur foot was created in India as an alternative foot/lower-leg prosthetic that was low-cost, durable and waterproof (see

Figure 4). The foot can be used in all of the actions that are necessary to be a farmer in the local region and can be worn with or without shoes. It was created by Master Ram Chandra Sharma (a craftsman) and Dr. P. K. Sethi (an orthopaedic surgeon). It is made using small-scale, local production methods and has been distributed to over 900,000 amputees in Asia, the Middle East and Africa. The Jaipur foot is distributed by Bhagwan Mahaveer Viklang Sahayata Samiti 
(BMVSS), the world's largest organization serving the disabled, which gives out devices for free to those in need. Their goal is to help restore mobility and dignity so that people can once again become respected members of their societies. However, it is much more difficult to talk about the economic success of a charitable project, since it depends on its own funds, and simply spending those funds and making people's lives better reflects on them as being successful (Smithsonian - Cooper-Hewitt National Design Museum, 2012b). This aspect of increasing dignity and empowering people with disabilities is also the goal of CanUgan and KADUPEDI in their distribution of assistive devices.

\subsubsection{One Laptop per Child (Business Model - Not Very Successful)}

The One Laptop per Child (OLPC) initiative was originally very highly regarded, as an amazing idea to bring equal-opportunity education to children around the world (Smithsonian Cooper-Hewitt National Design Museum, 2012c). The product looked child friendly and many in the West hailed it as revolutionary (see

Figure 5). However, very quickly the negative stories started emerging. OLPC was unable to get the cost down to their target (below \$100) and although students liked the products, many of the laptops went missing from schools or were unable to be used due to a lack of electricity or internet connectivity. The goal was for governments of the majority world to purchase laptops and roll them out in their public-schools; however, OLPC has recently switched to a market of a more expensive tablet format for underprivileged schools in developed countries instead. Based on this evidence, it seems clear that they have given up on their original goal (Kraemer, Dedrick, \& Sharma, 2009). 


\subsubsection{Drip Irrigation System (Business Model - Successful)}

The drip irrigation system by International Development Enterprises (IDE) allows farmers to efficiently water their crops in the dry season (see

Figure 6). It can increase yields by over 50\% while using 30 to $70 \%$ less water than traditional irrigation methods. It is also a modular system, so farmers can start with one unit and buy more as they have the money to do so. The kits can be used to improve existing crops or to cultivate crops that have a higher market value. They have sold more than 600,000 systems throughout India and Africa. Since IDE's system is not based on a charitable model, its success is obvious. Farmers would not continue to buy or use the system if it was not effective, and they would not be able to afford adding to their system if they were not able to sell the previous crop at a profit. Many of the poorest people in the world are small-scale subsistence farmers, and this product really targets their specific needs in a business-minded way. Since the product is affordable and modular, most of these farmers can afford at least one piece of the system, and can increase their system each year with the profits made from the last harvest, thereby improving their quality of life (Smithsonian - Cooper-Hewitt National Design Museum, 2012a).

\subsubsection{Methods for Participatory Design}

Participatory design, or co-design, focuses on involving the user of the product/service from the very beginning of the design phase. The common terminology involves designing with the user instead of for the user (see Figure 7). For this to work, it is important to pair the skills that designers have (such as sketching, material knowledge, ergonomics, etc.) with the knowledge of future potential device buyers and users. Some of the processes for working together include brainstorming (coming up with a large number of new ideas) and interviews 
(finding out about habits, values, needs, beliefs, etc.). Another important aspect of collaboration is working with your hands, or prototyping. Prototyping allows designs and users to both visualize solutions and work together to create something that fulfills all of the user's needs. One of the final steps is a field test, where a small number of devices are given out to the target group for use and feedback. This stage before implementing a huge roll-out saves a lot of time and money and makes the product better for the consumer in the end. By building trust throughout the entire process, the participants will be more likely to confide in the designers with their honest feedback about the initial device (Catapult Design, 2013).
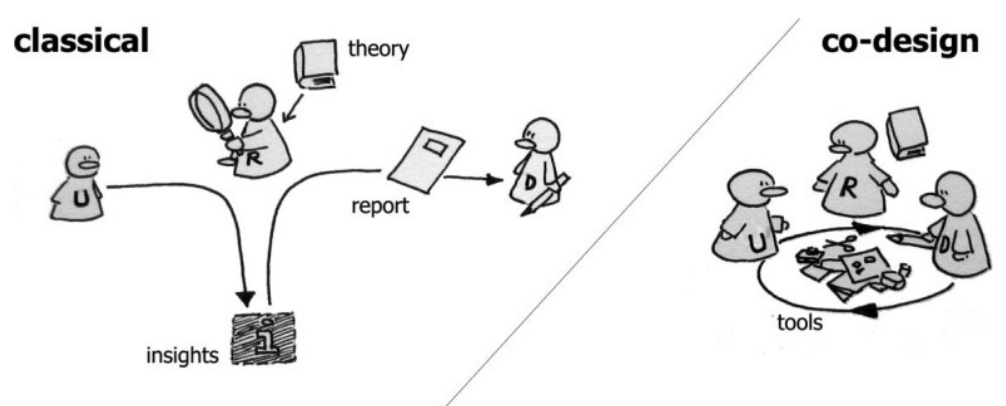

Figure 7: A simple depiction of the difference between classical design and co-design. Classical design involves the researcher telling a designer about insights, without the designer ever actually interacting with the user. Co-deign involves the user, designer, and researcher working together and prototyping to create a more appropriate design (Sanders \& Strappers, 2008) .

Co-design is all about community and collaboration. The difference between traditional design approaches is that co-design involves working with people to discover their needs, and coming up with solutions in collaboration with them throughout the design process. One method, described by the Australian Centre for Social Innovation, is an eight "loop" process (see Figure 8). This process begins with a big question, and some assumptions, and generally defines that question into a more narrow scope over time. It involves testing those assumptions through prototyping, and views real people as the experts in their own lives, meaning that it is necessary 
to visit them in their own homes and communities to find out what their lives are really like. The first step, frame, is to ask a big question, and understand the assumptions that go along with it. Step two is about identifying the sample of people the designer can test in order to answer this question. The third step is about doing the actual research and visiting people in their communities to do interviews and other ethnographic methods. The fourth step is to analyze all the themes and insights that have come from the research. The fifth step is where some designers might start if not co-designing, which involves creating through the use of stories and visualizations about the new product. The sixth step is also essential to co-design, and involves talking to the people about the proposed solutions to see their thoughts and comments. Step seven is a more detailed version of step five, and involves making physical prototypes that can be manipulated. Often, steps five, six and seven are repeated many times before completion, with more detailed revisions each time. Step eight involves sharing the information learned with others, which may be in the form of a report, presentation or model (The Australian Centre for Social Innovation, 2013).

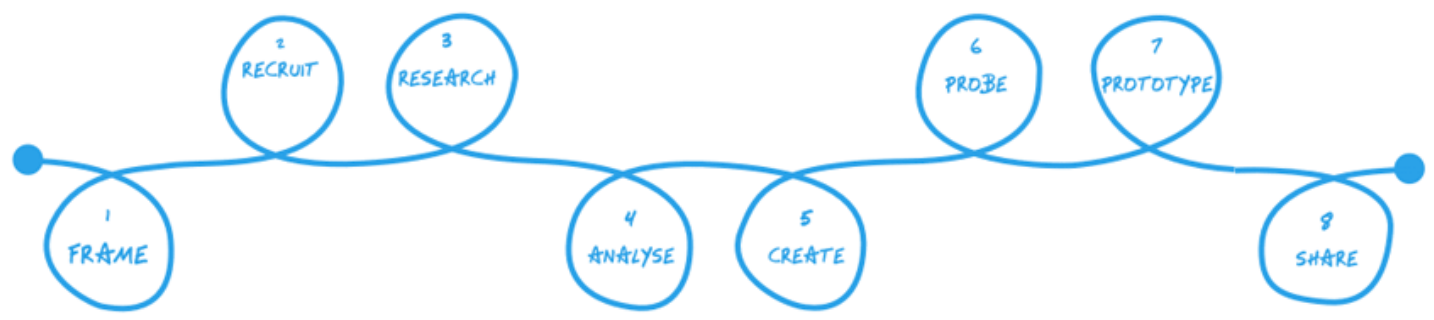

Figure 8: The Australian Centre for Social Innovation co-design approach diagram. The process can be visualized as loops that can be repeated but are never skipped (The Australian Centre for Social Innovation, 2013).

Participatory design (PD) has "the goal of working directly with users (and other stakeholders) in the design of social systems..." (Muller \& Kuhn, 1993). PD started over 40 years ago in Scandinavia, and was originally a democratic movement sparked by advocates of 
unions of workers in the software industry who wanted a stake in their work decisions (Muller \& Kuhn, 1993). As the movement progressed into Europe and then the United States, new methods emerged, and it was also applied to other related fields, such as product design (see Figure 9). As participatory design emerged, the techniques of fieldwork were integrated into the original PD techniques. The fieldwork techniques used include open-ended interviews and participant observations, which are often merged with the use of prototypes, mock-ups and scenarios to envision the future product, design or service (Kensing \& Blomberg, 1998).

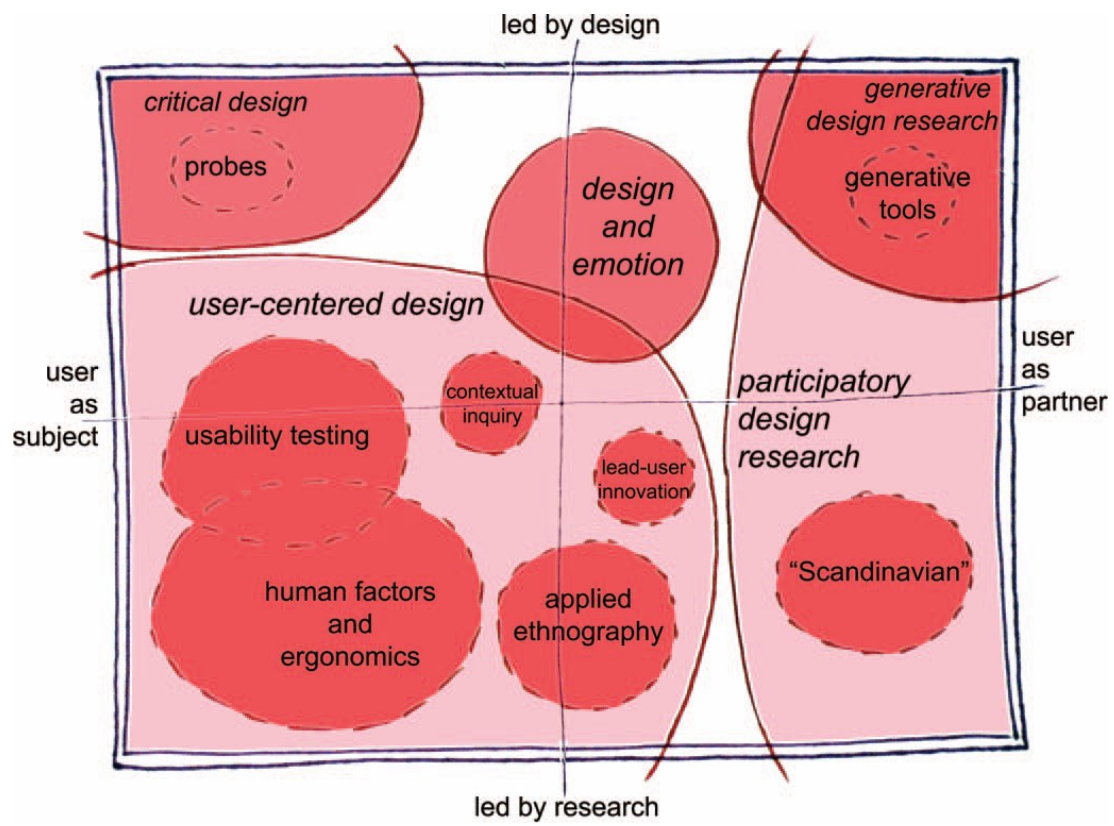

Figure 9: Co-creation has been known by many names. The diagram above shows differences that are found among different methods of designing with the end-user (Sanders \& Strappers, 2008).

Some participatory design methods (see Figure 10) that are commonly used include: Card Sorting, allowing users to sort concepts or pictures into meaningful categories in order to gain insight into how the user thinks; Creative Toolkits, giving users a collection of physical elements (often in different shapes, sizes and colours) and allowing them to manipulate these elements or 
configure them in different ways to show their preferences; Customer Experience Audit, observing and discussing with users about their experience with a product in the context in which they use it (such as their home or place of work); Evaluative Research, also called product testing, which involves having potential users test products to determine if they are usable, useful and desirable; Experience or Product Prototyping involves having users test out prototypes at various levels of refinement by acting out scenarios with physical objects in order to find out what users need and want from the product (Martin \& Hanington, 2012, pp. 25,28,56,74,78, 138). However, in "Design with the Majority" projects, ethnographic methods are also commonly used, which are explained further in chapter 3.

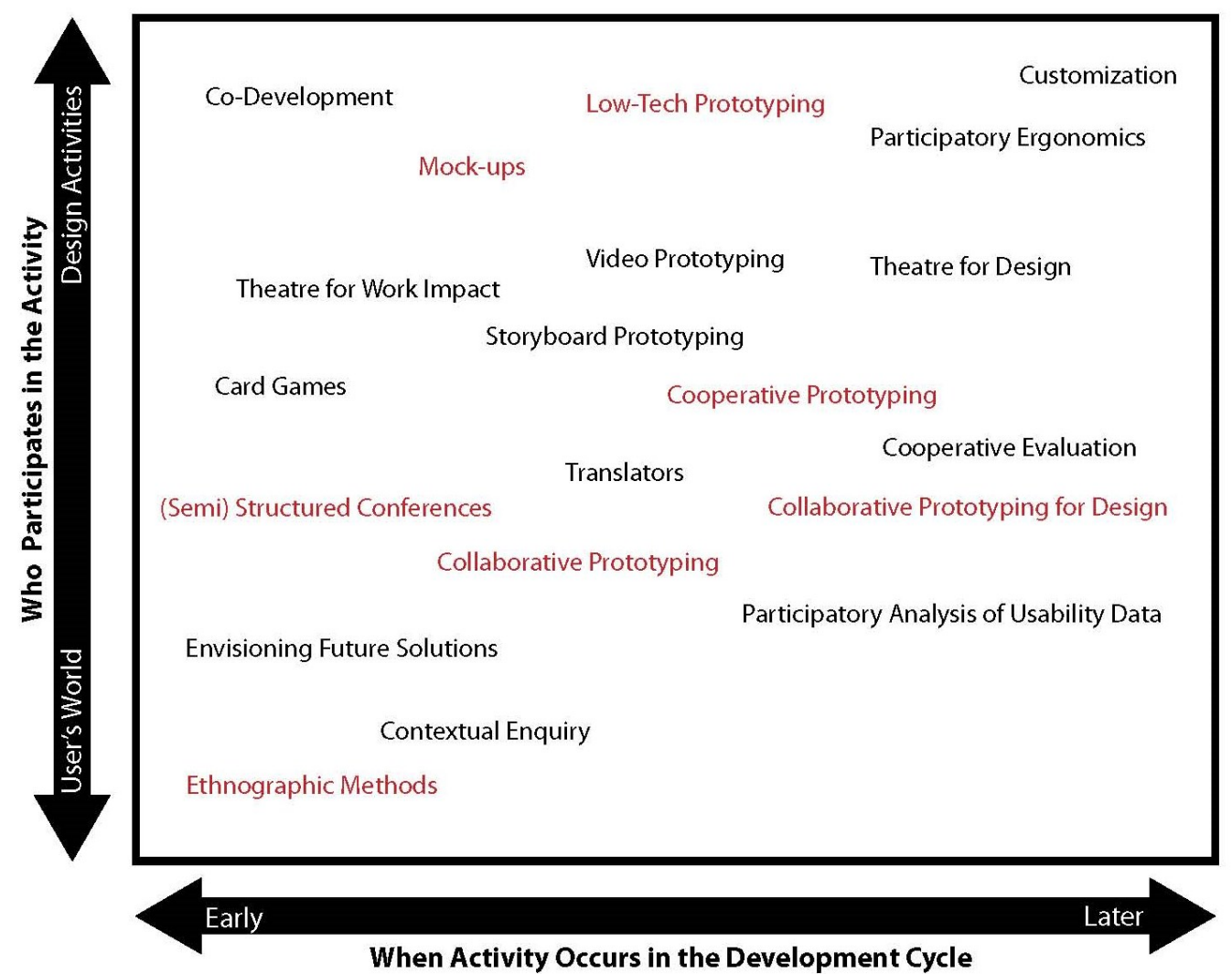

Figure 10: A diagram showing some of the methods that can be used for communicating and collaborating during the co-design process. Practices vary in a few key dimensions, such as the time it takes, at what part in the process they should be used and who participates in the activity. This diagram was reproduced for this thesis, and simplified to make it easier to read. The methods in red are those that were used by the designers in this project (Muller \& Kuhn, 1993). 
Design is not the only field that stresses the importance of stakeholder participation. The World Bank also recently published a report about participatory communication in development projects. This process is often divided into four main stages: research, design, implementation and evaluation. These stages correspond to similar steps in the design process. It is believed that participation in the process will help give a voice to the "beneficiaries", which helps to balance existing power-relations, and is especially important for the poorest and most marginalized groups, including women and the disabled (Tufte \& Mefalopulos, 2009).

\subsection{Poverty and Disability in sub-Saharan Africa and Uganda}

People living in extreme poverty are mostly concentrated in sub-Saharan Africa (World Bank, 2014b). Many of those who have surpassed the extreme poverty category came from Asian countries where people were living on only slightly less than a dollar a day, leaving the poorest behind (World Bank, 2014b). The poorest people often live in rural regions, suffer from malnutrition, and are less likely to have easy access to education or health services. In Uganda, it seems that most people associate poverty with disability (Magoola, 2014).

Uganda has a recent history of conflict which has led to a higher than average incidence of disability in the region. A lack of sufficient medical care also leads to people suffering from diseases that are preventable or treatable in other parts of the world. Those with disabilities in the majority world are also often left out of institutions and markets where they may be able to improve their welfare to become less impoverished. In surveys, long-term ill-health is often mentioned as contributing to poverty, and in one study, three-quarters of the participants traced their fall into poverty as being caused by unexpected ill-health (International Food Policy 
Research Institute, October 2007). According to the World Bank, not only does it cost money to treat the initial sickness or injury, but that person's future earnings are also lost. Sometimes additional family members are also unable to work since they must stay home to take care of the person who has become disabled. Conversely, those who are already in poverty are often at risk of becoming disabled due to malnutrition, a lack of access to clean drinking water, and less access to medical help, making it more likely for a minor illness to turn into a long-term disability (World Bank, 2014a).

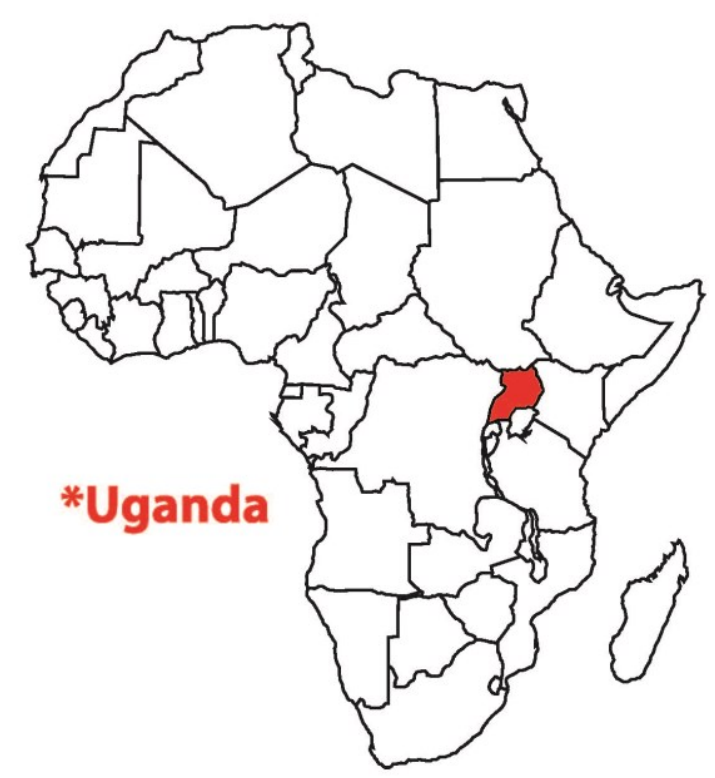

Figure 11: A simplified map of Africa, highlighting Uganda, which is in East Africa.

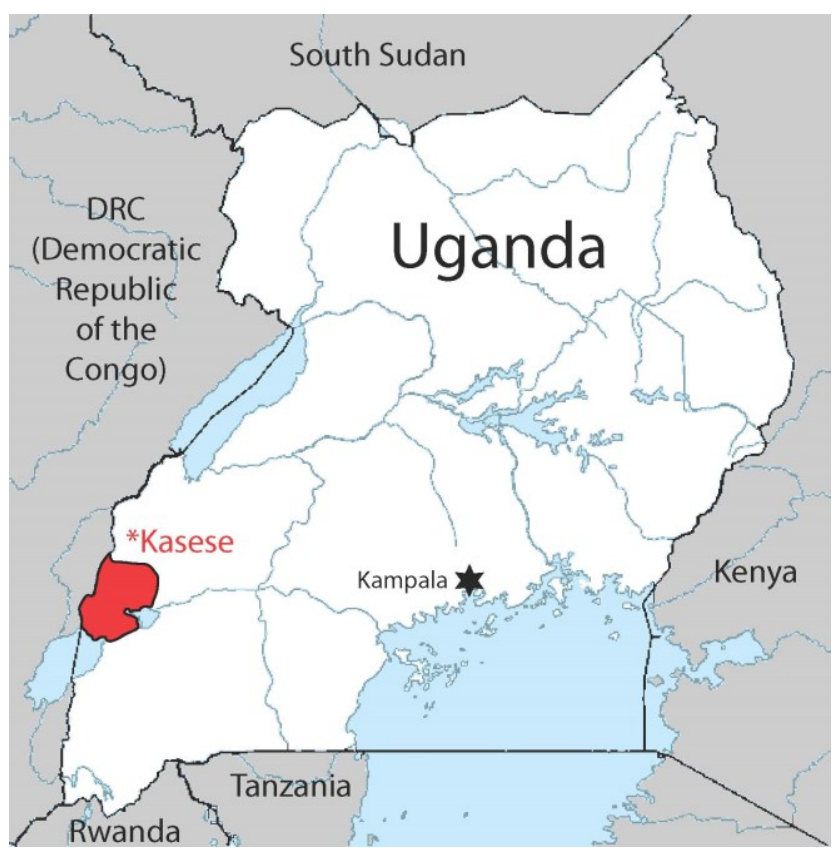

Figure 12: A simplified map of Uganda, highlighting Kasese District and Kampala.

In Uganda specifically (see Figure 11 and Figure 12), it was found that there is a 15 to $44 \%$ higher chance of a household being in poverty if the home has a disabled head of household. In urban areas the probability of poverty was $60 \%$ higher with a disabled head of household. Children with disabilities are also less likely to attend school, leaving them fewer 
high-income job opportunities in the future (International Food Policy Research Institute, October 2007). Uganda has tried to advocate for PWDs by mandating that a certain number of government representatives at all level be people with disabilities. However, there is still a societal stigma and discrimination for being disabled in Uganda.

Uganda is one of the forty-nine Least Developed Countries (LDC) according to the UN, which means they have an overall low level of per capita income and a high degree of economic vulnerability. It is estimated that $80 \%$ of people with disabilities live in developing countries (United Nations, n.d.). The proportion of the population that is below the poverty line has dropped from 56\% in 1992 to $31 \%$ in 2005, which is a major improvement. However, most of the population still relies on subsistence agriculture for their livelihoods (Ministry of Finance, Planning and Economic Development, 2010). The average annual per capita income (US dollars) is $\$ 280$, as of 2005 , which is less than $\$ 1$ per day (Farrell, 2007).

Disability plays a key role in influencing the perceptions that others have of disabled women in Uganda. In particular, it seems that in Uganda, being independent or self-sufficient instead of being seen as a burden to your family is a strong indicator of being more accepted as a respected person within the family and community (Shwartz, Park, \& Rebecca, 2011). An International Labour Organization study in Uganda looked at disability and its relation to the labour force. In Uganda, it is often difficult for a PWD to find a job, as they are often excluded from the labour market. This leads to lower productivity for people with disabilities, due to a discriminatory environment, a lack of education and training, a plethora of negative attitudes, and increased unemployment. The study concludes that economic losses related to disability are 
large and measurable, ranging from between three and seven per cent of GDP (Buckup, 2008).

\subsubsection{Assistive Devices for People with Disabilities in Uganda}

Funding for assistive devices is a huge challenge around the world. People with disabilities are often some of the most-restricted members of society in terms of generating an income (The Republic of Uganda - Ministry of Health, 2013). Without access to an assistive device, their ability to get around the community or to work is hindered even more. There are a few main avenues to look at for funding assistive devices, which include: the government (which may do so in the form of grants, tax breaks, subsidies, devices given out by public hospitals, etc.); non-governmental organizations (international, national or local); the private sector (which generally donates either money or resources to NGOs who distribute it to PWDs); or the individual who is need of the device themselves (possibly with help from friends and family). There are benefits and drawbacks to each of these potential revenue streams, and there is presently a serious shortage of funds for assistive devices within Uganda (The Republic of Uganda - Ministry of Health, 2013).

Within the context of Uganda, there are three main categories of assistive devices for those who cannot walk and need assistance for their mobility. These include donated hospital wheelchairs, locally made wheelchairs and tricycles.

- Donated wheelchairs are the most affordable (usually free to the organization and therefore free to the recipient); however they are not designed for the rough terrain of Uganda and tend to break quickly (see Figure 13). They are easy to fold for travelling over long distances and can be used indoors, but are often not properly fitted and cannot 
be easily maintained locally, since spare parts are often not available (Whirlwind Wheelchair, April 2004).

- The most popular locally made wheelchair is called the Huckstep Wheelchair, originally named after Dr. Huckstep who started the Mulago Orthopaedic Workshop in 1967 (see Figure 14). It is very durable and well suited to the environment in Uganda. It is affordable, since it is made in Uganda of locally available parts, but it is not foldable for long-range travel and cannot be used indoors (Whirlwind Wheelchair, April 2004).

- Tricycles are ideal for medium-length distances and can more easily manoeuvre over environmental barriers such as potholes or curbs, which may be difficult for wheelchairs (see Figure 15). They can be made in the region from locally available materials (such as bike parts), which make them easy to maintain. However, they also cannot be folded, are too large to be practical for indoor use, and are slightly more expensive than the wheelchairs (Whirlwind Wheelchair, April 2004).

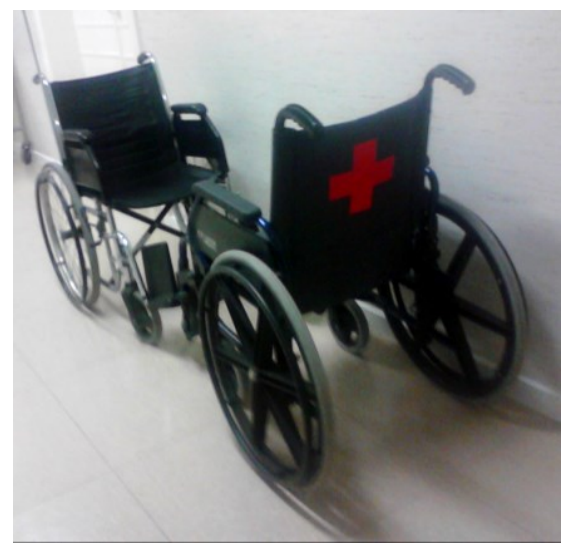

Figure 13: Used hospital wheelchairs are often donated (Toledano, 2014).

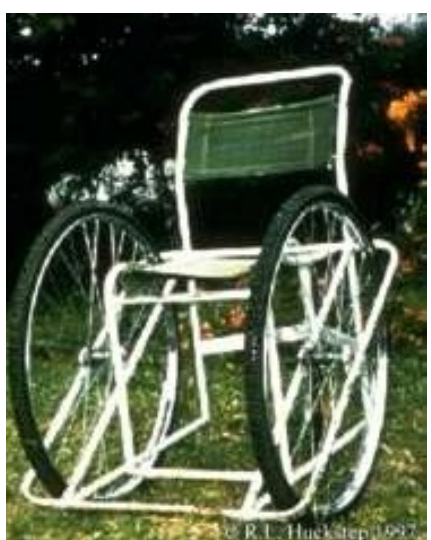

Figure 14: The Huckstep wheelchair (Krizack, 2000).

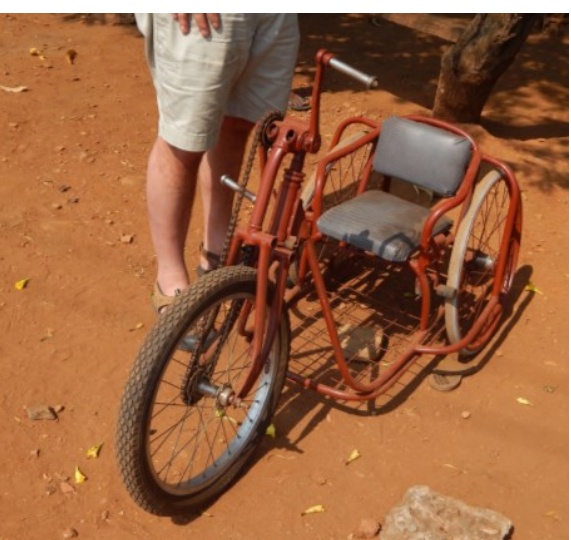

Figure 15: Hand-powered tricycles being produced in Uganda. 
Wheelchairs, and other mobility devices, are not only used for the purpose of transportation, they may also have other benefits for the user. These benefits may include improving social interactions, creating income generating opportunities, and increasing the ability to get a full education (Mukisa, 2008). Assistive devices are important for allowing the person to regain their independence and mobility.

\subsubsection{Telecommunications and Infrastructure in Uganda}

Since Uganda is in the majority world, some important factors must be taken into account for the project, such as the access to specific technologies that relate to the project. The statistics vary, but only between 1 and 3\% of households in rural Uganda have access to electricity in their homes. Even in major cities, only about $40 \%$ of homes are electrified. Since the Ugandan government is looking to create universal access to telephony, the lack of electricity is a huge barrier (Farrell, 2007). Therefore, the idea of using solar panels as phone chargers seems like a good way to increase access to renewable energy sources and also seems as a good way to earn an income, since most people do not have this service available to them in their house. There are approximately 9.8 million mobile phones in the country (which is about one in every three people) as of March 2009, and the number is still on the rise. In July of 1999, Uganda became the first country in the world where mobile phone ownership surpassed the number of landlines in the country. Mobile phones are not just used for talking and texting, Ugandans also use them as a banking service, by transferring mobile minutes, sending/receiving money and paying bills. Phones can also be used for finding out about prices in agriculture and education (ITU News, 2009). Therefore, by creating a business that facilitates the use of mobile phones, Uganda's economy and people can benefit in many important ways. 


\subsubsection{The Informal Sector and the African Artisan}

During this project, we worked heavily with Kio, a local manufacturer. The first step of this process was to have Kio Metalworks (the local manufacturer in Kasese) produce the tricycles with solar-charging capabilities. Kio runs a shop in the dirt yard between his house and the main road (see Figure 16 and Figure 17). He uses simple tools such as grinders and drills to create his products, and even his welding machine is hand-made. His shop is based on one "master" metal worker (Kio) who has a team of workers (he usually has three apprentices and perhaps one other "master" metal worker). He pays his workers per hour for their services. Before starting to work with KADUPEDI, Kio created simple house products like windows, bed frames and cooking stoves out of metal. He still creates or maintains these products on the side, and also fixes tractors during the farming seasons. He created the original design for the tricycle based on seeing another tricycle and trying to replicate it. He uses what he learns on each tricycle to change the next tricycle. Therefore, they are not standardized (which would have benefits in terms of replacement parts) but they are uniquely created for each order (which has benefits in terms of customizing each device to the particular user). Kio's shop has been making these tricycles since Navin Parekh, the founder of CanUgan, created the idea to distribute them in Kasese in 2010.

According to Bashir Rajab Kagere, a Policy Analyst for the Uganda National Council for Science and Technology, Kio would likely be known as a "Jua Kali." Jua Kali is literally translated as "hot sun" in Swahili, and is meant to describe their outdoor working conditions. Jua Kali are, in Kagere's (2011, p. 5) words, "small scale artisans eking out a living through manufacturing of products and offering services in the open scorching heat of the sun." These 
builders often are the sole owner of their business, which is very labour intensive. They use local materials to copy or imitate designs they have seen elsewhere. Often, they do not lay out plans in a formal way, and work more like an artist might. It is estimated that 800,000 of these small enterprises can be found in the informal sector of Uganda, which may contribute up to $20 \%$ of the GDP. These small businesses are so prevalent due to industries with poor performance and a high level of unemployment in the country (Kagere, 2011).

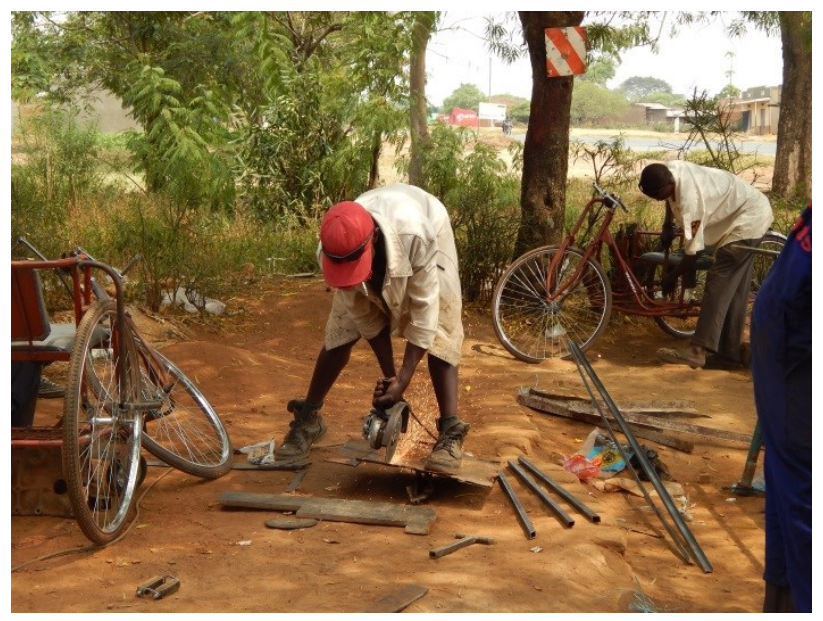

Figure 16: A photo of Kio (the manufacturer) grinding a sheet of steel for use on a prototype at his workshop in Kasese, Uganda.

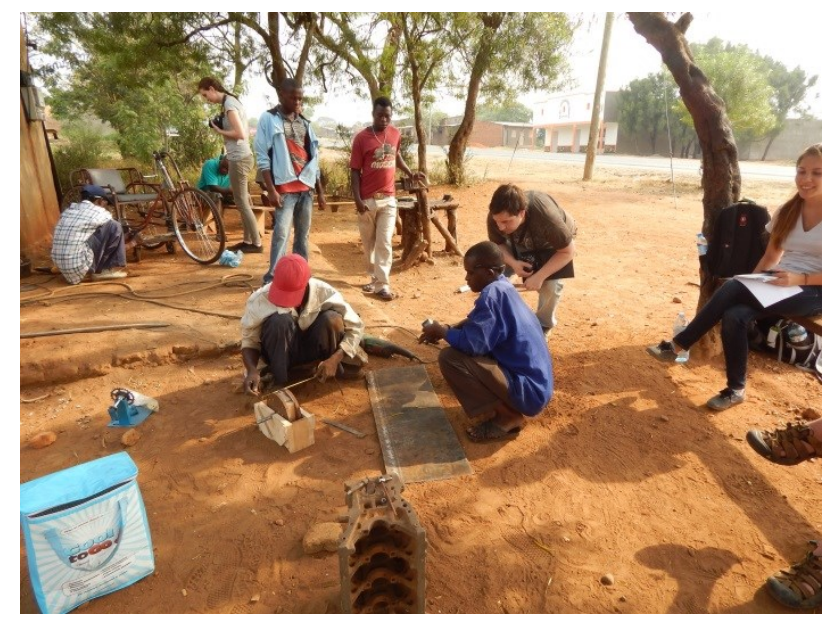

Figure 17: A photo of Charles Williams (Carleton University) working with Kio (the manufacturer) at Kio's workshop (with other workers and students in the background).

Jua Kali in the metal fabrication business (like Kio) often fix vehicles and build simple metal furniture and housing construction components (like bed frames, windows, tables and doors). Their products are often imitations of products they have seen, or built to fit a gap in the local market where no product exists. They have very low technology levels, and skills are learned on the job instead of through formal training. These businesses are small, with less than five employees, and never grow, since their money just simply goes to surviving, instead of back into the business. One interesting fact is that, according to a study done by Z.M. Nyiira et al in 
$2001,45 \%$ of these businesses didn't create any new products in their repertoire over a three year period. This means that collaborative relationships with designers and engineers might really help their businesses and inspire new profitable ideas (Kagere, 2011).

In the book, The African Artisan by Kenneth King (1977), he explores the informal sector in Kenya. He describes the African artisan as one who uses indigenous resources, has a smallscale business, uses labour-intensive technology, has informal skill acquisition and works in unregulated markets (Sheffield, 1979). This definition is very similar to the one of a "Jua Kali" and they should be taken as synonyms within this context. The World Bank and many other large aid agencies are interested in this aspect of the informal sector, and are looking into ways to tap into its productive potential (Sheffield, 1979).

\subsubsection{Kasese District}

Kasese is one of 111 districts in Uganda, and is comprised of 22 sub-counties. It is located on the western side of Uganda, and borders with the Democratic Republic of the Congo. Only $37 \%$ of the land in Kasese can be used for living and growing, since the rest is made up of national parks, bodies of water and land devoted to government projects. Kasese also has a very young and rural population. The primary economic activities in the region include cement and cobalt processing, tourism in the national parks, hydropower, coffee and cotton production, cross-border trading and farming. However, as of $2002,48 \%$ of the rural population was still living below the national poverty line. According to the report, the population of Kasese District was 523,033 in 2002, with it expected to rise to 1,087,133 by 2022 (Renno, Twinamasiko, \& Mugisa, 2012). Based on these population numbers, and using the average of $16 \%$ for the 
number of people in Uganda who are disabled, it is estimated that in the year 2002, 80,000 people had disabilities, with the number of PWD expected to reach over 160,000 in the region in eight years' time (CanUgan, 2014a). Specifically, people with disabilities are at a high risk of being or becoming poor due to a lack of economic opportunities, which also coincides with a lack of access to services. In recent years, a vast majority of PWDs have joined one of the local support groups for people with disabilities in their region, but many still feel that there are negative attitudes and discrimination from the rest of society towards them (Renno, Twinamasiko, \& Mugisa, 2012).

In 2012, the Kasese District Poverty Reduction Programme, in conjunction with the Kasese District Local Government and the Belgo-Ugandan Study \& Consultancy Fund conducted a study on poverty in Kasese. It was found that over two-thirds of the people in Kasese with a physical disability indicated that they had been disabled as the result of an accident or illness, which means many of these could be prevented in the future, thus reducing the number of people with mobility impairments. However, as life-expectancy rises, the percentage of elderly people also grows, which increases the number of people likely to need a mobility aid. According to the study, the primary issue affecting PWDs in the region is low incomes and restricted involvement in certain economic activities. Respondents indicated that their preferred assistance in their community would include loans, productive assets, assistive devices and vocational training. These findings imply that people with disabilities do not want to rely on their family for help, but want assistance to create their own independence through income-generation (Renno, Twinamasiko, \& Mugisa, 2012). 


\subsection{Conclusion}

This project is interdisciplinary in nature, so it was important to research many different factors which may affect the design process for people with disabilities in the majority world. After learning more about international development, participatory design practices and some of the economic and social contexts shaping PWDs living in Uganda, it was essential to revise the research questions and begin primary research. The methods used involved participatory design researching (on the author's part) and participatory design (by the undergraduate students). This literature review will be compared to the other methods used in the results section, in order to compare research generalities to specific findings in the case study. 


\section{METHODOLOGY}

\subsection{Introduction}

This chapter will describe the various methods used in order to obtain information about the topic of income generation for people with disabilities. All of the research was done in consultation with CanUgan and KADUPEDI. The groups were chosen because the School of Industrial Design at Carleton University already has a connection with them from the previous year, making it easier to communicate and network efficiently. KADUPEDI also has a unique focus on working with people with disabilities as well as working with a local manufacturer to produce new goods. This combination is perfect for looking at how design can influence the lives of people with disabilities in the majority world. The devices which were delivered by KADUPEDI are funded by CanUgan. Through this network of organizations, collaboration is possible and much more efficient. The project also involved a trip with a professor, four undergraduate students and the author to Uganda in February of 2014. The trip was an opportunity for the undergraduate students to test their design solutions and work with the local manufacturer. It was also an opportunity for the author to conduct primary research and to discuss the project with representatives from KADUPEDI and other relevant people in Uganda. The first section describes a detailed version of the research questions. Afterwards, the reader can find a timeline for the project which will better orient the reader to the scope of the project. The following section describes the various methods used, followed by the method of analysis used. 


\subsection{Research Questions}

Based on the literature review, the following research questions emerged. Although each of the questions individually is not brand new, the intersection of design, international development, and disability research is an interesting angle on some of the ideas that have already been developed in those areas. The primary research questions are listed below, and also include some hypotheses about the likely outcome of the research in that area.

\section{Issue \#1 - Income-Generating Devices}

Question 1 - What effect does this income-generating device have on the recipient in terms of both economic and social aspects of their lives?

Hypothesis 1 - It seems that earning an income in Ugandan society is an important aspect of being an adult family member, and thus would likely reduce the social stigma and the feeling of being a burden for the person with a disability. It is likely that all of the participants will make an income using the device, but it is unclear how much they will make, and if it is enough to sustain themselves and their families over the long-term.

\section{Issue \#2 - Independence/Dependency}

Question 2 - Does this system of giving away income-generating tricycles to people with disabilities eventually lead to people who are independent and not in need of anymore additional assistance or does it create a dependency relationship?

Hypothesis 2 - This depends highly on the type of device being given out and the cost of the device. However, it is important to look at the possible income that can be made, in order to see whether it is sufficient to pay for the device or not. If the device costs more to produce than the 
participant could ever make in the future, then maybe an alternative approach to poverty alleviation is necessary. Since this project has such a short time frame it is impossible to fully verify if it would be successful in becoming sustainable. However, it might be possible to show that it is likely to be sustainable or unsustainable based on certain issues that may come up (such as the amount of money they make being able to cover the cost of the device). Since the device is being given for free, this may lead to a higher chance of dependency, when it seems that CanUgan's overall goal is for the people to be completely independent afterwards in order to give their funds to other individuals in need.

\section{Issue \#3 - Design Efficacy}

Question 3 - Are the products which were disseminated appropriate for these people in this context (looking at the design efficacy of the products designed) in terms of mobility and income generation?

Hypothesis 3 - Ideally the products would be perfect for the users, however it is likely that some issues may be found which could be solved in future iterations. It is unclear whether a solarpowered charging station is the ideal product for this market. It is important that researchers continue project evaluation after the project is complete and products have been given to recipients, since this is more likely to lead to successful implementation. This is why pilot programs are generally a good idea before complete roll-out.

\section{Issue \#4 - Complexities of "Design with the Majority" Projects}

Question 4 - What are some of the complex issues that come into play when working on a collaborative, cross-cultural "Design with the Majority" project? 
Hypothesis 4 - Some of the benefits of a Canadian university design team working with others (such as recipients, local organizations, manufacturers, NGOs and other universities) in Canada and Uganda might include diverse knowledge sets, a more contextually appropriate design, and the ability to generate more funds. Some of the drawbacks might include difficulty communicating, different cultural perspectives, and an inability to understand occupation specific jargon.

By evaluating each of these research questions, separately and together, future researchers may be able to understand how to better design a product and implement a project for those with disabilities in the majority world. Furthermore, this thesis will assist designers in western countries with understanding how to effectively communicate and coordinate with NGOs and other organizations in different countries. Therefore, this research will employ the following methods to answer these research questions: questionnaires, interviews, and observations.

\subsection{Introduction to the Methods Used}

This research involves a case study in order to conduct an in-depth investigation of a single product and its influence on a single community, through the use of multiple participants. For an idea of the schedule of the project, refer to the timelines in Appendix A. The focus of a case study is on the depth of information collected about those involved, instead of about the breadth of the knowledge (which in this case would mean that the generalizations cannot necessarily be applied to different areas of the world or different product categories without further consideration of the differences involved) (Martin \& Hanington, 2012, p. 28). 
The primary research took on an exploratory approach, using four methods of ethnographic fieldwork, including: contextual inquiry, participant observation and interviews, workshops and questionnaires. Secondary research, which can primarily be found in the Literature Review (Chapter 2), was completed before the field study in Uganda, as a way of understanding some of the issues that may affect the participants before conducting the other methods of research involved in this study. This was especially necessary, since the researcher was unfamiliar with the context, and it allowed the researcher to properly formulate questions and criteria for the following methods (Martin \& Hanington, 2012, p. 154). Design ethnography is the way designers approximate the methods of immersion used in traditional ethnography based on the social sciences, and revolves around qualitative research of people in their natural setting. The primary method used was interviews and participant observation (Martin \& Hanington, 2012, p. 60). Contextual inquiry involves observing and interviewing in a very immersive and contextual way, instead of in a lab or another controlled environment. This type of inquiry involves more time and travel, and requires that researchers understand the day-to-day activities of the people who they are learning about (Martin \& Hanington, 2012, p. 46).

Design workshops allow many different people to come together in one setting in order to discuss a product and reflect on the different aspects of its design and usage. Although they require time to set-up, they are actually efficient, in that you can bring together many types of stakeholders at once. The workshop we held was evaluative in nature, which meant that it gave stakeholders the opportunity to collectively review concepts and offer feedback and other insights into the further refinement of the designs (Martin \& Hanington, 2012, p. 62). Questionnaires were used alongside interviews as a way to find out first-hand information from 
the participants. However, since the participants are not native English speakers, the questionnaires were administered by a volunteer in the local language who recorded the responses. The questionnaires used a mix of open and closed-ended questions, depending on the type of data the researcher was interested in, and thought would be useful (Martin \& Hanington, 2012, p. 140). Interviews were used to get a first-hand experience of the product from the pointof-view of the user, and to clarify and validate any questions that were unclear or unanswered after the first round of questionnaires. The author used a series of semi-structured interviews (based on interview guides found in Appendix E), depending on which stakeholder group the interviewee was representing. However, the researcher still wanted the interviews to be conversational in style, and allowed them to flow along with the natural conversation that occurred (Martin \& Hanington, 2012, p. 102). Participant observation was also carried out during the field-study, and allowed the researcher to understand the conditions in which the participants lived, as well as the condition of their devices. These observations were primarily documented with photographs, short video clips and field notes. Observations also took place during interviews, and were often followed-up by related questions to what was seen by the researcher (Martin \& Hanington, 2012, pp. 120,124).

The devices that were made are based on models that were created by the fourth year Carleton University Industrial Design students in their major studio class last year as part of a participatory design process with end users, disability organizations and the local manufacturer. Two of the prototypes were selected as being the most feasible for income generation. The original versions of these devices are still in Uganda, and it was important to look at how they are being used before distributing new ones. The first device is a grinder attachment that can use 
the hand crank from the tricycle to grind agricultural outputs; including turning groundnuts (a type of peanut) into flour (see Figure 18). Since the ground nut flour can be worth almost four times as much as the nuts in their raw form, there is a great opportunity to develop an income. The ground-up nuts are also a common cooking ingredient in the local cuisines of Uganda. According to KADUPEDI, the lady who originally received the device in February 2013, Biira Gatrida, was initially very satisfied with using it. Unfortunately, she is recently deceased and the device is no longer in use. It was found that the parts for this device could not be sourced locally, and some issues were discovered in the design related to its capacity and the effort necessary to use it, so it was decided that only the second device would be given out for the study.

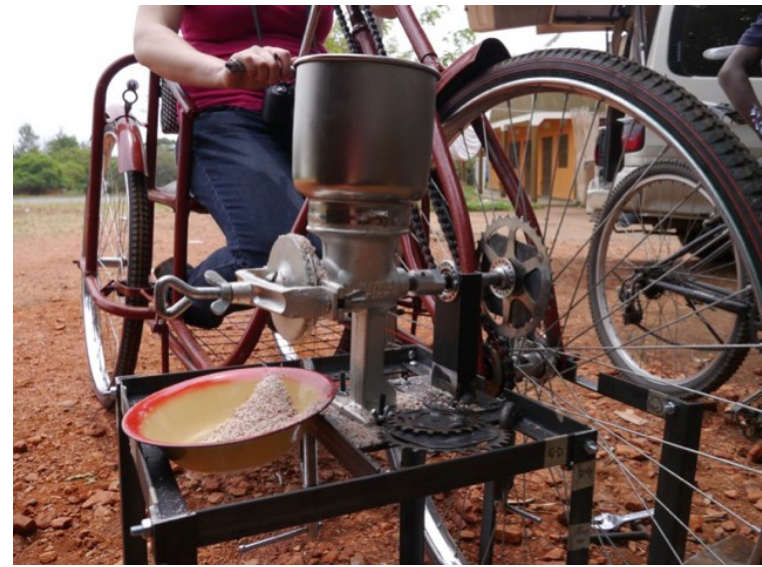

Figure 18: Original version of the nut grinding attachment from last year in Uganda.

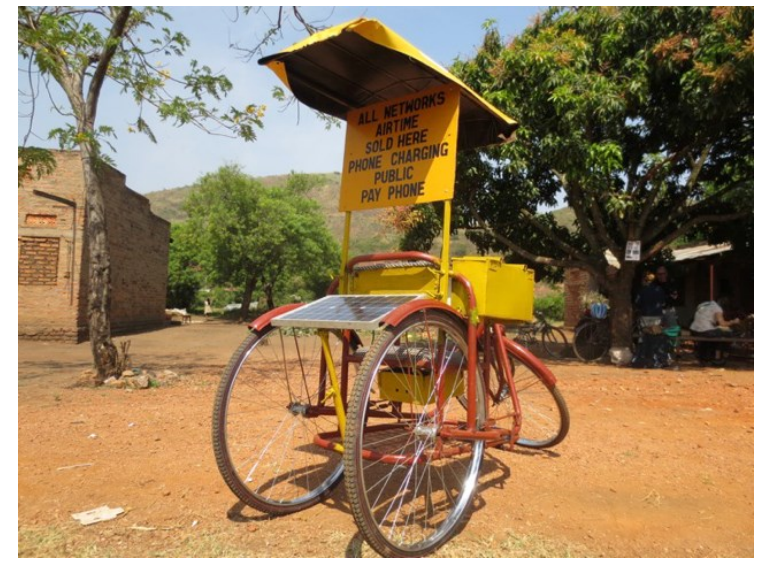

Figure 19: Original version of the solarcharging attachment from last year in Uganda.

The second type of device is a solar panel station, which attaches to the tricycle. The solar panel powers a battery, and an inverter allows the power to charge people's phones. Since most people have phones but do not have electricity in their homes, this is a useful service and can be used as a business (see Figure 19). The solar-charging kiosk also has an umbrella to protect the user from the elements and give visibility to the business. The original solar-charging 
kiosk tricycle was given in May 2013 to a lady named Margaret who is currently using the device. Many questions about her experience with the device were asked throughout the process.

In collaboration with CanUgan and KADUPEDI, we developed criteria for who would receive the devices (see Appendix D). It was useful to develop a questionnaire for these recipients in order to determine their current condition and lifestyle (such as type of disability, estimated income, daily tasks, social standing, etc.). KADUPEDI selected six recipients who would receive a device for the project and had them fill out the initial questionnaire. During the next month, one of these potential recipients actually received a device, and, sadly, one of the potential recipients died. Therefore, during the field-work in February, four of the potential recipients were left to interview before receiving a device. However, due to issues with the construction, payments and the timeline, the team decided that only two of the remaining four potential recipients would actually be able to receive a device. The two who did not receive a device were taken out of the project due to the research team's perception that the incomegenerating device would not be good for them specifically. In particular, one lady seemed to have trouble using the tricycle, due to her size and strength, and one boy wanted to go back to school and would have no time to offer this service.

The initial questionnaires were used to gauge the progress of each participant with using the device. During the trip in February, this information was compared to their current lives, in order to determine whether the devices have had a significant positive impact, and what changes needed to be made. The researcher interviewed each of the six recipients (the four potential recipients plus two who already had the device from last year) to ask similar questions. They 
were also visited again at the beginning of April by KADUPEDI with a new questionnaire created by the researcher. The new questionnaire focused on some questions for clarification as well as more current data, such as if the recipient had gone to school as a child, how much money they were able to make with the device, and how their life has changed since receiving their new device, in both economic and social dimensions. The representatives also took pictures of the recipients with their device for records purposes.

\subsection{Initial Questionnaire (Before Recipient Selection)}

Questionnaires were given by the researcher to representatives of KADUPEDI in Uganda to ask questions of the recipients, in order to learn about participants before heading to Uganda. This also allowed the manufacturer to give out the devices earlier in the process, in order to facilitate the recipients' potential to have a longer period of time with the device. The questionnaires were sent by email, and printed, and then filled-out in Uganda. The results were then scanned and sent back to the researcher by email in order to analyze the results. The initial questionnaire (see Appendix B) was meant as way to help select new participants and find out information about their life before getting the device.

Since the researcher was not in Uganda, Carleton University enlisted the help of the local organization, KADUPEDI, which supports people with disabilities in the community. The volunteers at KADUPEDI were in charge of asking the potential participants the questions and writing down their answers. The reason they wrote was because many of the participants were likely to be illiterate and most of them do not speak English. Therefore, they translated and transcribed the answers so they could later be included in the thesis. 
The contents of the questionnaire included basic questions about age, gender, disability and income and complex questions about family structure, household tasks and some basic business planning for the income-generating project. They looked at many issues including: what their typical day/week looks like; their role within the family; and about the social stigmas/ expectations for people with disabilities in the region. One interviewee had already received a solar-charging device, and two other interviewees were current users of the original tricycle. These interviews also included questions such as: how they located customers; how much time they spend selling; how much money they have made; what they have used the money for; if they had any issues with the device; suggested improvements for the device; and what has changed since they have received the device (the complete questionnaire can be found in Appendix B). These answers were given to the researcher, and served as a baseline for comparing with interviews and later questionnaires. It also allowed the volunteers a way to compare the participants in terms of the criteria for selection (next section).

\subsection{Criteria and Selection}

One of the most important aspects of interviews is deciding who to talk to. The people at KADUPEDI were given a list of criteria for the type of people who would be useful to include as recipients for the solar-powered tricycles, which was decided on by CanUgan and the researcher, with consultation from KADUPEDI (the entire criterion can be found in Appendix D). The basic criterion was that the user is disabled and needs a mobility aid but also has enough strength to use a hand-powered tricycle. This criterion also included equality guidelines for relevant distinctions like age, gender and type of disability. The original criteria stated that people chosen should be from different regions for equality purposes, however this was deemed impractical for 
the purposes of information collection, since it was difficult for the researcher and volunteers to travel often to these remote areas. For this reason, a convenience sample of participants close to KADUPEDI's office, or those who could easily travel to KADUPEDI for follow-up questions, were preferred for the study.

The criteria also contained aspects that the researcher felt would lead to higher likelihood of success, such as having business planning with details including where they might find customers, how much money they think they can make, etc. The people from KADUPEDI used the criteria document to decide which participants were chosen, and were able to explain their rationale to the researcher. KADUPEDI has a team of volunteers in each sub-county who nominate a PWD who might be appropriate for receiving a device, and KADUPEDI selected participants from this list according to who met the criteria.

\subsection{Devices Given Out}

In general, after KADUPEDI decides who the recipients should be, they are brought to Kio's workshop to test the tricycles. If they are able to use them, they are called when the tricycles are ready to be picked up. If they are unable to use them, due to a lack of strength or movement in their arms, they are recommended to go seek physiotherapy at the local hospital (which Robert, who works at the hospital, and is the Treasurer of the CanUgan project for KADUPEDI, says can be obtained for an affordable cost). After the tricycle is made, the recipients collect the devices at the office of KADUPEDI, and sign a consent form to ensure KADUPEDI is not at a legal risk if there are any problems related to the device. Two weeks later, representatives from KADUPEDI visit the recipients in their homes, to see how well they 
are doing with their new tricycles.

For this project, after the six new recipients were chosen they were to be given a device built by Kio to suit their needs (based on their size and disability). These devices were paid for with a generous grant from the IDRC. However, there were issues with payment and sourcing parts for the devices, so the timeline was pushed back. Therefore, only three devices were made before February, and it was deemed too late to start making new devices. Additionally, one potential recipient passed away before getting the chance to try the device. Therefore, initial questionnaires were completed for six people, in-person interviews were conducted with two people who had already received a device and four people who would potentially be receiving the device, and final questionnaires were carried out with three of the four recipients who ended up receiving a device by April 2014.

The device recipients are able to use the device for their own mobility needs in getting around town. They are also able to use the solar-charging attachments to generate an income for their family. For some this may mean setting up a kiosk in the local market or some may offer the services from their own home to those in their community. It is up to the participants how they use their device, but their strategy should be described in the business proposal section of the initial questionnaire. KADUPEDI's perception of the person being able to run a successful business was crucial in the selection of recipients. The success of the product obviously also depends on other factors, such as if the person is motivated, if they have good sales techniques, if they have time in their day dedicated to income generation, and many other factors. These factors were evaluated during the interviews and follow-up questionnaires. Devices were given 
out completely free, in exchange for full participation in the study, including taking part in questionnaires and interviews, and providing their accounting information. Further reflections on the information received from the participants can be found in Chapter 5 .

\subsection{Interviews}

\subsubsection{Meeting with Device Recipients}

During the month of February, the researcher travelled to Uganda for approximately two weeks. There were three types of recipients interviewed, though all had a physical disability that led to mobility impairments, were poor and lived in the region of Kasese. The first group is current tricycle users (two interviews), the second is current tricycle users who also have a solarcharging device (two interviews), and the third group is potential users of the tricycle who could potentially receive a solar-charging device (four interviews).

The researcher, with the team from KADUPEDI, travelled to the houses of two of the device recipients and one potential recipient, to spend some time with them, in order to get a better feeling of what their daily life is like. The researcher also interviewed them. The other three potential recipients were interviewed at Kio's workshop for convenience sake, since they were already there to try out their new tricycles. The researcher asked the past recipients (who were referred to by KADUPEDI) questions about their experience with the device and their ability to generate an income. The potential recipients were interviewed in their homes and at the KADUPEDI office, and were asked questions about their lives and their plans for the income-generating device. 
The interviews were conducted in a semi-structured manner, based on an interview guide (see Appendix C), which is "...a written list of questions and topics that need to be covered in a particular order” (Bernard, 2011, pp. 157-158). During interviews, it is often useful to use probes in order to gain more information from the interviewee, after the original question is answered. These probes may include reformulation of the question, making comments (uh-huh probe), summarizing the information (echo probe), a request for clarification (tell-me-more probe) and others (Gobo, 2008, p. 196) (Bernard, 2011, pp. 162-166). It is also important for the interviewer to try and avoid bias or leading questions, as this may influence the results. One factor that may affect the answers given is social desirability, where the interviewee tries to please the interviewer by giving the socially appropriate answer instead of a more accurate answer. People also have a limited ability to remember, especially over longer periods of time (Gobo, 2008, pp. 194-195) (Bernard, 2011, p. 180). Another factor that came into play was the Third-Party-Present effect, which may cause interviewees to answer questions differently than they might do alone (Bernard, 2011, p. 181). However, this was unavoidable in most cases since it was required that Peter from KADUPEDI attend the meetings for translation purposes as well as giving directions and making introductions to the recipient. Navin from CanUgan was also at all of the recipient interviews, since he was interested in knowing the same information.

The questions were created in order to help to answer the research questions (see Appendix E for interviews guides). To investigate the first research question, the researcher asked what their typical day/week looks like, their role within the family, how they find customers, how much time they spend selling, how much money they have made, what they have used the money for, what has changed since they have received the device, and about the social 
stigmas/expectations for people with disabilities in the region. To investigate the role of independence and dependency, the questions the researcher asked centred on how much the recipient was making and what their future plans were. During each participant meeting, it was also important to gauge whether it seemed like they still wanted assistance or whether they were striving to do things on their own. This included asking representatives from KADUPEDI their opinions as well. In terms of the actual design (research question three), the researcher asked questions about how people got around their home and town, if they had any issues with the device (such as breaking or not working properly), and if they had any recommendations for improvements. In order to examine the complexities of the project (research question four), the interviews focused on asking questions of stakeholders from many different groups about what their feelings and expectations were regarding the project and what they would change or do differently next time.

\subsubsection{Meetings with Other Stakeholders}

During the trip to Uganda, the researcher met with multiple stakeholders who could have different perspectives and opinions. The stakeholders consisted of groups who either already worked with PWD, those who were influential in the community or country, and groups whose services could help KADUPEDI in the future to create more effective assistive devices. These groups included two universities, KADUPEDI, CanUgan and local government officials in Kasese. People such as representatives of the local and federal government were an interesting group to talk to, as KADUPEDI has close ties with them and may be able to use them as a revenue source in the future. These representatives have a chance to influence the priorities of the government, especially in terms of financial resources, and other forms of incentives. The 
researcher was also curious to see what their perspectives were on the issues of people with disabilities, especially in terms of the proposed research questions.

Meetings were held in Kampala with both Makerere University and Kyambogo University, since they have departments that focus on engineering and fine arts, as well as disability studies and industrial design, respectively. The hope was to share ideas and transfer knowledge between the schools, given the research objective of building capacity in the region. . One student from Makerere University, Perez Magoola, had also been working on the nut grinder device in order to see if it could be made using local parts. Perez attended the meeting to meet the students and give them a tour of the school. He also joined the team from Carleton University in Kasese later in the week to meet with recipients and work with Kio and the students. After the meeting, Makerere University agreed to send representatives of their engineering faculty to a workshop that was being held in Kasese later in the week. In both meetings, the undergraduate students from Carleton University presented their preliminary concepts, which allowed them to get new insight and feedback that they could consider in their final design. It is also the hope of the researchers at Carleton University that students from Makerere might develop a relationship with CanUgan and KADUPEDI, in order for their students to assist in the designs in the future if Carleton is unable to find funding to send Carleton students overseas each year for their project. We also met with Kyambogo University, which has a school to train Community Based Rehabilitation (CBR) workers who play an active role assisting those with disabilities in rural areas within Uganda.

We would have liked to meet with members of both local and international NGOs who 
are working in the area, but since the trip was short in length, it was more important to focus on the recipients. This type of work could be useful for future research, since these people might have interesting insight into issues like aid dependence, funding avenues, cultural inclusion and other relevant issues. The NGOs may work in the local region (Kasese) or be based out of the capital (Kampala). Although these issues do not directly pertain to the actual project, they may allow the researcher to think about possible intersecting concerns and consider the work from a different perspective.

\subsection{Observations}

The observations were documented through field notes, audio recording, video recording and photographs. Each meeting with recipients lasted approximately one hour, with about 20-30 minutes of formal interviews. These interviewees were also asked questions about the tricycle itself, to find out whether or not it was working correctly or needed any maintenance. Other than income amounts, all of the data collected was of a qualitative nature and the importance of the research was in explaining the stories of individual people within a specific set of circumstances. Since there are a lot of factors that go into making a successful business, it can be difficult to tell which factor led to the success or failure of the business. However, through frequent meetings and in-depth interviews, there was a much better chance of discovering certain problems which may occur, such as a participant lacking motivation or simply lacking a customer base due to their location. This can be contrasted with other users who were successful because they spent a lot of time working or were better supported by their family network.

The observations were done while meeting participants and included looking for evidence 
of increased income (or what they said they had used the income for), watching their body language while answering questions, noticing if their answers seemed like they were genuine or if they seem like they are trying to please the interviewers, and getting the opinions of KADUPEDI representatives on the same factors. In terms of independence and dependency, the author attempted to gauge whether it seemed like they still wanted assistance or whether they were striving to do things on their own. This included asking representatives from KADUPEDI their opinions as well. To evaluate the design of the device itself, this involved watching how they interacted with the device, looking for signs of wear and tear, seeing if they had any difficulties while using it and asking representatives from KADUPEDI if they have noticed any issues. To understand the complexities of the project, the author looked at the difficulties that were found with different methods of communication, understanding how the project changed throughout the process based on the needs, actions and expectations of different stakeholders, considered what was learned from other groups, and looked at what worked and what did not, especially in terms of the effect each group had on the situation.

\subsection{Workshop/Idea Sharing}

In order to make the project more inclusive and sustainable, the project team wanted to involve universities from Uganda in the project. To do this effectively, the team decided to run a workshop in Kasese and invite all stakeholders, including: engineering students and professors from Makerere University in Kampala; the Industrial Design fourth year students and professor from Carleton University; local government officials; representatives from local organizations and associations (such as the survivors of land mines, advocates for women and children with disabilities, etc.); representatives from KADUPEDI and CanUgan; the local manufacturer; and 
one tricycle recipient. The workshop involved a series of speeches from representatives, and presentations by the students with their prototypes. The workshop allowed many different stakeholders to meet and discuss ideas which the researchers were told rarely happens normally.

\subsection{Secondary Questionnaires (After the Devices Were Given Out)}

Originally, it was proposed that the participants were to be interviewed periodically throughout the six months of the project, between November 2013 and April 2014. However, only one recipient had the device for the first two months (November and December), and only one additional recipient had the device after three months (in January). Two of the recipients were given their devices after four months (late February/early March). After they were selected and received the device, the team at KADUPEDI followed their progress, in order to ensure that any questions were answered or concerns dealt with, since they could talk to Kio about issues with the device, or talk to CanUgan or Carleton University about any issues with the study. A volunteer visited them at their house after two weeks of using the device to address any concerns and ask a few questions. The questions included whether they have issues with the device, how much money they are able to make and how close they are sticking to their business planning. The point was to resolve any obvious issues that came up (such as issues with maintenance of the device, difficulty getting customers, etc.).

Due to the issues with the timeline, the second questionnaire was actually given out at the beginning of April 2014. The goal was to collect information from all four recipients, but since one had moved away, only three questionnaires were collected. The questions included those about amount of money made, what money was used for, and past education. The entire 
questionnaire can be seen in Appendix C. It contains many more closed-ended questions for ease of filling out by volunteers from KADUPEDI.

The results from the secondary questionnaires were to be compared to the interviews performed by the researcher during the trip to Uganda in February; however, only one such questionnaire was able to be filled out before that time due to the delay in recipients getting the devices. Although the integrity of the individuals at KADUPEDI is trusted, the volunteers may have differing opinions and priorities compared to the researcher. Therefore the results of the questionnaires and interviews may contrast, highlighting differences between disciplines and cultures when working on this type of project. After the initial questionnaires, it was clear that their way of answering questions was slightly different than expected. For example, when the researcher asked about the "Extent, Cause and Length of the Disability", the answers would sometimes read something like "Sickness, 16 years." Therefore, it was important to clear up any missed information or potential questions in person during the interviews. Hence, the second questionnaire contained many more "fixed questions", with check boxes and other prompts in order to gain more precise results.

\subsection{Data Analysis}

Triangulation was used by the researcher to compare different results. Triangulation uses multiple methods to try and answer the same research questions in order to collect evidence from several different vantage points (see Figure 20). This helps to ensure that information is more accurate by reducing the limitations related to any one specific research method, and finding the "apparent truth" where results from each method emerge into one common answer. It is also 
common to combine observations (researcher evaluating the information they receive) with selfreport methods, such as questionnaires (where the user evaluates which information to share) (Martin \& Hanington, 2012, p. 188). However, even if results contrast between methods, insights can be found through the data, as it raises areas of interest, or questions the researcher may have. For example, it is often important to weigh what people tell others against what they actually do, for a multitude of complex reasons. Discrepancies noted between information gleaned using different methods can help the researcher to discover new insights into the recipient and the product that are not obvious from just one method alone.

Content Analysis is based on turning observations, conversations and data into themes or patterns that can be used to gain insights into the participants. This method involves analyzing qualitative data, which included filled-in questionnaires, transcriptions of in-person interviews, field notes and pictures of observations made in the field (Martin \& Hanington, 2012, p. 40). This type of analysis was done with the transcripts that were taken from the interviews.

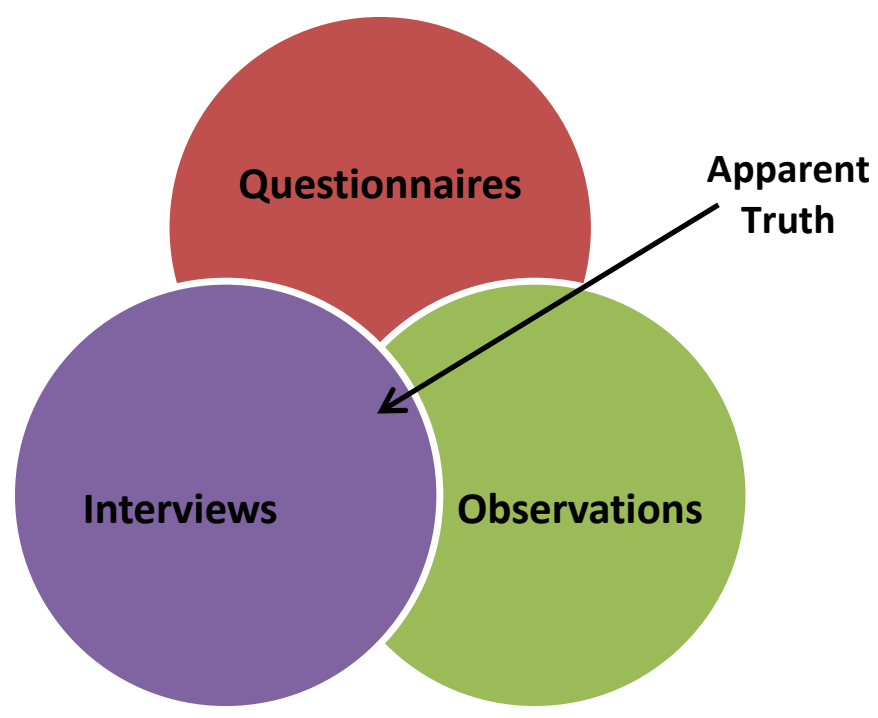

Figure 20: A Venn diagram showing the three methods of collecting data used in the research (questionnaires, interviews and observations). Where the three methods converge is the "apparent truth," when all methods are in agreement the answer is likely true (O'Grady, 2006). 
Coding is a method of organizing information into useful categories or themes. Hypothesis Coding was used as a secondary level of coding. This method involves arranging qualitative data into categories based on pre-determined categories. The author took the insights from her original Manual Coding, and arranged the categories and observations into the four main research category areas in order to analyze them again (Saldaña, 2013).

The researcher chose not to make use of Computer-Assisted Qualitative Data Analysis Software because the number of participants in the study was small, and most of the research took place over a short time frame (so there was less issue of using the computer in order to not forget over months of study). They also take time to learn, which would have taken away from time doing other things, which were deemed more important (Gobo, 2008, pp. 252-253).

\subsection{Summary}

The above sections describe the various methods that were used to understand this casestudy. The primary methods included a series of questionnaires and interviews over a period of a few months in order to evaluate the change in quality of life for the participants. The small sample allowed the researcher to collect more regular, detailed information. The next chapter will explain the results from the data collected during the various phases described above. It will also explain why the research plan deviated from its initial conception in some instances and any issues there may be with the results. The following two chapters (Results and Reflections) will be framed around the four research question on the topics of the income-generating device, its ability to influence dependency/independence, the design efficacy of the device, and the complexities involved in "Design with the Majority" projects. 


\section{RESULTS}

This chapter will discuss the results of the research, triangulating the findings from the questionnaires, on-site observations and in-person interviews. Section 4.1 is an overview of the recipients and the context in which they live. This information was researched before the fieldwork was completed, but could not be fully understood until the researcher was immersed in the culture of Uganda, generally, and Kasese, specifically. This should give the reader an understanding of what the lives of recipients are like, and why the assistive devices and incomegenerating attachments are so needed in the community. Sections 4.2 to 4.5 will describe the results as they pertain to each of the four different research questions.

\subsection{Recipients}

This section will help to explain what the lives and circumstances of KADUPEDI's recipients are like. This should help readers to understand the context when reading through the results, reflection and recommendation sections that follow.

\subsubsection{Environment and Context}

During the interviews, observations were made about where the participants were living and their quality of life, and questions were asked about their daily lives and access to services. None of the recipients or potential recipients had running water or electricity in their homes. Some lived in areas where electricity was available, but they could not afford it. Even in areas with electricity, power outages were common, and power could be out for days out of each week. Others lived in poorer areas that had no power. None lived in the main centre of town, but in 
smaller surrounding communities (semi-rural areas, not attached to main city infrastructure but lacking in agricultural land). Most areas had a public tap in the vicinity (within a couple of houses distance) in order to get water. They all used jerry cans to transport the water to their homes and store it. This water is used for all purposes: washing, drinking, cooking, etc. The communities are made up of simple homes, often made out of either concrete, corrugated metal sheets, or wood/mud thatched houses, with little furniture (none of the houses the researcher saw had any furniture except for perhaps a mattress on the floor). The houses are small in size, but most recipients said they owned the house and land and lived there with their families (though most did not have enough land for farming right by their house, and those that farmed often did so in another area, often in their home village where their parents still lived). All recipients (eight in total), except two, had multiple children. All the female recipients were either single or their husbands were no longer involved, while all of the men (except one who was still of schoolage) were married.

In this region, most men work, while their wives tend the farms, do the cooking, and look after the home and children. However, single women must work or rely on family and the community for support. It is common for men to leave their wives after they become disabled, or to not look after children they have had with women with disabilities, making it likely for mothers with disabilities to be single parents. However, people do tend to live with their extended family, which they can rely on for food, money and assistance if necessary. It is also assumed that all adult family members will contribute to their extended family, leaving people with disabilities who are unable to work with the feeling that they are a burden to their family since they are not contributing. In the region, most people without jobs are subsistence farmers. 
However, most of the recipients have difficulty farming due to their disability, and either pay someone to tend the farm, or buy their food from the market.

The main roads from the town are paved, but the areas within the community are made of dirt, often with many hills, ruts and rocks. There are no sidewalks in the region, and the rough condition of the roads makes it difficult for those with mobility impairments to get around, even with an assistive device such as the tricycle. Most large roads have large ditches on either side for drainage/sewage purposes, making them difficult to transverse to get to buildings unless a small ramp is placed on top or the ditch is wide with shallower slopes on either side.

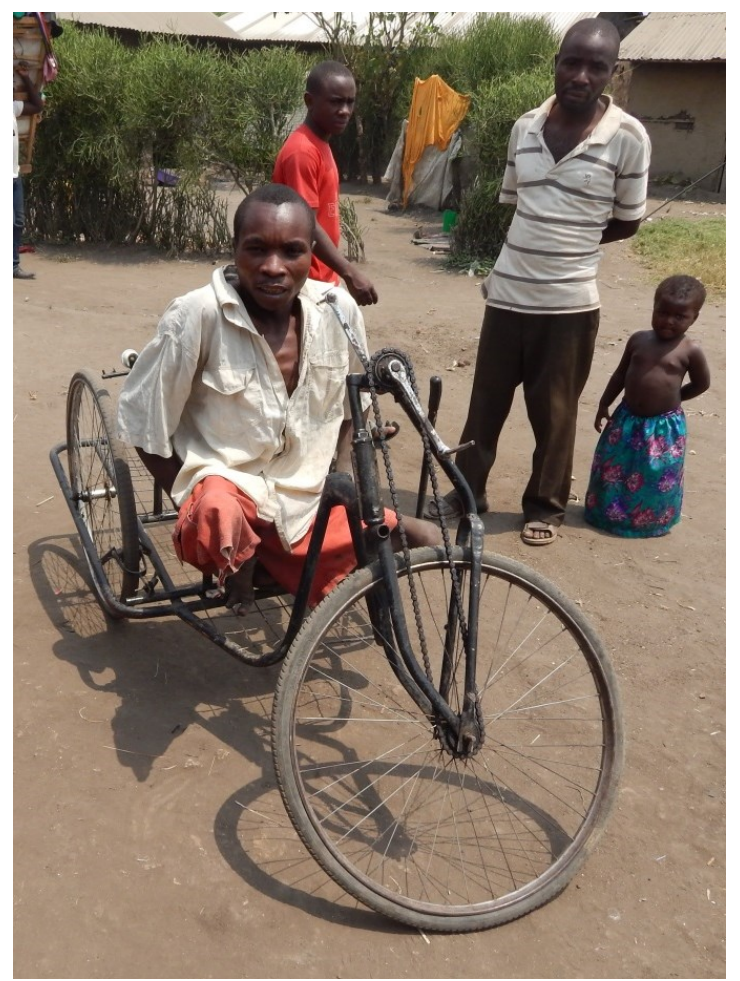

Figure 21: Salim - A current tricycle user.

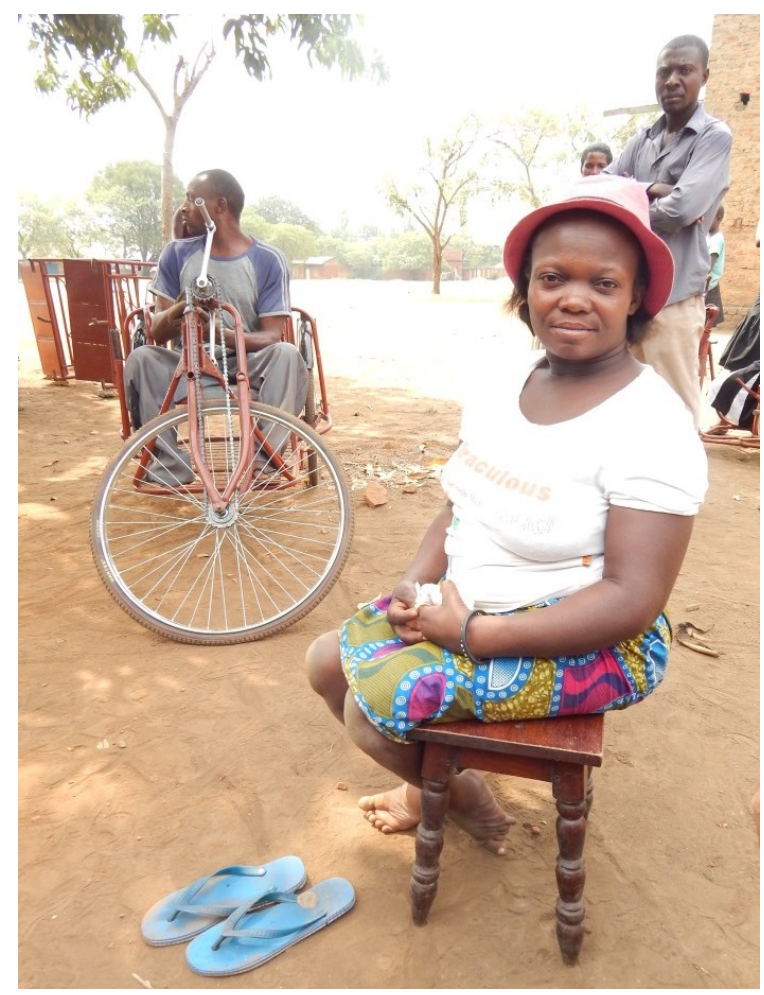

Figure 22: Maria - A potential tricycle user, who received a tricycle with solar-charging capabilities in March 2014. 


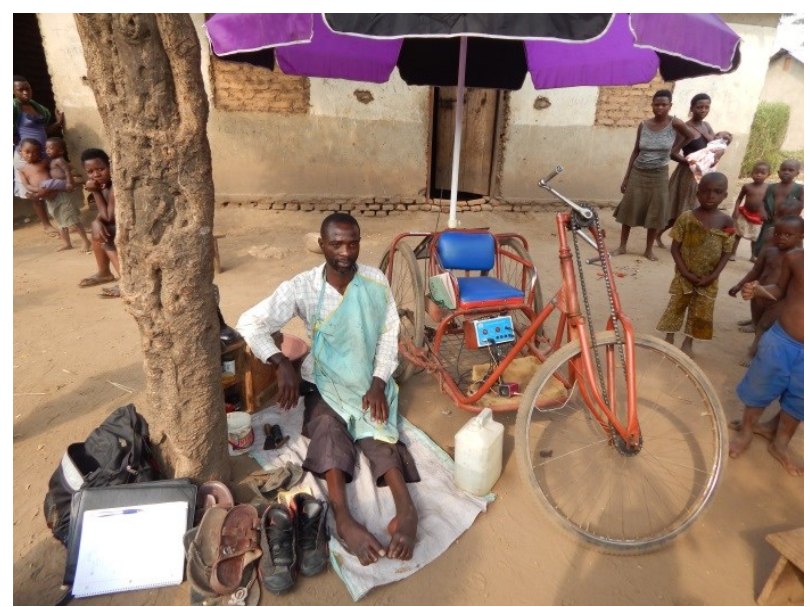

Figure 23: Fauza-A current tricycle user with a solar-charging attachment.

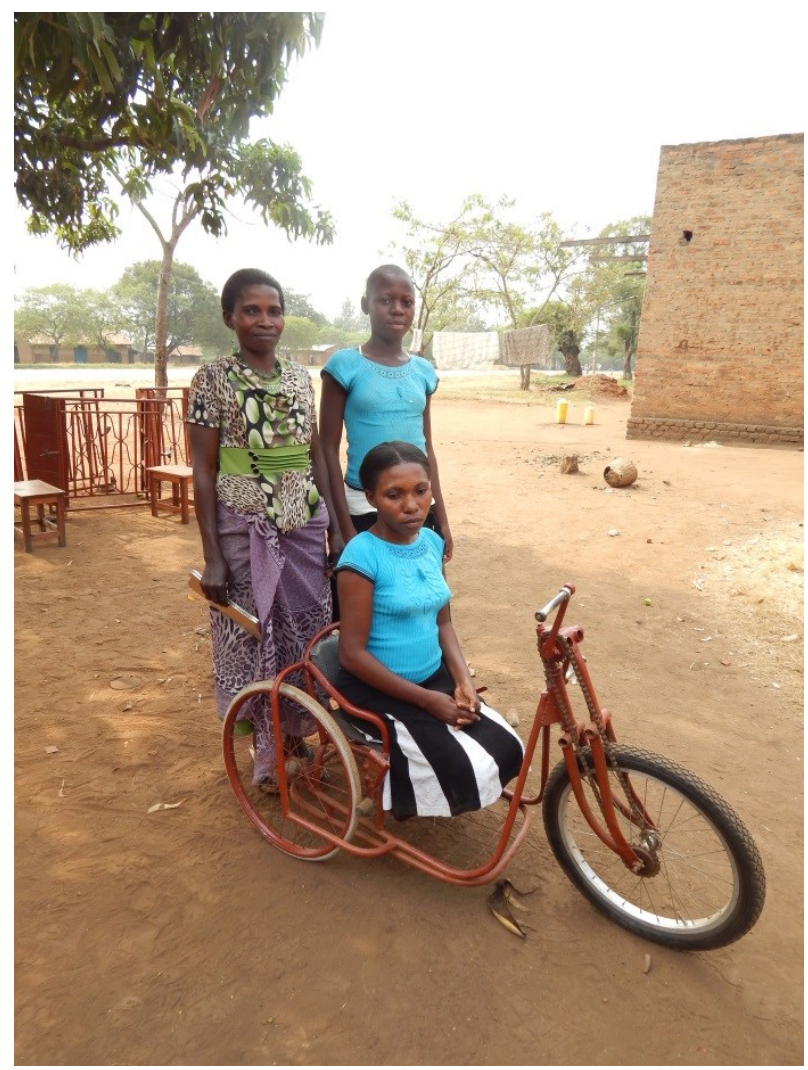

Figure 25: Doreen - A potential tricycle user

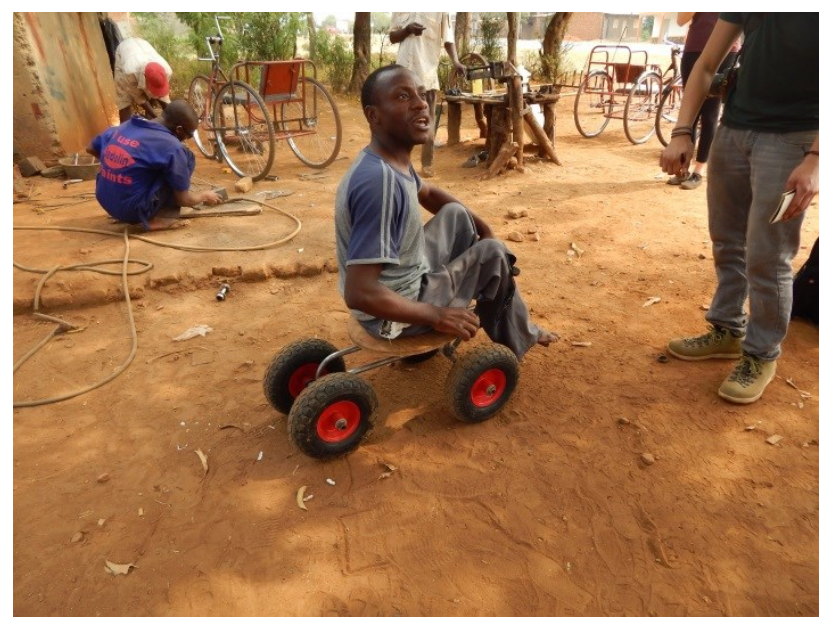

Figure 24: Mark - A potential tricycle user, who received a tricycle with solar-charging capabilities in March 2014.

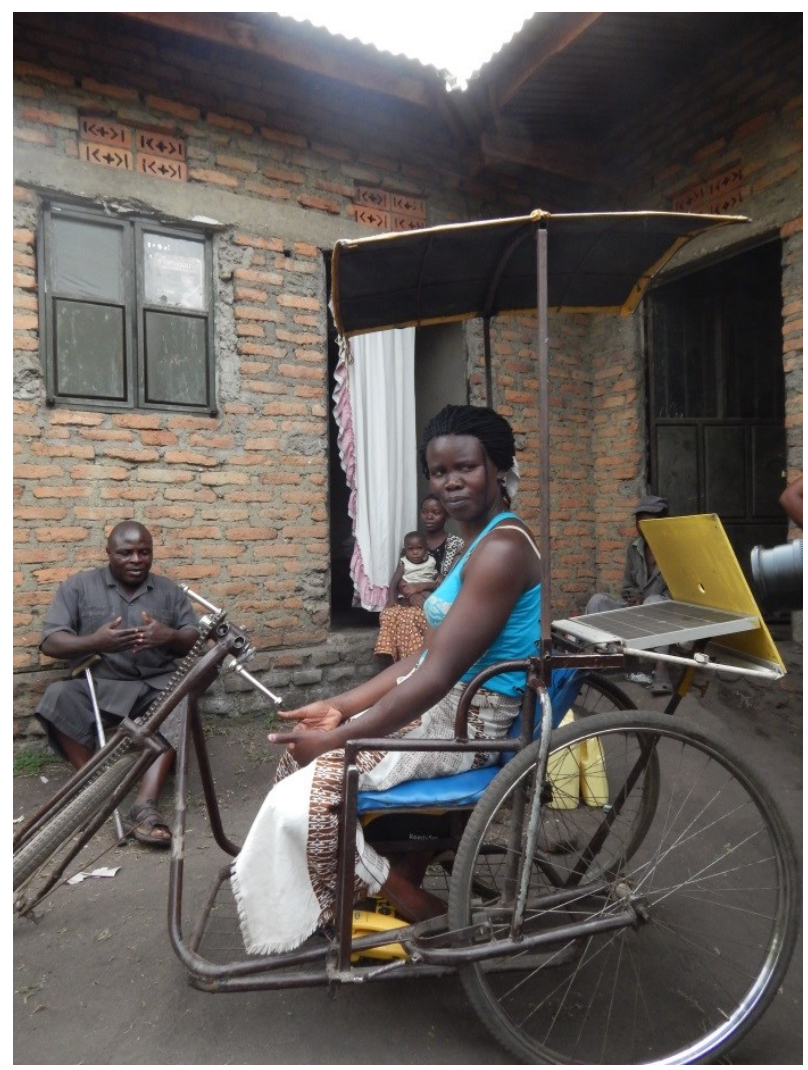

Figure 26: Margaret - A current tricycle user with a solar-charging attachment. 


\subsubsection{Being Disabled}

Many people with injuries or weakness in their legs crawl on the ground (locally referred to as "crippling"). Since the road is made of dirt, they get dirt on their body and clothes, and when it rains this turns to mud. Being dirty or muddy makes them feel bad about themselves, and discourages customers. Some recipients said when they are muddy others fear them. People with disabilities also often have trouble travelling around town without an assistive device. Since they have little access to money, they often cannot afford public transportation, and are thus confined to their homes unless they rely on their family or are able to generate an income. Even those that have assistive devices have a hard time travelling very long distances (longer than they can physically travel on the tricycle) since it is very expensive to bring the assistive device with them on public transport.

\subsubsection{Jobs/Income-Generation}

In Uganda most people do not have typical jobs, as they would be defined in North America, where they have an employer and are paid by the hour. Most people in Kasese are selfemployed and vending or providing a service, meaning they buy their own supplies, make their own hours, decide where to set up their business, sell merchandise, and handle their own finances. Typical income sources include selling second-hand clothes, selling handicrafts, making/fixing shoes, selling food, and local and cross-border transport of supplies such as matoke (bananas), crates of pop, etc. Also, businesses do not usually offer only one service; people need to have multiple revenue sources in order to survive. Marketing is not widely used, and even proper signage is rare for shops that are very small or run out of people's homes (see Figure 27 for an example of a small personal business sign). 


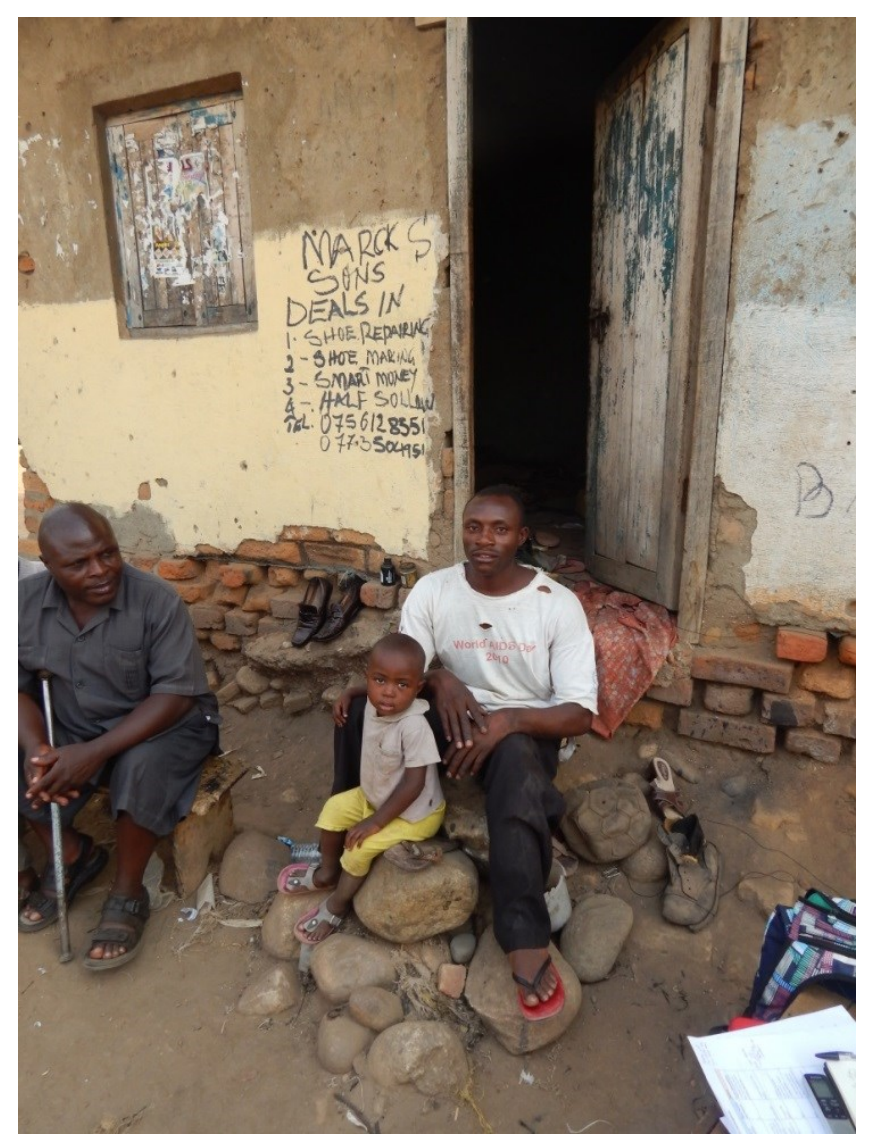

Figure 27: Mark and his son (right) sit in front of the building (with hand-painted sign) where he runs his shoe-repair business. Peter from KADUPEDI is on the left.

People with disabilities are considered poor, even in the poorest areas and are sometimes helped out by community members (since some cannot even pay for their own families' basic food needs, health care costs, clothes, etc.). Many PWD implied that they want an income not just to buy things, but also to not be seen as a burden to their family. They want to be selfsufficient and help contribute to their family. Most of the potential recipients already had a revenue source, such as selling food or repairing shoes. For instance, Fauza (see Figure 23) repairs shoes, and Maria (see Figure 22) sells French fries. However, most did this work from their homes, since they were too poor to pay for public transportation, which would add a cost to their business. They all had difficulty moving due to their disability and lack of assistive device, 
and travelling with supplies needed for their business would have been almost impossible. Most of the potential recipients wanted to use the tricycle to take their current business to the nearby market, which sometimes runs daily or certain days of the week, depending on the area.

\subsection{Income-Generating Devices}

\subsubsection{Income Generating Attachments}

The goal was originally to look at two different income-generating opportunities that could be attached to the tricycles. This would allow KADUPEDI to even further benefit people with mobility impairments by striving to empower them to take charge of their economic future. The first device was the solar-charging kiosk (see Figure 19), and the second device was a nut grinder (see Figure 18).

\subsubsection{Solar-Charging Device}

The tricycle currently costs 937,000 Uganda Shillings (\$402.91 CAD) with all of the solar-charging attachments: 400,000 UGX (\$173 CAD) for the tricycle and an additional 537,000 UGX ( $\$ 231$ CAD) for electronic components. However, based on the research, it seems that the electrical components could be sourced for less money, thereby reducing the cost of the device in the future. One positive aspect of this device is that it requires very little knowledge and training, and can be used right away (unlike other income-generating initiatives which require years of investment in training such as being a seamstress, learning a trade, etc.). It was found that people were also using their solar panel to light their house at night, thereby reducing the cost needed for lighting fuel. Also, power in Uganda goes out very frequently, meaning that the device is a way to make access to electricity more reliable. 
One lady, Maria, (who is a food vendor) originally said she would prefer a tricycle with storage on the back but then changed her mind and asked for the solar-charging tricycle. It seems that almost everybody wants the solar-charging device, especially since it is free, as observed during numerous interviews with current and potential recipients in Kasese. They probably realize how valuable it is and how useful it could be to their family for electricity.

\subsubsection{Nut Grinder}

The nut grinder was initially well-received in the area when it was introduced by Carmen Liu, one of the fourth year industrial design students, in early 2013. However, since then, the lady who received the device, Gartrida, had experienced many problems with it. Unfortunately she passed away, and the grinder was supposed to be given to a new recipient. However, the representatives of KADUPEDI did not want the device given out until what they called "the problems" were fixed. Based on the complaints from the woman who had received it, these problems included the amount of time grinding would take, the amount of force needed to grind the nuts, and the volume of nuts which could be put into the device at a time. As Gartrida and her family started using it, the original perception wore off and certain key issues became apparent (inherent design problems). Therefore, more of this device was not made for the project, and the future plans will be discussed in Section 5.1.2.

\subsection{Independence/Dependency}

\subsubsection{Possible Income Uses (Before and After)}

When interviewing the potential recipients, they were asked what they would do with the money if they were to receive a tricycle with a solar-charging attachment. Maria mentioned she 
would like to buy sheets of iron to construct a house with; Moses wanted to use the money for school supplies; and Mark wanted to take a course on repairing phones as another service to offer customers.

After receiving the device, one of the volunteers from KADUPEDI was able to speak with Maria about how she was doing. She said that she was doing well, and was using the money to buy herself sanitary pads (which she previously had to get money for from her family) and she seemed relieved that she now had this independence, and was in control of her own money. However, before the second questionnaire was sent out (approximately one month after she received the device), she decided to move to Kampala (nine hours away by car). Her brother had arranged her transport to Kampala since she now had the assistive device and would be able to make more money in the city. According to KADUPEDI, she is also now selling "Mobile Money" credits while she charges phones. Therefore, the questionnaire could not be filled out, and KADUPEDI is no longer able to get in touch with her.

After receiving the device, the remaining three tricycle recipients who had received a solar-charging attachment were given a second questionnaire (filled out by representatives of KADUPEDI). Based on their answers, Fauza used the money he made to buy food, charcoal for cooking, buying water, repairing his children's school uniforms, and sending his children to school. Margaret used the money to buy soap, to buy books for her daughter and "as a woman, buying personal materials", which the researcher assumes to also mean sanitary pads. Mark used the money to buy food, pay for water, and buy school supplies for his children. 


\subsubsection{Monitoring and Evaluation}

\subsubsection{Keeping Records}

Before getting to Uganda, nobody was certain whether or not any records were being kept. It turns out that both of the recipients who had already received the solar-charging device were keeping daily records of their accounts, which helped to verify how much they were able to make. They both charged the same price to everyone for charging their phone (300 and 500 shillings respectively), but the charging time could differ from thirty minutes to two hours depending on the phone. Both recipients had small books they kept in the box of the tricycle with three columns: the date, how many customers they served, and the total revenue for the day (see Appendix $\mathrm{G}$ for full accounting tables).

The first recipient, Margaret, had already had the device for approximately nine months, however there was recently a bad flood in the area, and the records for the first five months were lost. The last four and a half months of records for this recipient (see Figure 28: One page of accounting from Margaret's notebook (October/November 2013). showed that she charged no phones on some days and up to four phones on other days, with a profit ranging from 0 to 1,200 UGX (approximately $\$ 0-0.52 \mathrm{CAD})$. Her average daily profit was $385 \mathrm{UGX}(\$ 0.17 \mathrm{CAD})$. The second recipient, Fauza, had only had the device for approximately one month before being interviewed. The records (see Figure 29) show that he charged between one and seven phones each day, with an income ranging from 500 to 3,500 (equivalent to about $\$ 0.22$ to $\$ 1.52$ Canadian per day) in addition to what he makes from his other business washing and repairing shoes. His average daily profit (from charging phones) was 2,155 UGX (\$0.93 CAD). He said that he can also make around 25,000 UGX per week (\$1.54 CAD per day) by repairing shoes, 
which was his original job, making his total average income per day about \$2.47 CAD. This may seem above the extreme poverty rate (below $\$ 1.25$ per day), but it must be considered that he uses this income to provide for a family of five (his wife and three kids). This makes the total income per person still less than fifty cents per day for all clothing, school fees, and anything else they might need. However, they do have a garden that his wife tends which provides most of the food the family eats, but the dollar amount this equates to is difficult to calculate.

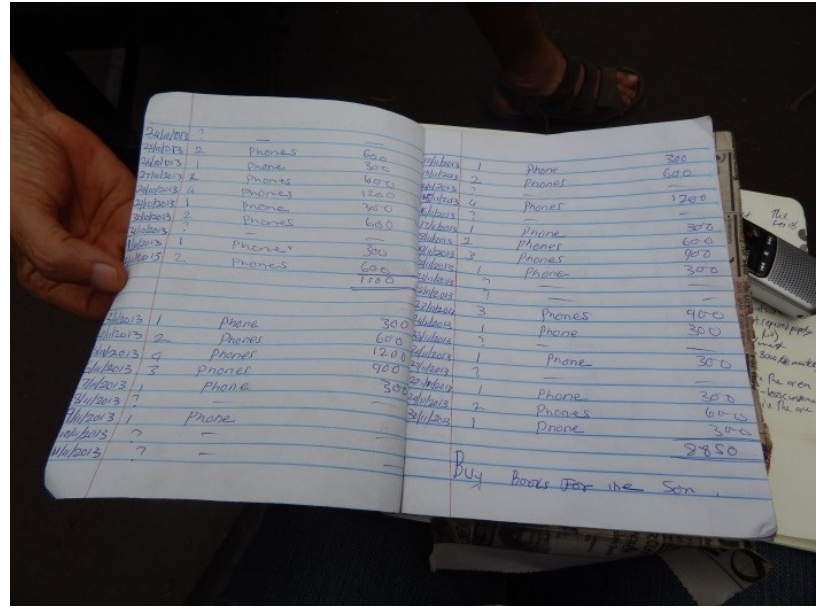

Figure 28: One page of accounting from Margaret's notebook (October/November 2013).

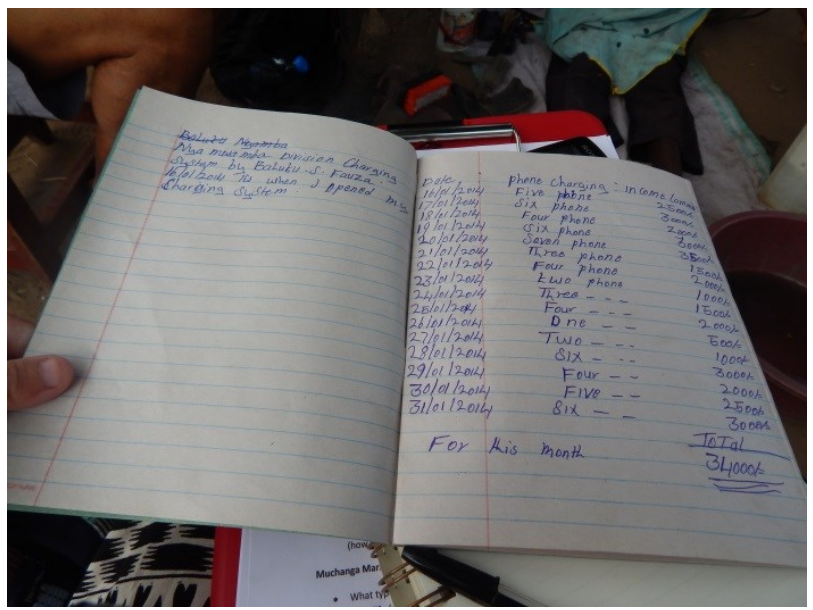

Figure 29: One page of accounting from Fauza's notebook (January 2014).

\subsubsection{Payment for the Attachments}

After receiving the solar-charging attachment, the recipients are able to save money on lighting, since they no longer require fuel (paraffin) to light their homes, and now they use a bulb instead (Fauza, 2014) (Margaret, 2014). According to recipients, they used to spend about 2,000 to $2,500 \mathrm{UGX}(\$ 0.86$ - $\$ 1.08 \mathrm{CAD})$ per week on fuel. Mobility aids also allow them to save money on public transportation. Some recipients have also mentioned in interviews that they can travel up to fifty kilometres (which would take about four hours) on their tricycles, which means they can avoid having to pay for a boda-boda (motor cycle taxi) or matatu (minibus taxi) to get 
around town (Fauza, 2014). Most people also have a house, or at least a family house, in the village, which is often where they do their farming, and they must travel there at least a few times a year, but more likely about once a month. This means that they could afford to spend at least as much as they are paying for fuel and transportation normally on paying back the solarcharging device.

\subsubsection{Additional Assistance}

Another question that was asked during the interviews was if they had any questions for the interviewers (the author and Navin from CanUgan, who attended all the interviews in order to learn more from the recipients). Many different questions were asked, but one common theme arose during many interviews, which was asking the interviewers for assistance with other aspects of their lives. These requests sometimes had to do with business, and sometimes other things. One of the potential recipients of a solar-charging tricycle, Doreen, was working as a hairdresser from her home, but had to borrow tools from neighbours. She asked how she could get money to buy her own hairdressing tools. Another potential recipient, Moses, was only 19, and had to stop going to school when he became disabled. Moses asked if there were any people who would be willing to pay for his tuition. Two recipients we interviewed, who had a tricycle only, said that the tricycle could be improved by adding a solar-charging attachment, and mentioning that they would like one (they had obviously seen or heard from others who had recently received this device). This will be discussed further in later sections. 


\subsection{Design Efficacy}

\subsubsection{Hand-Powered Tricycle}

All of the recipients had mostly good things to say about the device, and seemed reluctant to say anything negative. However, after talking to them for a while they mentioned some difficulties they were having with the current device.

One issue is that it is difficult to transport the tricycle to the recipients in the village (and if they ever need maintenance this can also be an issue). This can also be an issue if someone has to go to Kio's shop to test the device or pick it up, and they are unable to pay for public transportation at that point in time.

Another issue was found which contradicted previous information provided to the designers. The information provided to the researcher and other students at Carleton, through correspondence from Kasese prior to the field study, was that nobody would steal a tricycle because it would be frowned upon in the community. It was said that everyone knew who the device belonged to and the community would track it down from the thief. It was assumed that recipients would only take in the valuable electronics at night, which are small and easy to carry. However, it appears that this is not the case and most recipients fear theft of the entire device, not just the electronics. Therefore, most people we spoke to bring their tricycles inside at night (Fauza, 2014) (Margaret, 2014). This makes the size and weight of the tricycles more important than originally anticipated. Perhaps being light-weight and foldable is more important than the design team originally anticipated (especially since the houses are very small). 
Another issue is that people no longer seem as happy getting the tricycles if they do not include income-generating attachments. Even those who have tricycles already ask them to be "modernized" so they can make an income (Salim, 2014). It is good that there is a positive opinion about the new device, but this may make the job of selection more difficult for KADUPEDI and CanUgan in the future.

One unintended consequence of the device was the fact that the since the people are now very mobile, it is harder to do long term monitoring and evaluation. Since they now have the means of travel, they are more likely to go back to their village, or travel long distances, sometimes making long term efforts much more difficult, since people are always on the move. For example, Maria's brother assisted her in moving to Kampala to make more money a mere three weeks after she received the new device. Although this is great for them, it makes it more difficult for KADUPEDI to follow the successes or failures of the devices during actual usage.

\subsection{Complexities of "Design for the Majority" Projects}

\subsubsection{Working with Other Organizations}

\subsubsection{KADUPEDI}

One factor that the author was unsure of was the language barrier when working with the local organization (see Figure 30). Although the two representatives had very good knowledge of English, they were not native speakers, nor were the recipients. After sending the first questionnaire, it was obvious that their interpretation of some questions was different from a native English speaker. For example, when asking about multiple issues within one question, often only one part of the question was answered. Therefore, in the second questionnaire, the 
researcher made sure to separate multi-answer questions into different parts (more close-ended questions). This also made the questionnaires more self-explanatory and easy to fill-out.

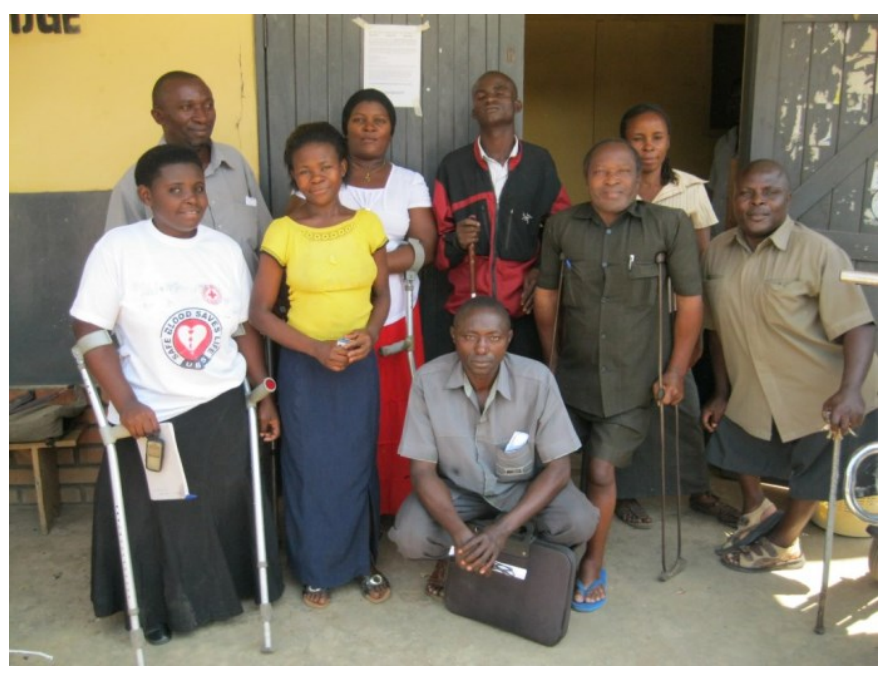

Figure 30: The Executive Committee of KADUPEDI in 2012. Back row: Bwambale Alone Secretary, Namusisi Asinah - Vice Chairperson, Ndand John - Vision-Impaired Representative, Monday Rosset - Treasurer Front row: Biira Reachel - Youth Representative, Bisogho Reachel Other Disability Categories, Mugenyi Joshua - Chairperson, Baluku Peter - Coordinator Seated: Kahyana Joseph - Parent Representative Absent: Mbabughabolho Teopista - HearingImpaired Representative (CanUgan, 2014b).

Both representatives of KADUPEDI seemed to think the project was a big success and would like to continue it in the future. Robert mentioned that the income-generating aspect is very important so that people with disabilities do not feel like a burden to their families, which we also heard from many of the recipients (Robert, 2014). Peter also thinks that KADUPEDI can go to local officials and tell them about the success of the program in order to get funding from them (but it is unclear why they haven't tried it yet) (Peter, 2014).

\subsection{Recipient Selection}

KADUPEDI has a community based rehabilitation worker come to evaluate the person before they receive the device. KADUPEDI also asks them questions but they do not have them written down. Peter thinks they should be written down so everyone gets asked the same 
questions (Peter, 2014). It is important that recipients have a medical assessment done before receiving the tricycle for two reasons. The first reason is so that they know whether the person has the strength and ability to use the tricycle and propel themselves. The second reason is a concern about giving the device to someone it will not help properly, because it can actually make them worse, for example through incorrect posture. If the recipient is unable to use the device due to a lack of strength or flexibility, they will be sent to physiotherapy at a hospital.

\subsubsection{CanUgan}

Working with Navin from CanUgan was a great help before the trip (see Figure 31 and Figure 32). He helped to phrase the questions in an appropriate way, and helped to mediate communication with KADUPEDI when any issues arose. During the trip, it was also useful to have Navin present during the interviews. His knowledge of both North America and Uganda was helpful in making both parties (Carleton University and KADUPEDI) understand the point of view of the other, even if everyone was speaking in English.

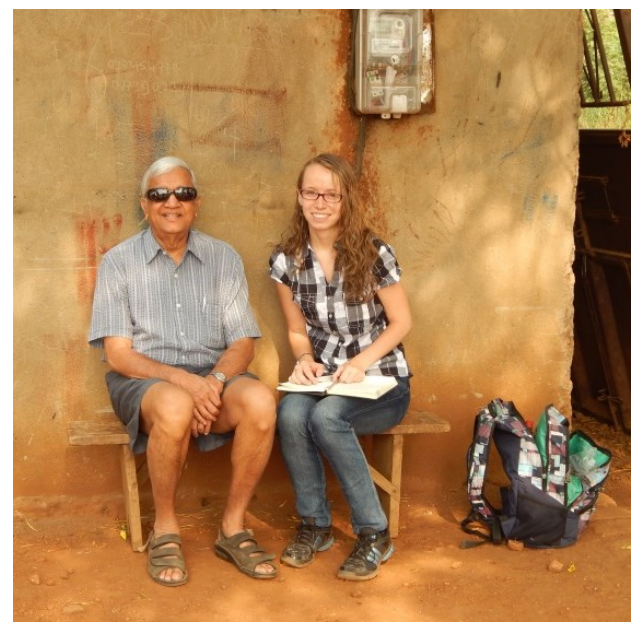

Figure 31: From left to right - A photo of Navin Parekh (CanUgan) and Amanda Cox (Carleton University).

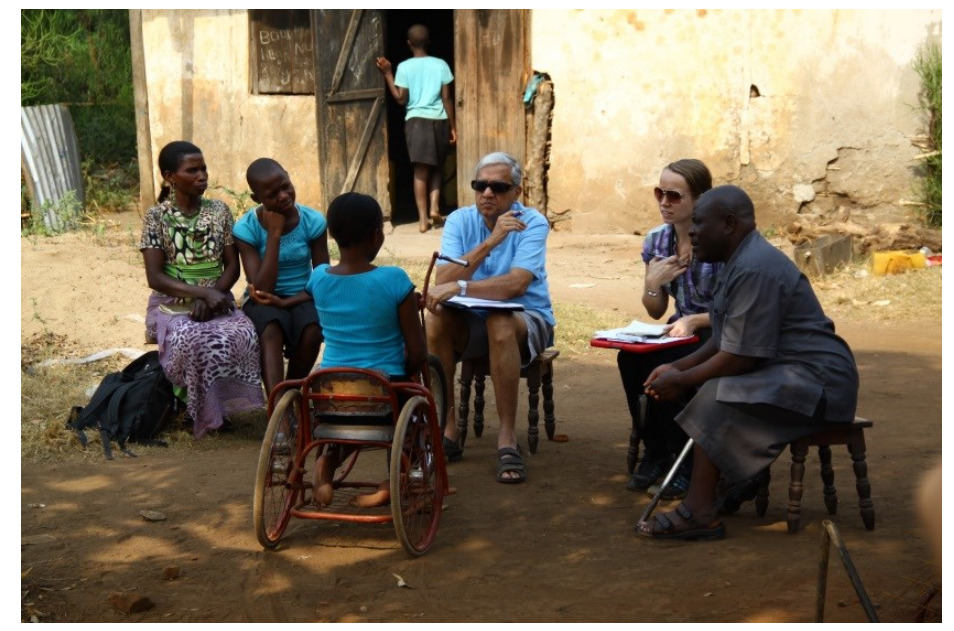

Figure 32: A photo taken during an interview. From left to right-Doreen's mother, Doreen's sister, Doreen (a potential tricycle recipient), Navin Parekh, Amanda Cox, Baluku Peter (KADUPEDI). 


\subsubsection{Knowledge Transfer and Capacity Building}

\subsubsection{Universities in Uganda}

We had long meetings with both Makerere and Kyambogo University in Kampala before heading to Kasese. It was interesting to see the differences between the two schools and understand the programs offered at each. The meeting at Makerere was much more in-depth and specific, while the meeting at Kyambogo was more general. This helped the research team to understand who would be a good partner for CanUgan or other projects in the future, as stakeholders who are more excited about the project are often more likely to make good allies.

\subsection{Makerere University}

The Carleton team met with Makerere University last year as well, and the meeting this year involved many more professors (see

Figure 33). The primary departments that Carleton has contacts with are the Department of Mechanical Engineering and the Department of Fine Arts. The meeting took place in a boardroom at the Centre for Engineering, Design, Art and Technology (CEDAT) (see Figure 34). The students were also given a tour of the shops, and got to meet Perez Magoola (see Figure 35), a fourth year engineering student, who later came to visit Kasese and work with the students, especially Charles Williams, and to work with the manufacturer. The students presented their project concepts and the professors from Makerere had a lot of feedback to offer for each design. 


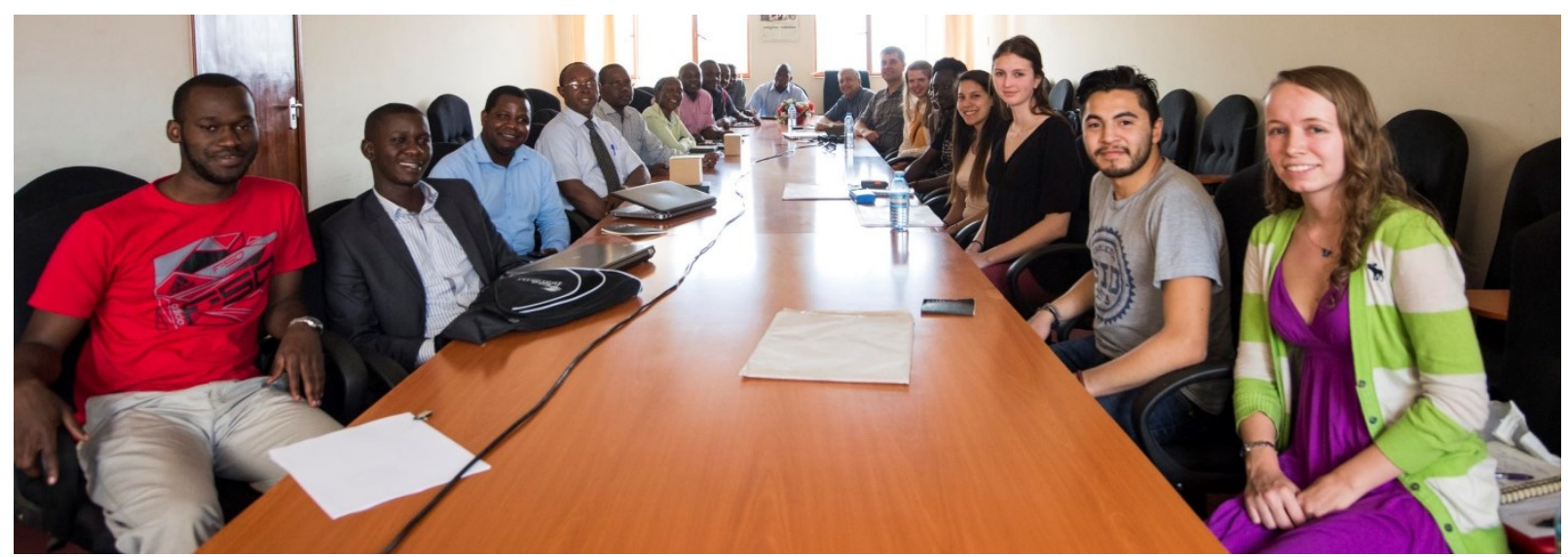

Figure 33: A group photo of the board meeting which took place at Makerere University. Professors and students from both Makerere University and Carleton University were present.

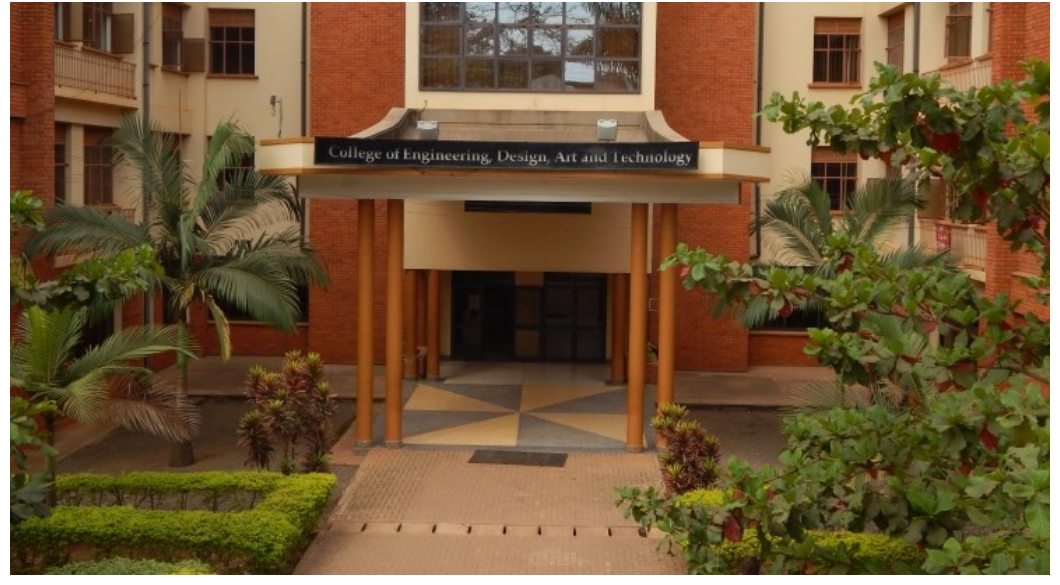

Figure 34: A view of the front of the building where the College of Engineering, Design, Art and Technology (CEDAT) is located at Makerere University.

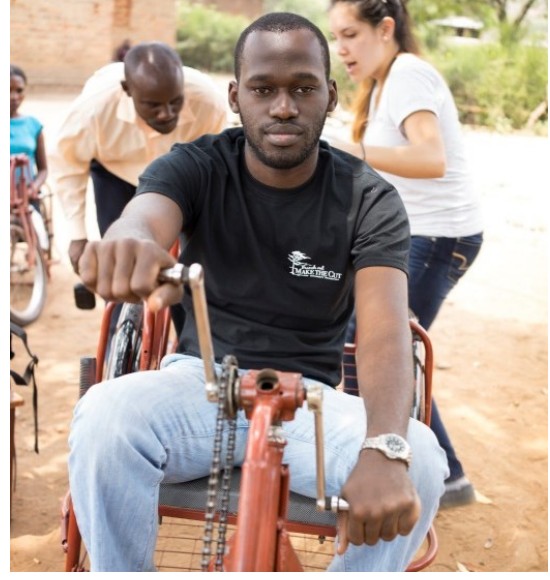

Figure 35: Perez Magoola, a 4th year Engineering student at Makerere University.

\subsection{Kyambogo University}

Carleton University has met with the Department of Disability Studies at Kyambogo University for the past two years. Kyambogo has a department of Industrial Design with whom the team wanted to meet but were unable to get in touch with them. The meeting was a bit more formal, involved less discussion, and did not lead to discussions of any concrete future steps. 


\subsubsection{Local Manufacturer}

During the trip, a majority of the time in Kasese was spent at Kio's workshop. The students and the professor worked with Kio to create new designs and revise old designs for their respective projects. Kio is quick to act, and not afraid of making cuts or welding things together just to try it out, which makes quick and messy prototyping a real possibility. It also allowed the students to understand the limitations of the materials and processes used in the construction of the tricycles and other devices. At one point the power went out, which Kio said happens frequently, making it impossible to use power tools, welders, etc., which may cause delays in the project (Kio, 2014a).

Something that was discovered while at his shop is that Kio is now in the process of creating his own inventions to sell. Although he has not started producing them in quantities yet, he has started prototyping a grinder and a popcorn machine. He also has ambitions to own a motorbike so that he can travel around to all of the recipients and do repairs on their tricycles. He said that he is willing to train others to make or fix the tricycles.

\subsection{Summary}

The preceding chapter has looked at what was found based on the observations, questionnaires, and interviews throughout the research process in regards to the four main research topics. The author hopes that the reader can now understand the information that was learned during the research process. The next chapter will discuss each of these four research areas again; however, it will offer the author's thoughts about each issue, in order for others to gain more insights onto the project and to plan future projects. 


\section{REFLECTIONS}

This chapter will be written from the researcher's perspective. This is because all of the insights, assumptions, and opinions are entirely those of the researcher, and are not necessarily all shared by every member of the project team. This will allow me to delve deeper into the outcome of the results in terms of interesting findings that might be of use for future projects or research teams.

This project (especially the trip) was a learning experience for me as a graduate design student with an interest in development. The following observations are written in my own point-of-view since they are based on my own perceptions, assumptions and lived experiences. Each section will offer my insights into one of the four research areas: income-generating devices; independence vs. dependency; design efficacy; and the complexities involved in "Design with the Majority" projects.

\subsection{Income-Generating Devices}

\subsubsection{Solar-Charging Device}

The solar-charging device was used successfully by all four of the recipients, meaning that they could earn money, contribute to their family, and become more self-sufficient, which would hopefully lead to increased dignity. However, there were differing degrees of financial success between recipients. We have accounting records for two of the recipients, and questionnaire answers for those two recipients and a third recipient. One of the recipients, which we have records for, was able to make more than five times what another recipient was making. 
Based on the questionnaire answer of the third recipient, he is making even more money than the first recipient (though this was not backed up with records). However, all recipients did make money, and were able to contribute to their family in meaningful ways, such as paying for school fees, buying food, charcoal and water, and buying sanitary pads (for the female participants, which is likely a relief to not have to rely on a male family member for these purchases). Therefore, the device is financially useful to all recipients. However, from KADUPEDI and CanUgan's perspective, it is worth investigating what causes these differences, and perhaps training some recipients on how to run a small business.

Based on the interviews, the recipients did not mention that their lives had changed that much in terms of social standing, as they often answered the questions in a different way, such as by describing what they have bought for their family. However, when recipients, potential recipients and representatives from KADUPEDI were asked, everyone agreed that PWD are seen as a burden in the family if they are not contributing. Although the family or community would still take care of these people, this led others to think less of them, and made them have low selfesteem with regards to their membership in the family and community. It seems that even if only a small amount is contributed to the family, the disabled person is no longer as stigmatized.

\subsubsection{Nut Grinding}

The nut grinding device was not used at all for this case study. The lesson to draw from this is that even though it was well conceptualized, researched and co-developed, it takes time to figure out if everything is right. It was a first generation device and still needed more iterative product development in order to succeed in the field. This is why it is so important to get new 
data after an extended period of time, in order to find out about issues like this and fix them. It is also an important lesson for those designers who are keen to develop new innovative products with people in the majority world, where long distance and infrequent contact makes follow-up harder.

\subsubsection{Payment for the Tricycle (and attachments)}

During interviews with the students at Carleton University, Navin from CanUgan and representatives from KADUPEDI, they all agreed that the recipient should have to pay something towards the cost of the solar-charging attachment, even if the tricycle is given away for free (Parekh, 2014) (Robert, 2014) (Peter, 2014) (Garcia, 2014) (Williams, 2014). However, there is not a consistent answer on how much they should pay or when they should pay it.

Originally, the Carleton students (the researcher included) believed that the recipients should pay back the entire cost of the solar-charging attachment over time, through a system similar to a micro-loan. It was believed that this would make the project more sustainable (since the cost would be borne by the recipient, so more people could receive mobility aids), that it would create a sense of ownership of the device for the recipient, and that this would be more fair to recipients who had little money to begin with before receiving the device (Garcia, 2014) (Williams, 2014).

Contrarily, the representatives of the NGO and the local organization felt that the money should be paid up-front, because they doubted that people would continue to pay over the long term, and were unsure what to do if people refused to pay. There is also a history of people 
moving to other areas once they have received the device (like Maria, who moved to Kampala), which would be a problem if they still owed money, and KADUPEDI would be unable to collect or enforce it. They agreed that the tricycle should be free, but were unsure how much of the cost of the solar-charging device should be paid back. Robert mentioned they should pay $10 \%$ of the cost, but it is unclear where he got this number (Robert, 2014). Navin and Peter were both unsure what to charge, but Navin mentioned that everyone should have to pay the same price (unless there was an emergency situation), since it is a tight-knit community and everyone would be aware of the price each person paid (Parekh, 2014) (Peter, 2014). They also mentioned that if the cost is small enough it should not be a problem, even for the poorest recipients, since their families would help them to pay for it, however this needs to be explored further.

\subsection{Independence/Dependency}

In North America, since we have a capitalist economy, it is often assumed that independence is the key to a good life, and is innately tied to different kinds of freedoms. However, within other cultures, it appears that dependency relationships work differently, and being in a dependent relationship may actually be seen as a benefit to an individual person or family due to the power, resources and social status that can be gained from these relationships (Ferguson, 2013).

The question probably should not be whether or not dependence is created and whether it is a bad or good thing, rather the question should be about what type of dependent and interdependent social ties are created as a result of the recipients receiving a device from KADUPEDI. It seems that CanUgan would like the recipients to be independent so that it can 
help more people, but it seems that the devices are actually creating a dependency relationship between the recipient and KADUPEDI. However, the income generated from the device is providing some measure of choice to the family in terms of what they would like to spend the money on.

\subsubsection{Social Dependency Relationships}

Based on the outcome of the accounting records, and the interviews with recipients, it appears the people who already have jobs are likely to be able to make more money. Perhaps it is best to give this new business to people who already have an existing business (as it ensures they are already entrepreneurial and likely have a good work ethic). However, this may leave out the neediest members of the population. For example, women with lots of children or those who live in more rural areas are likely going to have more difficulties dedicating time to the business or finding customers. It is up to CanUgan (and their donors) and KADUPEDI to decide whether they would like to give the device to the people most in need, or whether they should give the device to those who have the potential to make the most profit. It is difficult to make exact conclusions due to the small sample size, but these factors may influence a person's ability to run a business and make money.

While talking to recipients (those who already had a tricycle and those who were about to get a tricycle) we also found that they were keen to ask for more. It seems that the reason for this is that giving away things for free simply leads to people asking for more. For example, a teenage boy, Moses, who was going to be given the tricycle to go back to school, asked for a scholarship. Although his parents are poor, they were able to afford to send him to school 
before, so it is likely they still could. Another lady, Doreen, who was a hairdresser, asked how she would be able to afford better tools for her business. Recipients who already had tricycles with no attachments also heard about the solar-charging and grinding devices, and when asked if anything could be improved with their tricycle, they said they would like to have one as well. Although these requests make sense, they may make KADUPEDI's job harder.

We also heard some people making claims they could not work because of their disability, which, without further research, seemed possibly questionable. Even though their lives are harder than those in the same area who are able-bodied, it seems that some PWDs in the area put in much more effort than others. Even though all of the people we dealt with had mobility impairments, some were doing various activities to make money, while others said they could not earn money because of their disability. For instance, some people did not yet have tricycles, but they were already selling food, or starting other businesses from their homes. Others already had tricycles, and were able to get around to all of the different towns, but they told us they were unable to work (and instead they told us that they rely on the community for all of their family needs). It seems that some people who have skills/ability think they are unable to work simply because they are disabled.

\subsubsection{Financial Independence}

\subsubsection{Monitoring and Evaluation}

Monitoring seems very useful, and essential to CanUgan's ability to raise donor funds, but it also adds increased costs to KADUPEDI. Not only does it take time to reach the homes of these people, they must also pay for transport. Even small fees like photocopying, printing, 
using the internet and making calls add up when they are given to a volunteer who is donating their time in the first place. In order for them to do a good job without worrying about these expenses, CanUgan could give them a small stipend that covers these things.

The volunteers do seem to understand the importance of continual monitoring, and do not seem to complain about all of the time and effort this may take. In fact, the two principal representatives we worked with, Peter and Robert, both have very busy lives outside of KADUPEDI. Robert works at the hospital and is currently building his own clinic and pharmacy that will open shortly for his community. Peter is a local city councillor and also runs his own college, which has recently moved to a new location and is still partially under construction. It proves their dedication to the cause that they spend so much of their personal time meeting with recipients, because they feel it is a good thing to do, want to help in the community, and likely it is fulfilling to them in different ways.

\subsubsection{Keeping Records}

I did not assume that the recipients would keep accurate and detailed records, which was probably an unfair assumption, given my own perceptions of the people and the region. I was uncertain if the people had been to school to become literate, and I also assumed if they had not then they would be unable to record these things. I was proven wrong by the first two recipients who were keeping very good records. I also found out that at least three of the recipients have gone to school until at least Senior 4 , but this does not mean every child will have had the same experience, as schools for disabled children are not always available and regular schools are not always accessible to those with disabilities. Nonetheless, these records could allow CanUgan and 
KADUPEDI to actually quantify the change they are making in someone's life.

I found it interesting that representatives from KADUPEDI had the same assumptions about record keeping as I did. They mentioned that "Africans" are not generally people who keep records (Robert, 2014). I found it especially interesting, since they work with these people every day and live within the same community. Perhaps we all have certain prejudices about the marginalized in our own communities that may actually be just as false as regarding those in other communities. Even after seeing the two recipients with complete records, I asked Robert about records for the third recipient. He replied that he had not kept records since most people in the region keep everything in their heads. It seems that even though he experienced people keeping accurate records, he was unable to change his mental perception that this would be possible and likely for others as well.

Representatives from KADUPEDI thought that creating a template to keep accounts might be helpful, but it would be important to have the right headings in order for it to be easy for them to use. Both of the original recipients had kept accurate records, in the same type of notebook, with the same headings. However, CanUgan and KADUPEDI said they did not give them these books or any lessons, so it is unclear how they ended up being so similar. We were unable to collect records from Maria because she moved, and Mark had not been keeping records. I am not sure the reason why Fauza and Margaret were keeping records, but Mark was not. This could be due to personal preference and skills, or could be due to the instructions given to them by KADUPEDI when they received the device. 


\subsection{Design Efficacy}

\subsubsection{Hand-Powered Tricycle}

The current tricycle seems appropriate to the needs of the people, based on their lifestyles and environment. Some minor tweaks, such as using mudguards were mentioned, but do not affect the overall design much. One major obstacle with the current design is that the tricycle does not have gears, and it is very difficult to manoeuvre the tricycle uphill. This issue could be resolved in further iterations, particularly by an engineering student. Another issue is the angle of the front wheel. In the design made by Alyssa last year, the proper configuration was designed. However, it seems that the angle on some tricycles is off by less than five degrees, thereby allowing the front wheel to jack-knife if turned too far in either direction. It is unclear why Kio is producing the front portion at this angle, and it may be that he does not have the right tools to measure the angle, since the difference between the good and bad angles are barely distinguishable to the eye (see Figure 36). The device also cannot be brought indoors or transported easily, which can be a problem.

One benefit that does not relate to income generation or mobility is one related to dignity. The tricycle lifts people off the ground, which prevents them from getting dirt or mud on their body/clothes, and allows them to be more dignified. It also raises them up, so they are at a more appropriate eye-level, instead of being always looked down on. Although this was not mentioned in the interviews as a factor, it was mentioned in interviews before getting the tricycle, where people were looked down on due to their dirty clothes from crawling all the time to get around. 


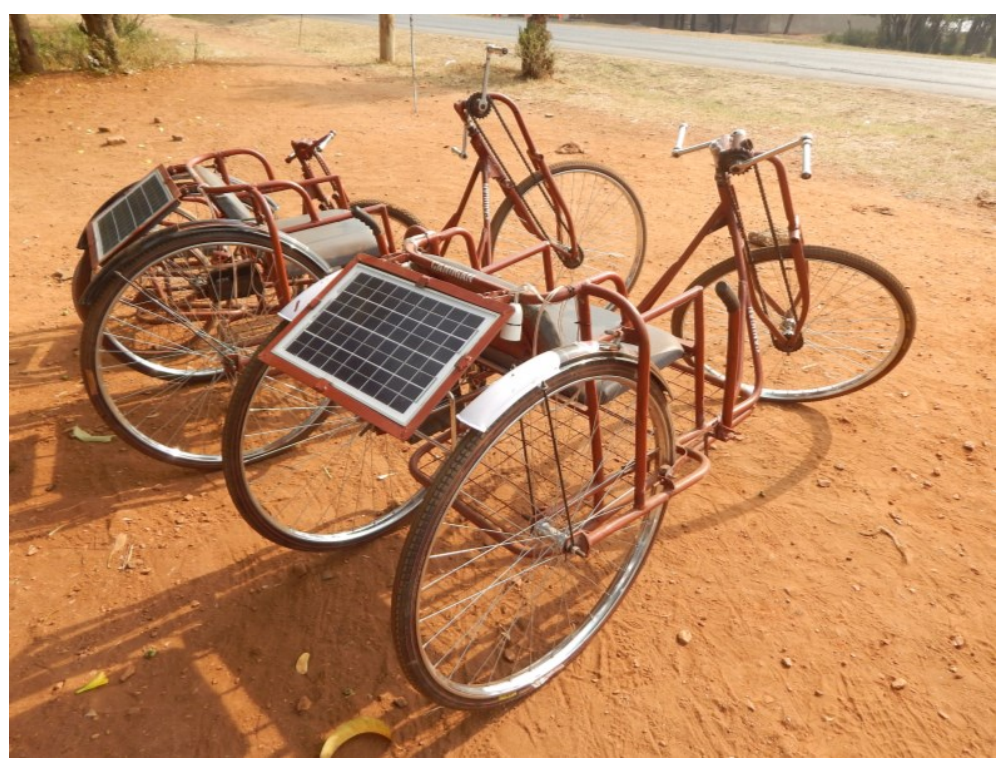

Figure 36: The two closest tricycles are almost complete, and although it is hard to tell the front wheels have very different angles.

Another issue that should also be factored into any product is the life cycle, which includes maintenance. This includes both regular expected maintenance (such as changing the tires or re-painting the frame to avoid rust) and unexpected maintenance (such as repairs when it breaks). It does not seem like CanUgan and KADUPEDI have any system in place for either type of maintenance. Some recipients mentioned that tires need to be replaced every three months, while others had not replaced their tires in two years (although Kio did mention there are different qualities of tires available in the region, which may lead to the discrepancy). It seems that sometimes the recipient pays for their own repairs, sometimes KADUPEDI pays, and sometimes Kio does the work for free. This should be factored into the design and cost of the device from the beginning.

\subsubsection{Solar-Charging Attachment}

The cost of the solar-charging attachment ended up being much more expensive than we 
originally anticipated. This is because Kio decided to use a new set of electronic equipment, and did not realize a battery was not included. Kio is not an electrician, and told us that he bought the solar panel because it said "Made in Germany", which meant to him that it was of good quality (Kio, Discussion with Kio about the solar-charging attachment, 2014b). The old design involved store-bought pieces, which formed a unit comprised of a solar panel, a pay-per-use phone, and a multi-prong adapter used for charging different types of phones. The new design has a solar panel attached to a battery (see Figure 37 and Figure 38). The battery is wired to an inverter, which changes the current of the power, so that it can be wired to a power bar, which allows customers to bring their own cords from home, and allows other devices to be charged as well (see Figure 39 and Figure 40). The new system is more robust, and allows greater choice of components. It also makes more sense in terms of charging, because it is likely that cord endings will change over time, and most customers have their own chargers anyways. Even if the recipient had to buy their own connecting cables, the charger for one phone is about 5,000 UGX (just over \$2 CAD), while the multi-ended toggle is about 15,000 UGX (about \$6.50 CAD).

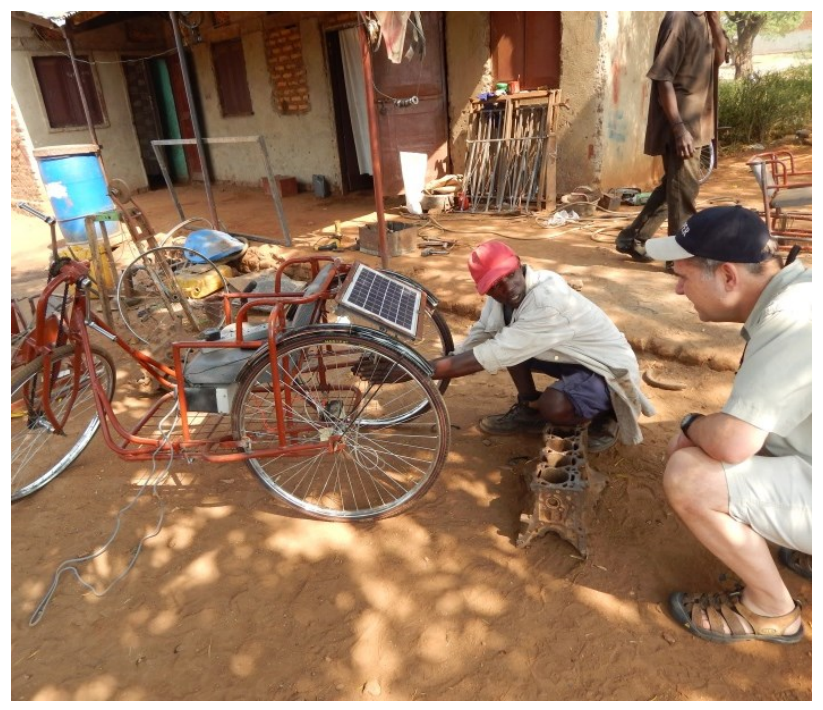

Figure 37: Kio and Bjarki talking about the tricycle with solar-charging attachment.

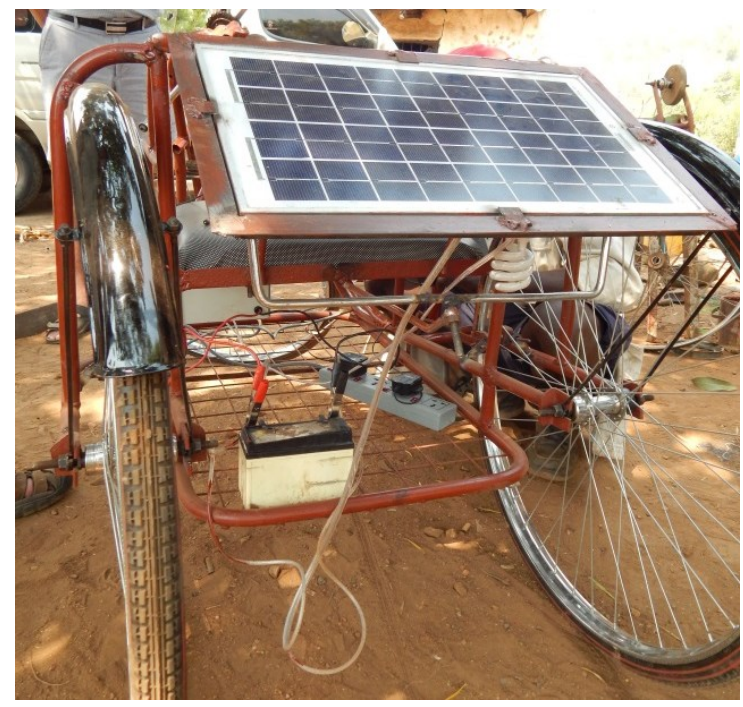

Figure 38: A back-view of the tricycle with solar-charging attachment (solar panel, battery and power bar shown). 


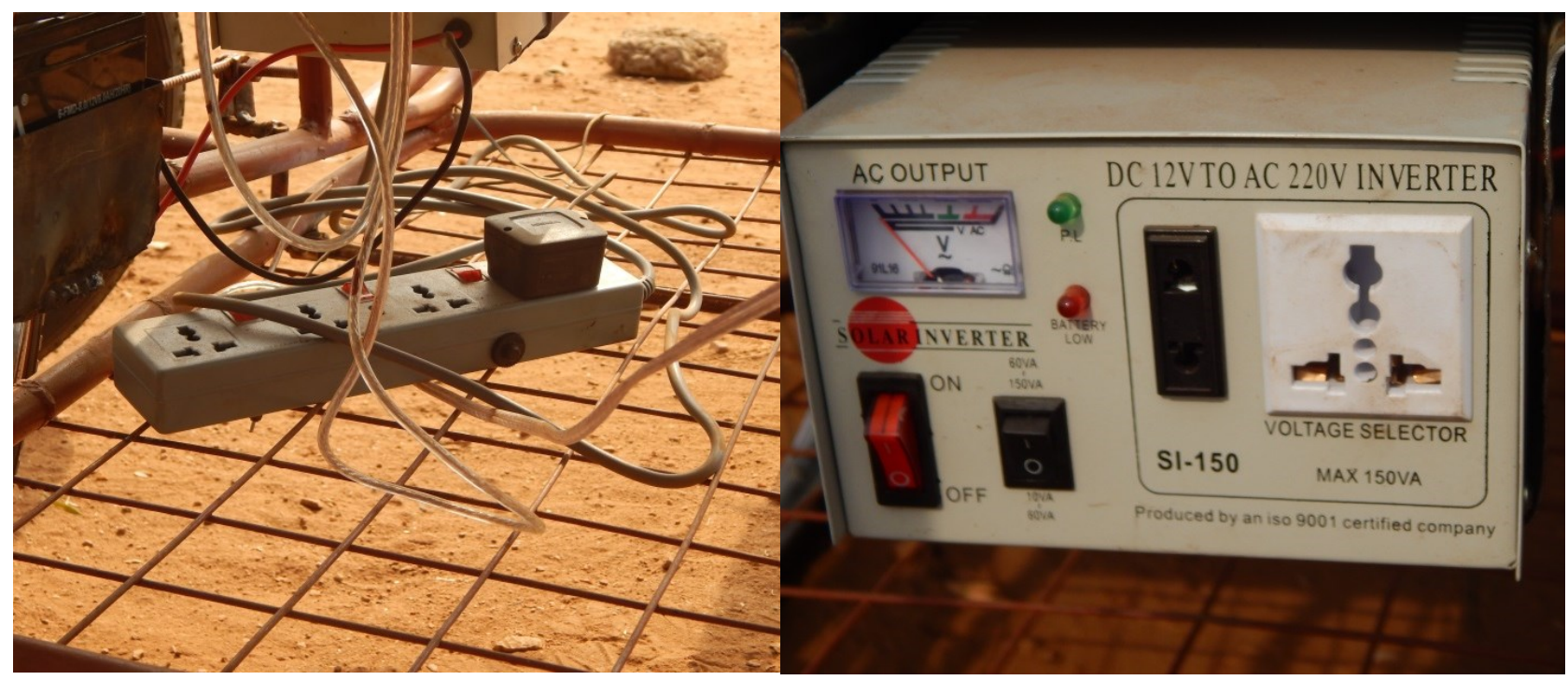

Figure 39: A close-up view of the underside of Figure 40: A close-up of the inverter on the the tricycle with solar-charging attachment (power bar-used for charging phones tricycle with solar-charging attachment. shown).

We observed another issue while visiting some of the solar-charging recipients at their homes. Fauza's solar panels were not even facing the sun, and their umbrella was up so that direct sunlight would not be able to hit it even if it was (Fauza, 2014). Fauza mentioned that even using his device (with the new design) in this way, there was enough power to last for three days without the sun. It therefore seems that the device is too powerful for its need, and the recipients could still have an appropriate income generating device at less cost if the system was downgraded to a smaller panel, battery, etc.

We believe it is possible to bring down the cost of the solar-charging devices that go on the tricycle, as there are many different systems and shops that sell solar devices in the area, of different qualities and at different prices. For example, a shop near KADUPEDI's office has a complete solar-charging package for 160,000 UGX (\$68 CAD), compared to about 537,000 UGX (\$231 CAD) that was paid for the current system. The cost would be further reduced if 
buying in bulk, as the shop owner said that the cost would be reduced to 128,000 UGX ( $\$ 55$ CAD) per unit if over six units were bought. The solar panel on this unit is five Watts (the same as the current design) and does not require an additional battery or inverter. It can also charge three phones at once, which seems sufficient.

Although the design team at Carleton University has never seen this particular unit, it seems reasonable that the price could be dropped considerably for future units if new components were sourced. Perhaps this project could be taken on by an electrician or electrical engineering student to best determine how much sun is needed, how many phones could be charged, and other similar calculations.

\subsection{Complexities of "Design for the Majority" Projects}

\subsubsection{Logistic Challenges of Fieldwork}

\subsubsection{Timeline}

One issue that the project ran into multiple times was time. Things tended to come up that were important to those in that culture and may not seem relevant to my project, like visiting other organizations, having meals at people's houses, visiting their places of work, and visiting local government officials, to name a few. It is important not to refuse their hospitality, as they would like to do these things for you, but they may be a bit far away, involve meals with different courses, or contain long speeches that eat into the day. The time for these should be considered in the plan before going.

There will also always be unforeseen circumstances. Students at Carleton ran into many 
challenges with communication, which were similar in some ways to the challenges expressed by the student at Makerere University, Perez. Whereas Perez experienced problems with understanding why the project was important and why we were working with those specific organizations, Carleton students experienced issues about knowing what it was like in Uganda, and having their projects directions chosen and verified by those in the region.

It is difficult to know how to improve communication overall, but improved communication among these parties could help both with their situations, as students from each university might have the answer to the questions that the students from the other university are asking. This issue should be discussed at the beginning of the process, and perhaps some ideas for how they would best like to communicate might be shared and thought through together. This may include different methods at different steps in the process, or one person communicating in one way (by sending emails or messages via cellphone applications like WhatsApp), while the other communicates in another way (by posting to a blog or creating videos). The engineering student also said he learned from the design students' ability to iterate, and the design students wished they had more technical knowledge when doing the designs for their project. Therefore, the idea of having design and engineering students from different countries pair up seems extremely beneficial to all parties involved. Students at Carleton University expressed that they would have liked more background information, general research and photos from previous years before starting the project to get a head start on what's expected and what their project should be. 


\subsubsection{Payments}

In Uganda it is often impossible to pay with debit or credit, as they are mainly a cashedbased society. Even in places that take credit, it is often treated by the credit card company as a cash-advance, which costs interest. Therefore, large sums must be paid in cash, which was an issue faced during the field-work.

\subsubsection{Lessons Learned from the Methodology}

\subsubsection{Questionnaires}

The questionnaires were a good way to learn about the recipients before going to Uganda. It helped me get a feel for what the people were like, and allowed interview questions to be planned in advance. Also, by having a questionnaire filled out at the beginning, it allowed me to understand how the representatives from KADUPDI communicated, especially in their writing. This allowed me to revise the questions for the second questionnaire to be more closed-ended (when applicable) in order to ensure that all questions were answered in a more specific way. Questionnaires are also an appropriate tool to use if you cannot be in the country and want to know more information about a certain group of people. However, these would never have been possible without the help of KADUPEDI, who helped formulate the wording of the questions, selected people to interview, translated and transcribed the questions and answers, and sent them back to the researcher in Ottawa. For other projects, this vast amount of help at barely any expense may not be possible, and other alternatives would have to be explored.

\subsubsection{Interviews}

Although the interviews asked similar questions to those of the questionnaires, they 
helped to reveal much more information. This is because when you interview someone in person, it is possible to reword a question or clarify its meaning in order to get a more accurate response. Also, by having multiple people acting as interviewers, it is possible to have new questions that one interviewer never thought to ask, especially as follow-up to another interviewers questions.

During the process of design education, a student learns how to conduct interviews, generally through the context of software interface design or that of a psychologist (as it is taught at Carleton University). However, this training generally does not include consideration for the context, such as people who speak different languages and might also think in different ways. Therefore it was important to be less rigid and structured and to be open to asking questions as they arose naturally in conversations, or as certain observations were made. Often many questions had to be asked of the translator for clarification, such as to repeat something, asking what something meant, or simply re-asking a question that was answered in an unexpected way. It is up to the translator/interpreter to ask questions in a way which makes sense to the person being interviewed, meaning that the exact question or answer may not be conveyed exactly, and may change slightly each time it is translated (once into the local language, and once back to English), and each time it has to be interpreted (another two times).

It is important to think on your feet during the interview to ask probing questions based on answers given, to provide further explanation or new questions based on ideas, the environment, who is around, etc. Having family nearby can help to clarify the answers to questions that may impose some bias on what the answers will be, depending on how personal 
the questions are. This may be more helpful for quantitative (e.g. how much does school cost?) vs. qualitative (e.g. how do you feel about this?) type of questions. People also might be shy when speaking in their second or third language. Give them the option of using a translator or allowing them to speak in English. Still have a translator nearby in case they are unable to articulate their thoughts, as they may not be able to perfectly explain an idea in their non-native language.

\subsubsection{Discrepancies}

It was often difficult to tell which answer was correct, as conflicting answers were sometimes given. It is possible that they did not think of it earlier, perhaps they calculated or spoke incorrectly, or maybe they did not think of it when they were asked the first time. On different occasions, with different recipients, the interviewee gave differing answers to different people or gave different answers to what they had previously written down. For example, Margaret said she could make 1,500 to 8,000 shillings ( $\$ 0.65$ to $\$ 3.45$ CAD) per day when we asked her in the interview, but when we looked at her accounting records it seemed she only made a maximum of 1,200 shillings $(\$ 0.52 \mathrm{CAD}$ ) per day during the period (with four customers and a price of 300 to charge each phone). Another recipient, Maria, who is a food vendor said that she could make 30,000 (\$13 CAD) per day by selling French fries from her home. Although that might not seem like a lot here, it seems a bit unreasonable there. Especially since she said her dream was a house made from corrugated metal sheets, which cost 18,000 each (she would need 19 sheets). With an income of 30,000 per day, it seems that she might be able to purchase the sheets within a short amount of time. It seems that business planning would be helpful to allow them to better understand their costs, budgets, and incomes in order to realize their goals. 


\subsubsection{Knowledge Transfer and Capacity Building}

\subsubsection{Engineering at Makerere University}

The student from Makerere, Perez Magoola, made some recommendations based on his program that helps to give a better understanding of what their school and course work requires from the students. Therefore, if CanUgan continues to work with Makerere University in the future, they should take these points into consideration. For example, after the fall term the student is responsible for doing a large presentation about why their project is important and why they chose it. However, Perez was not fully briefed on the importance of the project and therefore the professors had many questions about the validity of his project that were perfectly good questions, but he was unable to answer. In order to prevent this in future years, it might be good to have the student from the previous year meet with them to explain everything and answer any questions. It is important that all essential knowledge transfer over as students change each year. This is also an important issue at Carleton University, which perhaps could be addressed more explicitly.

Another issue encountered was the communication between Carleton and Makerere. In Kampala paying for internet is very expensive and the Wi-Fi at school is very slow, especially during the day. Therefore, it is difficult for them to look at pictures and videos that we had uploaded. Skype is also unreliable if the connection is slow, and the time zone makes it more of a challenge. Perez suggested that blogs or forums could be viewed at any time, required less data, and could be updated each week. Although Skype or a phone call might be useful sometimes, a blog would be better for consistent reliable communication. Students from Carleton University did post on a blog during the year, however the students at Makerere could 
also be invited to post on this blog.

At Makerere, the students must use a lot of calculations and theoretical knowledge to form their engineering design solution and there is less emphasis on iteration in the process. The student mentioned that if the first prototype does not work, the students would often be stressed, and would sometimes try to fake the model so it looks good for their presentation, otherwise they may fail. This high pressure to succeed may steer some students away from doing a communitybased project with real people that may run into complications along the way. Students have to be taught how iteration can lead to success, and be convinced they will not fail by choosing this type of project. Professors must also understand the project, and possibly make new criteria to ensure these projects can also be successful engineering solutions. It may also help to have a design student work on the design aspects, and have an engineering student work on the technical aspects of the same device. This may give each of them more time and resources to succeed, and will allow them to bounce ideas off each other. For future collaborations between Carleton and Makerere universities, the student in Kampala can also act as a conduit for information about the recipients, Uganda, etc. while the student in Canada can help emphasize the needs of disabled users through their research and knowledge of user-centred design.

\subsubsection{Disability Studies at Kyambogo University}

While meeting with the dean and professors at Kyambogo University, they seemed eager to tell us about how unique, acclaimed and special their program was. Although all schools like to talk about their benefits in terms of what they can offer students, this may serve to make collaboration difficult. When collaboration with the faculty of Industrial Design at their own 
school was mentioned, it seemed there was some trepidation about designers taking over the project and not understanding the unique issues that come with working with PWD. In order for collaboration to be possible in the future, some of these attitudes might have to change in order to allow knowledge exchange and projects to be successfully implemented. This would allow both departments to share their knowledge with each other, thereby enriching both departments.

\subsubsection{Local Manufacturer}

An important aspect of the knowledge transfer is the design of the tricycle and other devices. Many of the improvements the students made last year are still being implemented now, because the mobility devices are stronger, use less material, etc. This shows that Kio thinks these aspects are useful and will continue to use them to change his design. However, he has not kept up with all of the changes, for various reasons. He has improved some parts of the design, and he has reverted back in other parts (mostly due to lack of equipment and trying to reuse bits of material instead of buying new pieces). It is important to understand his thought process in order to ensure important design recommendations are kept-up over time or are continuously reviewed.

One issue that was problematic was the fact that our funding agency and university needed very rigorous documentation. Writing up receipts in the specific way, as required by the policies of the IDRC and Carleton University, is sometimes difficult for Kio, and it is usually easier to write it out on another piece of paper as it should be written so that it can simply be copied. It was also problematic to get receipts for some restaurants, products, or methods of transportation, as this is not generally done for small purchases at low costs. Kio sometimes did 
not keep track of what things cost and what had already been paid, meaning that the research team had to be diligent to ensure that everyone was fairly compensated for their work and costs.

Uganda seems to be very much a culture of "yes". If we ask "Can we go see him?", "Can you make this?", or "Is it possible to find that part?" the answer is always yes. People always say yes even if they are not sure of the answer, they will try to make it work. This can be good because they are very resourceful and will try to make all requests come to fruition. However, it can also be bad because they might say yes before checking and find it is not possible to do what you asked. It seems impossible to avoid this, but it is definitely something that a researcher should be made aware of before starting their research.

One major issue is that Kio's workshop often loses power and he is unable to use grinders, cutting devices or the welding machine, which slows his process. He also has a lack of equipment, which makes it take longer to make the device than it might if he had the proper tools. One benefit of his process is he uses materials frugally, and will weld a bunch of pieces together instead of buying a new piece or will reuse scrap material in new projects, which lowers the cost, and increases the sustainability of each device.

A major aspect of his work process is spontaneity, which can be helpful or problematic. It is good because he can get things done quickly and try things out in order to visualize them and show others. It can be unfortunate because it may end up being a waste of materials, or it may be difficult to put back together once it is cut, for instance. It also may not allow enough time for everyone to think of alternative suggestions before taking action. 


\section{CONCLUSION}

\subsection{Factors that Influence Income-Generating Products}

In conclusion, it is important to look at what actually worked and what needed to be improved in this project, so that other designers can benefit from the knowledge when designing similar products. In terms of the design itself, the user base can be much larger if there is not a lot of training or practice involved to provide the product or service to customers. It is also ideal if the product or service is highly in demand in the area, and is not widely available to most customers. Alternatively, if the product or service is already readily available, the recipient could still have a good business by providing theirs at a lower price than the market, or making it portable, and therefore more convenient. The product should also consider the local context, including culture, environment, societal roles and traditional business methods.

It is often difficult to understand all of these issues as a designer, which is why a participatory process is essential, and will ideally include as many different stakeholders as possible. This allows for simple issues to be spotted and corrected early on. Monitoring and evaluation (as well as a pilot test) can also help to figure out problems in order to find new solutions. Using small-scale local manufacturers will allow changes in the design to be made quickly and at a lower price. It will also ensure that the recipients can have their devices repaired, and that they can be provided quickly, due to the close proximity. However, limitations of local manufacturers (including access to materials, availability of tools, and consistent services) should be factored into the design. 
One major factor in the success of the project is the partner organization and the recipients selected. Designers must understand that is not only the product itself that comes into play, but the people surrounding it. Having a partner who is knowledgeable of the area, able to help determine recipients, transparent about their practices, and able to ensure that participation can be included in the design is key to a successful product. Also, the same device given to multiple people will not yield the same results. In terms of income-generating products, for optimal financial success, it is ideal to give the product to someone with a good customer base who has a strong work ethic and plenty of time to earn income. However, the social impacts to a life are much more difficult to measure and compare.

\subsection{Limitations of the Study}

\subsubsection{Time}

Time is never unlimited, and the period of time for this research to be involved with this project was approximately eight months (since the project also coincided with a fourth year student project which took place over that time period in the school year, from September 2013 to April 2014). Originally, all of the devices were supposed to be made and distributed in the fall, in order to have at least two months of income-generation completed before the interviews in February. Unfortunately, there was a delay in getting approval from the funding agency, and also another delay in getting the funds released by the university. This meant that the devices could not be constructed until December. Once the money was approved, it had to be wire transferred. It turned out that the bank information given from the manufacturer in Kasese was incorrect, and the transfer had to be put through again. This entire process took over a month, which prevented the first recipient from getting his device until the middle of January. 
The subsequent two devices were just being completed during our field-work in February, meaning that those recipients did not receive devices until two weeks after we left, in early March. Since the project was to end in April, it was decided that no more devices should be made or distributed, since the data would not be useful to the research. Therefore, a lack of time led to a smaller sample size and a smaller amount of post-device information being tracked from each recipient. It is likely that with more time, and more recipients, most insights might have emerged.

\subsubsection{Budget}

The budget is an important issue when it comes to giving out devices to people with disabilities. Since the devices were made locally, the cost is reduced for materials, labour and shipping. However, because the product (the solar-charging attachment) is still in the conceptual stage, there were kinks to work out which added to the cost of the devices. Since there was a certain budget for the devices, issues in the costing meant that fewer devices could be made within the same budget. The case study would ideally have included ten to twelve participants in order to get a wider variety of experiences and still stay within the budget for creating new assistive devices. However, due to budget and time restraints, only four devices were made and tested. By testing more devices it would have been possible to tease out some of the factors which influence the recipient's ability to make an income, by comparing the results from a larger sample.

\subsubsection{Region/Partners}

A limiting factor of this study is that it was only done in partnership with one disability 
organization in one region of Uganda. This means that many of the factors represented are specific to the people and region involved in the project and will not necessarily be the same if working in a different part of the world, or working with a different type of local organization. One huge benefit of working with KADUPEDI is that they rely on dedicated volunteers who know every one of their recipients personally. This allowed us to schedule impromptu meetings, and allowed the recipients to be more comfortable answering questions. In a larger organization with less personal contact, this may have created some problems. Their dedication also allowed us to have questionnaires filled out while we were not in Uganda, and translation services while in Uganda, without having to pay large fees, which should also be taken into account when budgeting for a similar project, if volunteers are not already readily available. The opinions and lifestyles of both recipients and the organization would change if the people were of a different culture or from a different country. There may be differences in access to services, the types of income generation, and family structure, however many of the issues related to disability and poverty are likely to span across cultures.

\subsubsection{Assumptions and Results}

It is important to understand your own assumptions as a researcher. Before getting to Uganda, the researcher made a number of assumptions which may have led to a bias in the results. For example, the researcher assumed that some PWD would not have been able to go to school as children, and thus would not be able to keep accurate records. However this was not the case, and may have influenced the way some questions were asked, or the way correspondence with KADUPEDI was structured. Another assumption was that dependency is a problem and that independence is preferential, as it is often viewed that way in a North American 
context. However, this is not always the case in Uganda, and the researcher was made aware of this during the process. It is impossible to avoid all assumptions but they may have had some influence on the formulation of the research questions or the subsequent results.

Also, even though four recipients were given a solar-charging device, one lady (Maria) moved to Kampala to start a business. Although this was outside the control of the research and KADUPEDI, it makes monitoring and evaluation more difficult, and reduces the amount of results that were collected for the second questionnaire (and any future research that KADUPEDI or CanUgan is interested in pursuing).

\subsection{Recommendations for KADUPEDI/CanUgan}

This project would not have been possible without the collaborative efforts taken by CanUgan and KADUPEDI, since they provided so much insight and on-the-ground assistance in the data collection and recipient selection. The author would like to offer these organizations some recommendations, based on the results of the research.

During interviews with KADUPEDI, it was mentioned that the local and national government of Uganda might be possible future donors to KADUPEDI, due to the success of their device dissemination program. The author suggests that all funding options be explored, as additional funding could help many additional people with disabilities in the area. It seems with current funding there is no way to meet the demand of people with disabilities, even if solely focusing on those with physical impairments. 
During the research, it was unclear what type of records KADUPEDI was keeping, and the exact criteria for recipient selection, as answers from different representatives varied. A representative from KADUPEDI agrees that having more detailed criteria would be beneficial for record keeping purposes and would also allow consistency between results from multiple recipients. The author would also recommend standardizing any forms that relate to reporting, recipient selection, etc. and creating a database where these documents can be easily found and compared, in order to aid in any future research that CanUgan and KADUPEDI are interested in pursuing. It also became obvious that recipients were supposed to be visited regularly; however the actual visits really just happened when someone was in their region for another region. Perhaps KADUPEDI could make more efficient use of their sub-county representative volunteers for collecting this regular information, in order to ensure it happens on the timeline that they were interested in achieving, instead of just based on convenience.

In order to understand the effect of income-generating devices on the recipients, proper accounting is essential. Not only will these records help prove the recipients have a better quality of life in a quantitative way, it will help to understand the complexities that come with running a business, and will answer the questions of donors and funding agencies of CanUgan back in Canada. The author recommends that KADUPEDI should offer a short course to all new income-generation recipients. KADUPEDI (or an outside person who they contract) could teach the recipients about simple business practices like accounting, marketing and other useful strategies. The course should also teach the recipient how to take accounts for their business, in terms of how much they pay for inputs (perhaps maintenance for the tricycle, or stock if they are in a vending business) and how much they take-in from customers each day. 
Another important skill may be regarding setting goals and future plans. This would allow recipients to say "Okay, I need X amount of shillings in 30 days to pay for my child's education, how much do I need to make each day in order to cover that cost?" and other similar questions. They could also chart their expenditures (non-business related) in the booklet, or a separate booklet, in order for CanUgan, KADUPEDI, and the recipient to better understand the economics of the recipients' family over time. This course should also include a small booklet that they can use for their notes, as well as a template for the structure of the rows and columns (which could already be in the book or separate, depending on KADUPEDI's preferences).

One aspect of the product dissemination that is not currently being addressed is maintenance. It is unclear who should pay for both regular (such as replacing the tires) and unexpected maintenance (such as brake problems). It would be useful for everyone involved to understand who is responsible for this maintenance and the associated costs. If Kio will do the maintenance for free, then perhaps CanUgan should factor this into the amount he is paid for each device. If the recipients are responsible for paying, this should be clearly articulated when they receive the device, and they should be told (and perhaps taught) about how much they should set aside from their earnings for this purpose, based on what expected maintenance might cost and how often it is likely to occur. It is also likely that if the recipients run into issues with their new solar-charging system, Kio will be unable to solve these problems. Therefore, a plan should be put into place for what should happen if he cannot do the repairs.

As mentioned in previous sections, the cost of the solar-charging device ended up being much higher than expected. Kio is not an electrician, and is unable to completely understand 
which products (battery, solar panel, inverter, etc.) should come together to make the ideal system for this use. It would be useful to have an electrician or electrical engineer (perhaps from a local university as part of a school project, in order to keep costs down) look at the device, in order to create specifications for the ideal system. Based on these decisions, it would likely be possible to source all of the components locally, and could greatly reduce the cost of the solarcharging device. The electrician or electrical engineering student could determine how much sun is needed, how many phones could be charged, and other similar calculations.

Also, although the partnership with Carleton University in Canada was a great learning experience for the students, it came at a large expense, and was only possible due to generous funding from the IDRC. It seems that it would therefore be in CanUgan's best interest to solicit the help of local universities in Uganda (such as those that we met with during this project). The benefit of working with local students are reduced costs, knowledge of local culture, materials, processes and language, and an increased ability to travel and meet with all stakeholders continually throughout the process. It would also prepare Ugandan University students to work in rural areas and help with the poor and underserved in their own country, which may inspire them to eventually work in that sector in the future. Potential projects for Makerere University students include redesigning the tricycle to have a gearing system (mechanical engineering) or looking into the system for the solar-charging attachment (electrical engineering).

\subsection{Recommendations for "Design with the Majority" Projects}

Based on this research, the author gained insights about working with those in other communities on multi-disciplinary, cross-cultural design projects. This list is meant as a 
guideline for future design professionals, students and researchers who are interested in working on "Design with the Majority" type projects. Given the complexity and varying nature of such projects, the list cannot be comprehensive, but rather offers designers a starting point in order to consider what issues may come up along the way in different project areas and regions.

\section{Understand project management fundamentals}

Projects of this nature are inherently complex, time consuming and logistical. Timelines, travel, and logistical problems can eat up a lot of time and be the difference between success and failure. This is inherently related to the fact that these projects are "not easy" and have to be performed in areas that are foreign to us. Project management responsibilities for any designer working on such a project requires liaison work with clients and other stakeholders to articulate their priorities before the process starts. Many of these factors are competing priorities, and this can often be dealt with through creating a design brief or list of product specifications.

Designers need to keep excellent records throughout the project, and should have an ongoing project plan and checklist of items that need to be taken care of in anticipation of critical milestones such as travel and meetings. Try to calculate expenses throughout the trip, in terms of how much money and when it will likely be needed as ATM machines may not be working. Also understand that prototyping will often cost more than the final product, and try to factor this into the budget as much as possible, since multiple iterations will have to be produced and tested.

\section{Let research drive the project}

These types of projects are also inherently research driven due to the large number of unknown issues. Traditional design research includes investigation of existing products in the category, 
and looking at statistics and figures related to the problem. Secondary research is also important, such as reading articles to try and understand the local culture, and looking into the history of the problem area. However, primary research is the key participatory design, and contributes to a successful project. Some methods include questionnaires, interviews and collaborative prototyping. Questionnaires are a useful distance tool. Ideally, these can be filled-out by volunteers from local organizations if the local language is not spoken by the researcher and/or the people are illiterate. Depending on the subject matter, it is important to understand whether closed-ended or open ended questions should be used. Interviews are essential during field work and it is important to ask questions in a way that is culturally appropriate, as this will yield the most accurate and open answers. Always have a translator available, as your primary language may not be the end users first language. Depending on the subject matter, it may be useful or detrimental to have a third-party in the room for interviews. Prototyping can be done in conjunction with both a local manufacturer and the end recipients, and should be seen as an iterative process. It is important to go through many stages, and have the recipients available to offer criticism or other feedback about the design. As they see the design change, they will be less hesitant to offer solutions that may change the design

\section{Make partners with local organizations and other stakeholders}

Local tie-in is a key aspect of "Design with the Majority" projects. Since the project team will likely disperse after a few years, and the designers likely do not live in the area, it is important to have a local authority in charge of sustaining the project, which hopefully will lead to its continued success. Local partners will also help during the field work, where translation, transportation, local customs and other issues can be more easily negotiated with local assistance 
and knowledge. Local people who believe in the project will also act as advocates in their community for your success, and will encourage additional participation. It is essential to work with as many stakeholders as possible throughout the process. This always includes the final users and the manufacturers, but may also include government bodies, local organizations and community groups, NGOs, businesses, schools or families.

\section{Understand your recipients and all stakeholder assumptions}

It is unrealistic to have no assumptions or prejudices towards the group you are working with. Therefore, it is important to understand what pre-conceived notions you and other stakeholders

already have, especially if the recipients are marginalized. Also try to respect local customs and norms, which may include appropriate dress, ways of conversing, typical polite greetings, and other customs which may seem trivial. If working for a charity or NGO that is giving away devices for free, you may run into the issue of recipients wanting more. It is important to be polite, yet firm, in explaining the resources and selection process regarding your project, so that the recipients will not be offended when you cannot give them more than you have already. As designers we only have a limited understanding of complex issues that come into play when trying to understand people and the way they behave. If people are saying or doing things you do not understand, try to talk to local organizations, others in the community or another professional who would understand the issue better.

\section{Collaborate with experts specific to the field you are working in}

If you are working in a certain region, try to talk to people who are experts on the culture and history of that place. Most people in a particular field are happy to discuss their area of 
expertise, and it might be a good idea to fly these experts in for a workshop with the project team, in order to get a good overview of issue you may face. Although this adds a cost to the project, it may help to avoid a lot of obstacles in the future, and will likely cut down on the initial research time needed to understand the problems.

\section{Communication is often difficult}

In majority world countries and communities, there is often a lack of infrastructure, which means that access to internet may be unreliable. There are also time differences between stakeholders in different regions. Language, cultural and technology barriers may also come into play. It is important to understand the limitations and preferences of each group, so as to allow better teamwork. This also needs to be re-examined throughout the project. Communication is much more complicated when multiple countries, currencies, organizations and time zones are involved.

\section{Always leave extra time}

There will always be unforeseen circumstances that come into play that have to be anticipated with some flexibility in schedules. Cultural events and local customs may be influential factors while in the country, as those participants from afar may be invited to local government offices, houses for dinner, a community party or other events that were unplanned. Hospitality in some cultures is also very important, and it will be offensive not to participate. Local holidays, and religious observance should also be accounted for in the timeline, depending on the region. 


\section{Understand that people may try to please you}

Recipients might think that working with you can give them some sort of advantage (such as status, money, resources, etc.) in the future, even if this is not necessarily the case. Therefore, it is likely they will give you the answers you want to hear, and never say "no" to your requests. When talking to stakeholders, try to understand the motivations behind their answers, and ask follow-up questions as needed. Additionally, when doing follow-up interviews with users, it is important to ask how the device is working. Although they may say everything is fine, looking for signs of wear and tear and watching their interactions with the device may give you insights into issues they were too polite to mention.

\section{Understand the workflow and resources of local manufacturers}

The local workers tend to be very resourceful and spontaneous. They are willing to take on new ideas, and can read drawings and manufacture products by looking at them. This means that iteration and designing with the manufacturer are important, as watching them make the product will likely help you to understand which processes take the most time, what the raw materials look like, and how much time everything takes. By understanding the processes they use, it is likely some inefficiencies can be removed. It is also important to understand the limitations of the workshop, as they may only have access to simple tools, and their access to services like water and electricity may not be reliable.

\section{Plan for follow-up over an extended period of time}

Long distances can often lead to infrequent contact, which makes follow-up more costly, timeconsuming and difficult. Some designers may feel content just designing a beautiful product, but 
products can break or need maintenance and must be appropriate to the environment and people who use it. Some of these findings likely will not come to light until the products have been used for some time. By designing for follow-up, the designer is given the opportunity to ensure the design is appropriate, robust, and will be used by people for many years instead of being quickly discarded or forgotten about. Designers must also be prepared to find problems or failure, and be willing to be honest about what went wrong, in order to prevent more failure in the future.

\subsection{Potential Future Research}

Since this project was a case study, it could not cover the whole range of issues that were discovered during the project. Some of these issues might be of use to other researchers when thinking of prospective future research topics.

Since this case study had so many new insights, it would be interesting for other researchers to conduct similar case studies, perhaps using different devices and in different regions, in order to compare findings and to give more case studies to the field of "Design with the Majority". This case study, done on a more longitudinal basis may also offer insights into how relationships change over time, if income rises or decreases over time, and how the devices fare over many years (regarding maintenance, end of life, etc.). Researchers looking into this area might also want to meet with other organizations and NGOs in the product area or region, in order to gain a better understanding of the context and gain new perspectives (which we were unable to do because of time restrictions). These topics of research would likely need to involve a design researcher with an interdisciplinary focus, or a designer working in collaboration with 
those in the social sciences (such as African Studies, International Affairs, etc.).

In recent years, there seems to have been an emergence of income-generating devices or training programs aimed at those in extreme poverty as a form of aid or international assistance offered by wealthy countries, multilateral organizations and NGOs. There seems to be a lack of research on whether these types of programs are successful in the long-run (since many of them are very new), and if these programs can change the dependency and independence of the participants involved. As a designer, these issues affect the people we work for and the products we design. However, these issues relate to socioeconomic status, culture and psychology, and therefore fall outside the scope of this researcher's field of expertise. An area for further research could be how public opinion and self-conceptions affect the income-generating success of people in extreme poverty and people with disabilities specifically. This topic would not necessarily need a design focus, but could be available for someone looking at economics or social sciences related to international development.

In terms of future devices that would be useful, KADUPEDI and some of the recipients have stressed the importance of building a tricycle that is good on steep slopes, since Kasese is a very hilly region and the tricycle users must exert a lot of energy to overcome some slopes. Sometimes the current users get stuck and other people have to help them up the hill. They are also thirsty for more income-generating ideas, and would likely be interested in offering a number of different income-generating devices that were geared towards the specific skills and interest of the recipient. It is likely that a designer or engineer could help with these issues. 


\subsection{Final Comments}

This project was a case study about the appropriateness of devices for income-generation in rural Uganda. An interesting aspect of the research was the multi-disciplinary approach taken by the researcher. This involved assistance from supervisors in two very different departments. Blair Rutherford, from the Institute of African studies shed light on historical narrative related to the context of rural and east Africa, while mentioning dialogues on the issues of dependency and poverty and helping to formulate research methods along a social sciences approach. Bjarki Hallgrimsson, from the School of Industrial Design, on the other hand, offered insight into prototyping, design efficacy, and other device specific issues. Without the help of these two departments, the author would have never been able to investigate this case study in the same depth. The author hopes that more work of this type of interdisciplinary nature can be done, as it explores complex problems from multiple vantage points in order to get a more complete picture of the complexities that are found in the real world. 


\section{BIBLIOGRAPHY}

Architecture for Humanity. (2006). Design like you give a damn: Architectual responses to humanitarian crises. (A. f. Humanity, Ed.) New York, NY, USA: Metropolis Books.

Balaram, S. (2010). Universal design and the majority world. In W. F. Preiser, \& K. H. Smith, Universal Design Handbook (pp. 3.1-3.6). Ney York, NY, USA: McGraw-Hill.

Bernard, H. R. (2011). Research methods in anthropology: Qualitative and quantitative approaches (Fifth Edition ed.). Plymouth, UK: AltaMira Press.

Buchanan, R. (2001). Human dignity and human rights: Thoughts on the principles of humancentered design. Design Issues, 17(3), 35-39.

Buckup, S. (2008). The price of exclusion: Executive Summary of the economic consequences of excluding people with disabilities from the world of work. Employment Sector Working Paper No. 43, ILO, Geneva.

CanUgan. (2014a). Responding to a need. Retrieved April 16, 2014, from CanUgan Disability Support: http://www.canugan.org/what-we-do/

CanUgan. (2014b). Who we are. Retrieved February 1, 2014, from CanUgan Disability Support: http:/www.canugan.org/who-are-we/

Catapult Design. (2013). Learning labs: Hands-on workshops. Retrieved December 15, 2013, from Catapult Design: http://catapultdesign.org/services/learning/

Collier, P. (2007). The bottom billion: Why the poorest countries are failing and what can be done about it. Oxford: Oxford University Press.

Crilly, N., Moultrie, J., \& Clarkson, P. J. (2004, November). Seeing things: Consumer response to the visual domain in product design. Design Studies, 25(6), 547-577.

Dracup, R. (2013, July 30). Flushed down the toilet: Why aid projects don't always deliver. Retrieved November 5, 2013, from New Internationalist Blog: http://newint.org/blog/2013/07/30/aid-projects-dont-always-deliver/

Easterly, W. R. (2006). The white man's burden: Why the west's efforts to aid the rest have done so much ill and so little good. New York: Penguin Press.

Er, H. A. (1997). Development patterns of industrial design in the third world: A conceptual model for newly industrialized countries. Journal of Design History, 10(3), 293-307.

Farrell, G. (2007, June). ICT in education in Uganda. Retrieved November 4, 2013, from http://www.infodev.org/infodev-files/resource/InfodevDocuments_435.pdf

Fauza. (2014, February 13). (A. Cox, Interviewer, \& Baluku Peter, Translator) Kasese, Uganda. 
Ferguson, J. (2013, June). Declarations of dependence: Labour, personhood, and welfare in southern Africa. Journal of the Royal Anthropological Institute, 19(2), 223-242.

Fox, K. (2011, July 24). Africa's mobile economic revolution. The Guardian: The Observer.

Fuse-Project. (2006, July 8). File:LaptopOLPC a.jpg. Retrieved May 3, 2014, from Wikimedia commons: http://commons.wikimedia.org/wiki/File:LaptopOLPC_a.jpg

Garcia, L. (2014, February 27). (A. Cox, Interviewer) Ottawa, Ontario, Canada.

Gobo, G. (2008). Doing ethnography. (A. Belton, Trans.) London: SAGE Pulications Ltd.

Hallgrimsson, B., Liu, C., \& Hadley, R. (2013, August 21). Design for extreme poverty and disability: A social innovation project case study in rural Uganda. IDSA 2013 Education Symposium. Chicago.

International Food Policy Research Institute. (October 2007). The world's most deprived: Characteristics and causes of extreme poverty. International Food Policy Research Institute.

ITU News. (2009, July/August). Communications in Uganda: A look at one of Africa's fastest growing markets. Retrieved December 14, 2013, from ITU News: http://www.itu.int/net/itunews/issues/2009/06/31.aspx

Jaipur foot. (2013). Below-knee prosthesis. Retrieved April 19, 2014, from Jaipurfoot: http://jaipurfoot.org/what_we_do/prosthesis/below_knee_prosthesis.html\#.U1NO0_ldWS o

Kagere, B. R. (2011, November 7). Challenges of integrating the "Jua Kalis" into the national science and technology system in Uganda. Kampala, Uganda.

Kensing, F., \& Blomberg, J. (1998). Participatory design: Issues and concerns. Computer Supported Cooperative Work, 7, 167-185.

King, K. (1977). The African artisan: Education and the informal sector. London: Heinemann.

Kio. (2014a, February 18). (A. Cox, Interviewer, \& B. Peter, Translator) Kasese, Uganda.

Kio. (2014b, February 17). Discussion with Kio about the solar-charging attachment. (A. Cox, \& B. Hallgrimsson, Interviewers) Kasese, Uganda.

Kraemer, K., Dedrick, J., \& Sharma, P. (2009). One laptop per child: vision vs. reality. Communications of the ACM, 52(6), 66-73.

Krizack, M. (2000). Wheelchair history made in Uganda. Retrieved April 20, 2014, from Disability world: http://www.disabilityworld.org/Aug-Sept2000/tech/Uganda.htm

Magoola, P. (2014, February 20). (A. Cox, Interviewer) 
Margaret, B. (2014, February 18). (A. Cox, Interviewer, \& B. Peter, Translator) Kasese, Uganda.

Martin, B., \& Hanington, B. (2012). Universal methods of design: 100 ways to research complex problems, develop innovative ideas, and design effective solutions. Beverly, MA, USA: Rockport Publishers.

Ministry of Finance, Planning and Economic Development. (2010). Millenium development goals report for Uganda 2010. Kampala: The Reublic of Uganda.

Moyo, D. (2009). Dead aid: Why aid is not working and how there is a better way for Africa (Vol. 1st American ed.). New York: Farrar, Straus and Giroux.

Mukisa, M. F. (2008). The status of the wheelchair in Uganda. The Republic of Uganda Ministry of Health, Disability Prevention and Rehabilitation. Kampala, Uganda: National Wheelchair Committee.

Muller, M. J., \& Kuhn, S. (1993, June). Participatory design. Communications of the AGM: Special issue on participatory design, 36(6), 24-28.

NUDIPU. (2013a). Disability and human rights. Retrieved January 5, 2014, from National union of disabled persons of Uganda: http://nudipu.org/programmes/disability-and-humanrights/

NUDIPU. (2013b). History. Retrieved December 15, 2013, from National union of disabled persons of Uganda: http://nudipu.org/about/background/

NUDIPU. (2013c). Mission and vision. Retrieved December 15, 2013, from National union of disabled persons of Uganda: http://nudipu.org/about/what/

O'Grady, J. V. (2006). A designer's research manual: Succeed in design by knowing your clients and what they really need. Gloucester, MA: Rockport Publishers Inc.

Papanek, V. (1971). Design for the real world: Human ecology and social change (Vol. 1st ed.). Chicago: Academy Chicago Publishers.

Parekh, N. (2014, February 18). (A. Cox, Interviewer) Kasese, Uganda.

Peter, B. (2014, February 18). (A. Cox, Interviewer) Kasese, Uganda.

Pilloton, E. (2009). Design revolution: 100 products that empower people. New York, NY, USA: Metropolis Books.

Polak, P. (2009). Out of poverty: what works when traditional approaches fail. San Francisco, CA: Berrett-Koehler Publishers.

Prahalad, C. K. (2006). The fortune at the bottom of the pyramid. Philadelphia, PA: Wharton School Publisher. 
Renno, D. C., Twinamasiko, J., \& Mugisa, C. P. (2012). Kasese district poverty profiling and mapping 2011-2012. Kasese: Kasese District Local Government.

Robert, B. (2014, February 17). (A. Cox, Interviewer) Kasese, Uganda.

Sachs, J. (2005). The end of poverty: Economic possibilities for our time. New York, NY: Penguin Books.

Saldaña, J. (2013). The coding manual for qualitative researchers (Second Edition ed.). London: SAGE Pubications Ltd.

Salim. (2014, February 18). (A. Cox, Interviewer, \& B. Peter, Translator) Kasese, Uganda.

Sanders, E. B., \& Strappers, P. J. (2008). Co-creation and the new landscapes of design. CoDesign, 4(1), 5-18.

Sheffield, J. R. (October 1979). [Review of the book The African Artisan, by K. King]. Comparative Education Review, 23 (1).p. 470. Retrieved April 18, 2014, from http://www.jstor.org.proxy.library.carleton.ca/stable/1187616

Shwartz, K. D., Park, Y.-Y., \& Rebecca, S. (2011). Partnership for research on Ugandan women with disabilities: Final technical report. Winnipeg: Canadian Centre on Disability Studies.

Singer, P. (2009). The life you can save. New York, NY: Random House Publishing Group.

Smith, C. E. (2007). Design for the other 90\% (Vol. 1st ed.). New York, NY: Cooper-Hewitt, National Design Museum, Smithsonian Organization.

Smithsonian - Cooper-Hewitt National Design Museum. (2012a, January 5). Drip irrigation system. Retrieved December 15, 2013, from Design for the other $90 \%$ : http:/www.designother90.org/solution/drip-irrigation-system/

Smithsonian - Cooper-Hewitt National Design Museum. (2012b, January 5). Jaipur foot and below-knee prothesis. Retrieved December 15, 2013, from Design for the other $90 \%$ : http://www.designother90.org/solution/jaipur-foot-and-belowknee-prosthesis/

Smithsonian - Cooper-Hewitt National Design Museum. (2012c, January 5). One laptop per child. Retrieved December 15, 2013, from Design for the other 90\%: http://www.designother90.org/solution/one-laptop-per-child/

Stanford University. (2012). Design for extreme affordability. Retrieved April 19, 2014, from Stanford University: http://extreme.stanford.edu/

The Australian Centre for Social Innovation. (2013). Our co-design approach. Retrieved April 19, 2014, from Bold ideas. Better lives. - The Australian centre for social innovation: http://www.tacsi.org.au/services/co-design/ 
The Republic of Uganda - Ministry of Health. (2013). Annual health sector performance report: Financial year 2012/2013.

Toledano, A. (2014, January 30). File:Hospital de la Cruz Roja Córdoba - Sillas de ruedas.jpg. Retrieved May 3, 2014, from Wikimedia commons:

http://commons.wikimedia.org/wiki/File:Hospital_de_la_Cruz_Roja_C\%C3\%B3rdoba__Sillas_de_ruedas.jpg

Tufte, T., \& Mefalopulos, P. (2009). Participatory communicaton: A practical guide. Washington, DC: The World Bank.

UN Secretary General. (2006). Goals, targets and indicators. Retrieved December 14, 2013, from Millenium project: http://www.unmillenniumproject.org/goals/gti.htm\#goal1

United Nations. (2014). The universal declaration of human Rights. Retrieved January 31, 2014, from United Nations: http://www.un.org/en/documents/udhr/

United Nations. (n.d.). Fact sheet on persons with disabilities. Retrieved January 6, 2014, from United Nations enable: Development and human rights for all: http://www.un.org/disabilities/default.asp?id=18

United States Department of Agriculture. (2005, Septmber 23). File: Drip tubes-GAP.jpg. Retrieved May 3, 2014, from Wikimedia commons: http://commons.wikimedia.org/wiki/File:Drip_tubes-GAP.jpg\#file

Whirlwind Wheelchair. (April 2004, April). Feasibility study on production and provision of wheelchairs and tricycles in Uganda. Sinted Health Research.

Williams, C. (2014, February 27). (A. Cox, Interviewer) Ottawa, Ontario, Canada.

Woods, N. (2005). The shifting politics of foreign aid. International Affairs, 81(2), 393-409.

World Bank. (2014a). Disability Overview. Retrieved March 15, 2014, from World Bank: Working for a world free of poverty: http://www.worldbank.org/en/topic/disability/overview

World Bank. (2014b). Measuring poverty. Retrieved March 15, 2014, from World Bank: Working for a world free of poverty: http://www.worldbank.org/en/topic/measuringpoverty

World Bank. (2014c). Poverty overview. Retrieved March 15, 2014, from World Bank: Working for a world free of poverty: http://www.worldbank.org/en/topic/poverty/overview 


\section{GLOSSARY}

Term

Boda-Boda

CanUgan

CBR

DIDK

Ground Nuts

IDRC

KADIWAD

KADUPEDI

Kasese

Matatu

Matoke

NGO

NUDIPU

PWD

READ

UN

UGX

\section{Explanation}

A small motorcycle used as a taxi, which is a very popular method of transport in Uganda.

CanUgan Disability support. An Ottawa based NGO who raises money for the assistive devices which are given out by KADUPEDI.

Community-Based Rehabilitation (can refer to the program or CBR workers, who are health workers who go into the community to assess needs, deal with simple medical issues and refer to clinics or hospitals for more complex issues).

The Design Innovation for Disability in Kasese (DIDK) Project

A type of peanuts that are slightly smaller than North American peanuts and have a redcoloured inside skin. They can be used to make ground-nut/G-nut sauce, which is a very popular local dish, which is pinkish in colour.

International Development Research Center (Ottawa, Canada)

Kasese District Union of Woman with Disabilities

Kasese District Union of People with Disabilities

A region of Uganda in the Western part of the country, on the border of the Democratic Republic of the Congo (DRC). The capital city is Kasese Town.

A large van or mini-bus that are used as taxis or buses in the region, and are often filled with more people than seats.

The term used for bananas (which are a staple food item in the area) whether raw or cooked.

Non-Governmental Organization

National Union of Disabled Persons of Uganda

People with Disabilities

The Research, Education, Accessibility and Design (READ) Initiative at Carleton University

United Nations

Uganda Shillings ( $\$ 1 \mathrm{CAN}=$ approx. 2,200 UGX) 
Appendix A

\section{Timelines}




\section{A.1 Timeline for the Project}

\begin{tabular}{|l|l|}
\hline Time Period & Activity \\
\hline Before & - Started learning about the fourth year students' projects from 2012/2013 \\
September 2013 & - Began to look at the literature \\
& - Margaret was given her tricycle with solar-charging attachment \\
\hline September 2013 & - Proposed thesis plan and direction \\
\hline November 2013 & - Project planning started \\
& - Began discussions with CanUgan and KADUPEDI
\end{tabular}

\section{A.2 Timeline for Field-Work}

\begin{tabular}{|c|c|}
\hline Day & Activity \\
\hline Saturday, February 8, 2014 & - Left Canada \\
\hline Sunday, February 9, 2014 & - $\quad$ Arrived in Uganda \\
\hline Monday, February 10, 2014 & - Acclimatized to Uganda \\
\hline Tuesday, February 11, 2014 & $\begin{array}{l}\text { - Met with Makerere University (large meeting with } \\
\text { Engineering and Fine Arts Departments, plus tour of the } \\
\text { school) } \\
\text { - Met with Kyambogo University (Dean and professors from } \\
\text { the School of Disability studies) }\end{array}$ \\
\hline Wednesday, February 12, 2014 & $\begin{array}{l}\text { - Travelled from Kampala to Kasese } \\
\text { - Met with representatives from KADUPEDI (Robert and } \\
\text { Peter) at hotel to discuss plan for while in Kasese }\end{array}$ \\
\hline Thursday, February 13, 2014 & $\begin{array}{l}\text { - First meeting with Kio (Manufacturer) } \\
\text { - } 4^{\text {th }} \text { year students worked with the manufacturer } \\
\text { - } \quad \text { Conversations with Bjarki and Kio about changes to the } \\
\text { solar-charging device since last year } \\
\text { - } \quad \text { Interviewed Peter, Robert (KADUPEDI) and Navin } \\
\text { (CanUgan) about Kio (manufacturer) } \\
\text { - Interviews with Fauza (Solar-charging Tricycle Recipient) }\end{array}$ \\
\hline
\end{tabular}




\begin{tabular}{|c|c|}
\hline & and Mark (Potential Recipient) - outside their homes \\
\hline Friday, February 14, 2014 & $\begin{array}{l}\text { - } 4^{\text {th }} \text { year students worked with the manufacturer } \\
\text { Interviews with Doreen, Maria and Moses (at Kio's shop) - } \\
\text { Potential Recipients } \\
\text { - Workshop with various stakeholders at our hotel } \\
\text { (government representatives, Makerere University } \\
\text { student/professors, Carleton University students/professor, } \\
\text { CanUgan, KADUPEDI, other local disability organizations, } \\
\text { the manufacturer and a device recipient) }\end{array}$ \\
\hline Saturday, February 15, 2014 & $\begin{array}{l}\text { - } \begin{array}{l}\text { Explored the area (time off while manufacturer works on } \\
\text { devices) }\end{array} \\
\end{array}$ \\
\hline Sunday, February 16, 2014 & $\begin{array}{l}\text { - Explored the area (time off while manufacturer works on } \\
\text { devices) } \\
\text { Had meeting with students to go over any concerns and } \\
\text { ensure projects were on track } \\
\text { Created plans on what to accomplish over the next } 2 \\
\text { days in Kasese }\end{array}$ \\
\hline Monday, February 17, 2014 & $\begin{array}{ll}\text { - } & 4^{\text {th }} \text { year students worked with the manufacturer } \\
\text { - } & \text { Interview with Rebecca (Tricycle Recipient) } \\
\text { - } & \text { Interview with Robert (KADUPEDI) } \\
\text { - } & \text { Visited RAP-CD (School for Children with Disabilities) } \\
\text { - } & \text { Visited Peter's (KADUPEDI) college }\end{array}$ \\
\hline Tuesday, February 18, 2014 & $\begin{array}{l}\text { - } 4^{\text {th }} \text { year students worked with the manufacturer } \\
\text { - } \quad \text { Interview with Navin (CanUgan) and Peter (KADUPEDI) } \\
\text { - } \text { Meeting with Navin, Bjarki and Kio about plan for devices } \\
\text { - Interview with Salim (Tricycle Recipient) } \\
\text { - Interview with Kio (Manufacturer) } \\
\text { Interview with Margaret (Solar-charging Tricycle } \\
\text { - } \quad \text { Luncipient) } \\
\end{array}$ \\
\hline Wednesday, February 19, 2014 & - $\quad$ Travelled from Kasese to Kampala \\
\hline Thursday, February 20, 2014 & 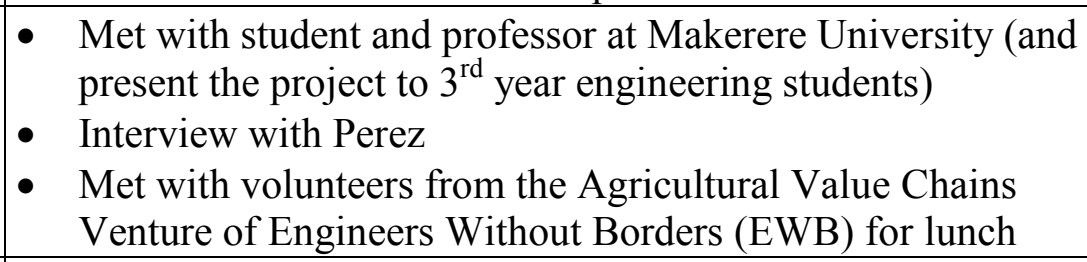 \\
\hline Friday, February 21, 2014 & - Left Uganda \\
\hline Saturday, February 22, 2014 & - Arrived back in Canada \\
\hline
\end{tabular}




\section{Appendix B}

\section{First Questionnaire - Blank (Before Being Given the Device) December 2013}




\section{Questions to Ask Recipients of New Devices}

\section{Before Being Given Device - 2 Pages}

Script for Robert/Peter to read to potential participants before asking questions: Hello, (If they don't know you - We are Peter and Robert from Kadupedi). We are working with a student from Canada who is interested in learning about how people with mobility impairments in Uganda make an income. We have a few tricycles with attachments to distribute, but we wanted to ask everyone a few questions first. The two different attachments include a grinder and a solar-powered charger for cell phones. We hope to distribute a few of each in the next 2 months. The people who are chosen will have to come to Kadupedi every 2 weeks in order to report on their progress with the device. If this is not possible, a representative from Kadupedi can come to your home instead, but you must let them know in advance. They will also be asked more questions about things like their income and their experience with the device. The student from Canada (Amanda) will also come to visit in February to hear about their experiences. Do you have any questions?

Do you mind if we ask you a few questions about your life right now?

FOR ROBERT/PETER: Please ask them the following questions and record their answers. Once the sheet has been filled out, please email it to Amanda (acoxdesign@gmail.com) at your earliest convenience.

Name:

Age:

Gender (male/female):

Where they live (village/sub-county):

Device Received (Grinder Attachment or Solar-Panel Attachment):

Extent, Cause and Length of Disability:

Do they (or anybody in their family) currently work/generate income? If so, doing what, and how much do they earn in a year (estimate)?:

How do they get around now (in the house and around town)?: 
What does their typical day/week look like (household chores, shopping, looking after kids, farming, work, cooking, school/training, etc.)? Does this change with different seasons (e.g. rainy season, dry season)? If so, how?:

Family members (spouse, children, extended relatives they live with, etc.) and their responsibilities (generate income, go to school, help with household tasks, etc.)

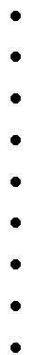

FOR ROBERT/PETER: Find out what their plan is for the device. How are they going to use it, where will they find people to make money from, how will it fit into their day, how much money do they think that they can make, etc. Please write down as much as possible about what they say in a way that they will understand later and will be able to compare it to what actually happens:

Finally, do you have any questions for us or about this project?

Script for Robert/Peter to read to potential participants after taking the survey: Thank you for taking the time to meet with us. We appreciate you answering all of our questions. We have to talk to some other people first, but we will let you know who when we decide who is going to get the attachments. If you have any more questions or concerns please let us know. 


\section{Appendix C}

\section{Second Questionnaire - Blank \\ (After Being Given the Device)}

April 2014 
Name:

Date:

\section{Questions to Ask Solar-Charging Recipients}

1. Was it easy for you to learn how to use it (the tricycle and solar-charger)? Did you need much help?

2. Do you keep track of how much money you make each day? Is that difficult for you?

3. How much money have you been able to make on average, per day, by charging phones? How much do you charge per phone, and how many customers do you normally get?

Average income per day:

Number of customers:

Cost Per Customer:

4. Do you do any other business on the side (making/repairing shoes, selling food, selling clothes, hairdressing, transporting cargo, etc.)? If so, which business(es)?

Yes $\square$ No $\square$ If yes, what business:

5. How much money can you make from your other business?

Average income per day:

Number of customers:

Cost Per Customer:

6. Do you charge phones at home, or at the market? How many days/hours of each?

Home $\square$ Number of days and hours per day:

Market $\square$ Number of days and hours per day:

7. What have you bought with the money you have earned (housing materials, paid for children to go to school/books/uniforms, food, water, business expenses, other)? Please list everything you used the money to buy:

- 
8. Are you now seen differently by your family? How are you treated?

9. Are you now seen differently in the community? How are you treated?

10. Have you had any difficulties/problems with the tricycle/charger?

Yes $\square$ No $\square$ Problems:

11. Are you able to light your home? Yes $\square$ No $\square$

12. How much did you spend before on fuel to light your home (per day/week/month)?

Cost of Fuel (per day/week):

13. What else do you use the electricity for?

-

14. Do you bring the tricycle and solar-charger inside at night?

Yes $\square$ No $\square \quad$ Reason:

15. Did you go to school as a child? Yes $\square \quad$ No $\square$

a) If yes, did you graduate from secondary school? Yes $\square$ No $\square$

b) If not, when did you stop going?

Age/Grade:

c) If you stopped going, what was the reason (to work, not enough money, difficult to get there, social stigma, etc.)?

Reason:

Peter/Robert - Please take a picture or scan their accounting records (all pages)

Peter/Robert - Please take a few pictures of them with their device 


\section{Appendix D}

\section{Recipient Selection}




\section{D.1 Original CanUgan Criteria}

- Have a physical disability (mobility impairment)

- Be in need of assistance (not currently have a properly functioning device, or be able to buy one on their own)

- Must be medically assessed (to ensure they are able to use the tricycle, and would benefit from it)

- Equality between men and women

- People of all ages

- Recipients should come from different areas (sub-counties), including both urban and rural area

\section{D.2 Revised Criteria (for Solar-Charging Devices)}

- Have a physical disability (mobility impairment)

- Be in need of assistance (not currently have a properly functioning device, or be able to buy one on their own)

- Must be medically assessed (to ensure they are able to use the tricycle, and would benefit from it)

- Equality between men and women

- People of all ages

- Recipients should live close to KADUPEDI or be able to travel to KADUPEDI often for follow-up questions and interviews

- Have some business planning (not formal, but can articulate what they will do with the device) 


\section{Appendix E}

\section{Interview Guide (Sample Questions)}




\section{E.1 Questions for Recipients with a Tricycle and Solar-Charging Device (2 people)}

\section{Lifestyle}

1. What is your disability?

a. When did you become disabled?

2. Who do you live with?

a. Do you have any children?

i. If so, how old are they, and are they in school?

3. Do you have running water in your home?

4. Do you have electricity in your home?

a. Is there electricity available in your community?

i. If so, how often does it go out?

5. Do you have a farm?

a. Do you sell any, or have to buy any additional food to feed your family?

i. If you sell it, how much are you able to make?

6. Has anything in your life changed (mobility, social, etc.)?

7. Has your typical week changed?

8. Have you been able to do any new activities since receiving the tricycle?

\section{Income-Generation}

9. How much money have you made with the device?

10. What do you use the money for?

11 . Who are your customers?

a. Do you travel (e.g. to a market) to do business, or do you do it from home?

b. How many days/hours per day do you spend on your business?

2. Are there other people offering mobile-phone charging in your area?

a. If so, where are they and how much do they charge?

12. Do you have any other businesses?

a. If so, what is it, and how much can you make per day/week/month?

13. Do you use the solar-charger for anything besides business (such as lighting your house)?

14. Would you still want the solar-charging device if you had to pay for it?

\section{Device}

15. Have you had any problems or difficulties with the device?

16. Do you have to do any maintenance (such as replacing the wheels)?

a. How often and how much does that cost?

b. Who does this maintenance?

17. Is there anything you would change?

18 . Do you have any comments or questions for me? 


\section{E.2 Questions for Recipients with a Tricycle (2 people)}

\section{Lifestyle}

1. What is your disability?

a. When did you become disabled?

2. Who do you live with?

a. Do you have any children?

i. If so, how old are they, and are they in school?

3. Do you have running water in your home?

4. Do you have electricity in your home?

a. Is there electricity available in your community?

i. If so, how often does it go out?

5. Do you have a farm?

a. Do you sell any, or have to buy any additional food to feed your family?

i. If you sell it, how much are you able to make?

6. Has anything in your life changed (mobility, social, etc.) since receiving the tricycle?

7. Has your typical week changed since receiving the tricycle?

8. Have you been able to do any new activities since receiving the tricycle?

\section{Income-Generation}

9. Do you have a business?

a. If so, what is it, and how much can you make per day/week/month?

\section{Device}

10. Have you had any problems or difficulties with the device?

11. Do you have to do any maintenance (such as replacing the wheels)?

a. How often and how much does that cost?

b. Who does this maintenance?

12. Is there anything you would change?

13. Do you have any comments or questions for me?

\section{E.3 Questions for Potential Recipients (4 people)}

\section{Lifestyle}

1. What is your disability?

a. When did you become disabled?

2. Who do you live with?

a. Do you have any children?

i. If so, how old are they, and are they in school?

3. How do you get around now?

4. Do you have running water in your home?

5. Do you have electricity in your home? 
a. Is there electricity available in your community?

i. If so, how often does it go out?

6. Do you have a farm?

a. Do you sell any, or have to buy any additional food to feed your family?

i. If you sell it, how much are you able to make?

7. How are you seen in your family/community due to your disability?

8. What is your typical week like?

9. Are there any activities you cannot currently do now that you would be able to do after receiving the tricycle?

\section{Income-Generation}

10. Do you have a business?

a. If so, what is it, and how much can you make per day/week/month?

11. If you get the solar-charging device, what is your plan (where would you use it, how would you get customers, how much would you charge, etc.)?

12. Are there other people offering mobile-phone charging in your area?

a. If so, where are they and how much do they charge?

13. What would you use the money for?

14. Would you still want the solar-charging device if you had to pay for it?

15 . Do you have any comments or questions for me?

\section{E.4 Questions for CanUgan (1 person)}

1. What were your overall impressions with the project?

a. Is there anything you would change?

b. Is there anything that went really well, which you would hope continues?

2. How do you think the new projects are going?

a. How would you compare them to last year's projects?

3. What are your hopes for the future?

4. What is CanUgan's goal or mission statement?

a. What are the plans for the future?

5. How does CanUgan make decisions about funding?

a. Do you anticipate the funding increasing/decreasing in the future?

b. What would you change is funding levels changed?

6. Are you okay with the current process of collecting data from recipients and choosing recipients (by KADUPEDI)?

7. How do you feel about the idea of making people pay for their own income-generating devices?

8. Have you thought about who you will give the devices to and have you have you promised them the devices already?

9. Do you have any comments or questions for me? 


\section{E.5 Questions for KADUPEDI (2 people)}

1. What were your overall impressions with the project?

a. Is there anything you would change?

b. Is there anything that went really well, which you would hope continues?

2. How do you think the new projects are going?

3. Have you learned anything from this process?

a. Has anything within KADUPEDI or the community changes as result of this project?

4. Did you find any issues in the process?

a. Did you have any issues filling out the questionnaires?

5. Was it difficult to decide on recipients?

a. What were your criteria?

i. Is the emphasis on mobility or income?

b. What do you think is the right way to decide on who gets the devices?

6. Do you think recipients should have to pay for (or at least contribute) to get incomegenerating devices?

a. If so, how much? And how will you decide?

7. Are the recipients currently keeping accounting records?

a. Do you think this is a reasonable thing to ask?

8. Do you have any comments or questions for me?

\section{E.6 Questions for the Manufacturer (1 person)}

1. Have you learned anything from working with the students?

a. Can you give me some examples?

b. Have you changed the way you've done anything?

2. What do you think needs to be improved in the designs or processes?

3. What did you do before you were working with KADUPEDI?

4. Do you think that CanUgan will continue ordering tricycles?

a. If they stop, what will you do?

b. If they have more demand what will you do?

c. Can you train people to build or repair tricycles?

i. Would you like to do that?

5. Where do you see yourself 5 years from now?

6. Do you have any comments or questions for me? 


\section{E.7 Questions for Students (3 people)}

1. How do you feel about the project in general?

2. What was it like to work with the students at the other university?

3. Did you learn anything from this project?

a. Can you give some examples?

b. Will you do anything differently because of this project in the future?

4. What challenges did you have in the process?

a. How would you suggest fixing some of the problems for similar project in the future?

5. Did anything go really well?

6. Why did you choose this project?

a. What were your expectations?

b. (For Perez) Why didn't other students want this project?

i. Why did other students drop out of the project?

7. Do you think it is worth continuing the project in the future?

a. How could we make it more successful?

8. Do you have any comments or questions for me? 
Appendix F

Summary of Recipient Information from First Questionnaire 
*The red text and question marks indicates information that was not provided on the questionnaire and needed to be clarified during the in-person interviews.

\begin{tabular}{|c|c|c|c|c|c|c|c|c|c|c|c|}
\hline Name & Gender & Age & Region & $\begin{array}{l}\text { Type of } \\
\text { Disabilitiy }\end{array}$ & $\begin{array}{l}\text { When Disability } \\
\text { was Acquired }\end{array}$ & Current Responsibilities & Name & Family Members & $\begin{array}{l}\text { How Does Their Family } \\
\text { Currently Make Money }\end{array}$ & $\begin{array}{l}\text { How They Currently Get } \\
\text { Around }\end{array}$ & Status \\
\hline Biira Margaret & Female & 30. & $? ?$ & $? ?$ & thos & $\begin{array}{l}\text { - Work around the home } \\
\text { - Cooking for the family } \\
\text { Not much time for phone } \\
\text { charging (big family) } \\
\end{array}$ & Biira Margaret & $f+\frac{1}{4}$ & $y_{1}$ & (n) & $\begin{array}{l}\text { Received Device } \\
\text { (June 2013) }\end{array}$ \\
\hline Baluku S. Fauza & Male & 35 & $\begin{array}{l}\text { Kizungu- } \\
\text { Nyamwamba } \\
\text { Division }\end{array}$ & $\begin{array}{l}\text { Some type of } \\
\text { sickness (took } \\
\text { too long to go to } \\
\text { hospital) }\end{array}$ & 19 Years Old & $\begin{array}{l}\text { - Works (only one in the } \\
\text { family) }\end{array}$ & Baluku S. Fauza & \begin{tabular}{|l|} 
- Baluku Fauza (head of family) \\
- Biira Swazi (Wife, cares for home \\
- Mumbere Haruna (in school) \\
- Muhindo Husina (primary school) - \\
Mabiira Elia (in school)
\end{tabular} & $\begin{array}{l}\text { - He works at home } \\
\text { (repairing shoes) }\end{array}$ & \begin{tabular}{|l|} 
- Crippling (at home) - \\
Usesgloves/slippers \\
during rainy season \\
- Takes a boda-boda (to \\
town)
\end{tabular} & $\begin{array}{l}\text { Received Device } \\
\text { (Jan 2014) }\end{array}$ \\
\hline $\begin{array}{l}\text { Bwambale Saldi } \\
\text { Ribomderya }\end{array}$ & Male & & $\begin{array}{l}\text { Kizungu- } \\
\text { Nyamwamba } \\
\text { Division }\end{array}$ & $\begin{array}{l}\text { Gunshot } \\
\text { (confined in a } \\
\text { seat) }\end{array}$ & $\begin{array}{l}27 \text { Years Old } \\
\text { (ago?) }\end{array}$ & - Works & $\begin{array}{l}\text { Bwambale Saldi } \\
\text { Ribomderya }\end{array}$ & $\begin{array}{l}\text { - Muhindo Regina (hou sewife) } \\
\text { - Muhindo Moses } \\
\text { - B wambale Moris } \\
\text { - Kule Simons } \\
\end{array}$ & $\begin{array}{l}\text { Maintenance/contracting? } \\
\text { Works } 10 \mathrm{~km} \text { away } \\
(1,200,000 \text { Uganda Shillings } \\
\text { per year }) \\
\end{array}$ & \begin{tabular}{|l|} 
Has an old wheelchair \\
(difficult during rainy \\
season to get to work - \\
no helper)
\end{tabular} & Potential User \\
\hline Masika Doreen & Female & 22 & $\begin{array}{l}\text { Kisojo Maliba Sub- } \\
\text { County }\end{array}$ & Polio & Age 5 & \begin{tabular}{|l|} 
- Keeping the home \\
Likes church \\
Wants to go to nearby \\
Trading Market \\
\end{tabular} & Masika Doreen & $\begin{array}{l}\text { Bvauhanga John (Father) - Sickly } \\
\text { Bjaruhanga Reginah (Mother) }\end{array}$ & Doesn't...?? & $\begin{array}{l}\text { Crippling on the ground } \\
\text { (stayshome) }\end{array}$ & Potential User \\
\hline $\begin{array}{l}\text { Muchanga Maria } \\
\text { Gorret }\end{array}$ & Female & 30 & $\begin{array}{l}\text { Kikongo-Hima } \\
\text { Town Council }\end{array}$ & $? ?$ & Birth & $\begin{array}{l}\text { - Food Vendor (wants to } \\
\text { attract more customer s) } \\
\text { - Likes to socialize at church } \\
\end{array}$ & $\begin{array}{l}\text { Muchanga Maria } \\
\text { Gorret }\end{array}$ & \begin{tabular}{|l} 
- Mutongonia Tereza (Sister) \\
Aguma Diadone (Brother) \\
Kacinga Oliver (Sister) \\
\end{tabular} & $\begin{array}{l}\text { Involved in petty bu siness } \\
\text { (food vendor) }\end{array}$ & \begin{tabular}{|l}
-Crippling on the \\
ground (at home) \\
Brother take sher on \\
bike (around town) \\
\end{tabular} & Potential User \\
\hline $\begin{array}{l}\text { Byaruhanga } \\
\text { Moses }\end{array}$ & Male & 19 & $\begin{array}{l}\text { Ibanba II Vialge - } \\
\text { Bugove }\end{array}$ & $? ?$ & $\begin{array}{l}\text { Primary Seven } \\
\text { (age?) }\end{array}$ & $\begin{array}{l}\text { - Local farming } \\
\text { Wants to go back to school } \\
\text { (needs to buy books) }\end{array}$ & Byaruhanga Moses & $\begin{array}{l}\text { - Byarulanga Pascal (Father) } \\
\text { - Mbambu Byarulanga (Mother) } \\
\text { (Both Farmers) }\end{array}$ & $\begin{array}{l}\text { Father - Retired Soldier } \\
\text { (training) } \\
\text { - Farming (sell harvest) }\end{array}$ & $\begin{array}{l}\text { Crippling on the ground } \\
\text { (stayshome) }\end{array}$ & Potential User \\
\hline $\begin{array}{l}\text { Thamwanza Mark } \\
\text { Jotton }\end{array}$ & Male & & $\begin{array}{l}\text { Rabatunda- } \\
\text { Ryabarmgira Sub } \\
\text { country }\end{array}$ & Polio & Age 3 & $? ?$ & $\begin{array}{l}\text { Thamwanza Mark } \\
\text { Jotton }\end{array}$ & $\begin{array}{l}\text { - Bwambale Charles (Father) } \\
\text { - Biira Yoniva (Mother) } \\
\text { - Bwambale Joel (Brother) } \\
\text { - Muhinda Julia (Sister) } \\
\text { - Masereka Rabisan (Brother) } \\
\text { - Biira Zaneti (Sister) }\end{array}$ & $\begin{array}{l}\text { - Peasent Farming (approx. } \\
\text { 2,000/day) - } \\
\text { More crops during rainy } \\
\text { season (twice/vear) }\end{array}$ & $\begin{array}{l}\text { Old tricyde helpshim } \\
\text { get around town }\end{array}$ & Potential User \\
\hline
\end{tabular}




\section{Appendix G}

\section{Accounting Records}




\section{G.1 Fauza's Accounting Records}

*Fauza charges 500 UGX for each phone

\begin{tabular}{|c|c|c|c|c|c|c|}
\hline \multicolumn{2}{|l|}{ Date } & $\begin{array}{l}\text { Number of } \\
\text { Customers/ } \\
\text { Phones } \\
\text { Charged }\end{array}$ & $\begin{array}{l}\text { Income } \\
\text { Earned }\end{array}$ & Date & $\begin{array}{l}\text { Number of } \\
\text { Customers/ } \\
\text { Phones } \\
\text { Charged }\end{array}$ & Income Earned \\
\hline 16-Jan-14 & 5 & \multicolumn{2}{|c|}{2500} & 01-Feb-14 & 7 & 3500 \\
\hline 17-Jan-14 & 6 & \multicolumn{2}{|c|}{3000} & 02-Feb-14 & 5 & 2500 \\
\hline 18-Jan-14 & 4 & \multicolumn{2}{|c|}{2000} & 03-Feb-14 & 4 & 2000 \\
\hline 19-Jan-14 & 6 & \multicolumn{2}{|c|}{3000} & 04-Feb-14 & 6 & 3000 \\
\hline 20-Jan-14 & 7 & \multicolumn{2}{|c|}{3500} & 05-Feb-14 & 3 & 1500 \\
\hline 21-Jan-14 & 3 & \multicolumn{2}{|c|}{1500} & 06-Feb-14 & 2 & 1000 \\
\hline 22-Jan-14 & 4 & \multicolumn{2}{|c|}{2000} & 07-Feb-14 & 4 & 2000 \\
\hline 23-Jan-14 & 2 & \multicolumn{2}{|c|}{1000} & 08-Feb-14 & 1 & 500 \\
\hline 24-Jan-14 & 3 & \multicolumn{2}{|c|}{1500} & 09-Feb-14 & 7 & 3500 \\
\hline 25-Jan-14 & 4 & \multicolumn{2}{|c|}{2000} & 10-Feb-14 & 6 & 3000 \\
\hline 26-Jan-14 & 1 & \multicolumn{2}{|c|}{500} & 11-Feb-14 & 5 & 2500 \\
\hline 27-Jan-14 & 2 & \multicolumn{2}{|c|}{1000} & 12-Feb-14 & 3 & 1500 \\
\hline 28-Jan-14 & 6 & \multicolumn{2}{|c|}{3000} & 13-Feb-14 & 4 & 2000 \\
\hline 29-Jan-14 & 4 & \multicolumn{2}{|c|}{2000} & \multicolumn{2}{|c|}{ Total for January } & 28500 \\
\hline 30-Jan-14 & 5 & \multicolumn{2}{|c|}{2500} & & & \\
\hline 31-Jan-14 & 6 & \multicolumn{2}{|c|}{3000} & & & \\
\hline \multicolumn{2}{|c|}{ Total for January } & & 000 & & & \\
\hline & & & $\begin{array}{l}\text { al Earned i } \\
\text { Ionth }(29 \mathrm{c}\end{array}$ & $\begin{array}{l}\text { imately } \\
\text { Sx }\end{array}$ & 500 & \\
\hline & & & $\begin{array}{l}\text { al Earned } \\
\text { lonth }(29 \mathrm{c}\end{array}$ & $\begin{array}{l}\text { imately } \\
A D\end{array}$ & 6.88 & \\
\hline & & & rage per [ & & 55.17 & \\
\hline & & & rage per $D$ & & 93 & \\
\hline
\end{tabular}




\section{G.2 Margaret's Accounting Records}

* Margaret charges 300 UGX for each phone

*Dates with a 0 either had a "?" or were skipped in the ledger

\begin{tabular}{|c|c|c|}
\hline Date & $\begin{array}{l}\text { Number of } \\
\text { Customers/ } \\
\text { Phones } \\
\text { Charged }\end{array}$ & $\begin{array}{l}\text { Income } \\
\text { Earned }\end{array}$ \\
\hline 01-Oct-13 & 2 & 600 \\
\hline $02-$-Oct-13 & 4 & 1200 \\
\hline $03-O c t-13$ & 1 & 300 \\
\hline 04-Oct-13 & 3 & 900 \\
\hline 05-Oct-13 & 4 & 1200 \\
\hline $06-$-oct-13 & 0 & 0 \\
\hline 07-Oct-13 & 1 & 300 \\
\hline $08-O c t-13$ & 1 & 300 \\
\hline 09-Oct-13 & 2 & 600 \\
\hline $10-$ Oct-13 & 3 & 900 \\
\hline $11-$ Oct-13 & 4 & 1200 \\
\hline $12-$ Oct-13 & 0 & 0 \\
\hline 13-Oct-13 & 1 & 300 \\
\hline 14-Oct-13 & 0 & 0 \\
\hline $15-$ Oct-13 & 0 & 0 \\
\hline 16-Oct-13 & 1 & 300 \\
\hline 17-Oct-13 & 2 & 600 \\
\hline $18-$ Oct-13 & 0 & 0 \\
\hline 19-Oct-13 & 0 & 0 \\
\hline 20-Oct-13 & 0 & 0 \\
\hline 21-Oct-13 & 1 & 300 \\
\hline 22-Oct-13 & 2 & 600 \\
\hline 23-Oct-13 & 4 & 1200 \\
\hline $24-O c t-13$ & 0 & 0 \\
\hline 25-Oct-13 & 0 & 0 \\
\hline 26-Oct-13 & 2 & 600 \\
\hline $27-$ Oct-13 & 1 & 300 \\
\hline $28-$ Oct-13 & 2 & 600 \\
\hline 29-Oct-13 & 4 & 1200 \\
\hline 30-Oct-13 & 1 & 300 \\
\hline 31-Oct-13 & 2 & 600 \\
\hline \multicolumn{2}{|c|}{ Total for October } & 14400 \\
\hline
\end{tabular}

\begin{tabular}{|c|c|c|}
\hline Date & $\begin{array}{l}\text { Number of } \\
\text { Customers/ } \\
\text { Phones } \\
\text { Charged }\end{array}$ & $\begin{array}{l}\text { Income } \\
\text { Earned }\end{array}$ \\
\hline 01-Nov-13 & 1 & 300 \\
\hline 02-Nov-13 & 2 & 600 \\
\hline 03-Nov-13 & 1 & 300 \\
\hline 04-Nov-13 & 2 & 600 \\
\hline 05-Nov-13 & 4 & 1200 \\
\hline 06-Nov-13 & 3 & 900 \\
\hline 07-Nov-13 & 1 & 300 \\
\hline 08-Nov-13 & 0 & 0 \\
\hline 09-Nov-13 & 1 & 300 \\
\hline 10-Nov-13 & 0 & 0 \\
\hline 11-Nov-13 & 0 & 0 \\
\hline 12-Nov-13 & 1 & 300 \\
\hline 13-Nov-13 & 2 & 600 \\
\hline 14-Nov-13 & 0 & 0 \\
\hline 15-Nov-13 & 4 & 1200 \\
\hline 16-Nov-13 & 0 & 0 \\
\hline 17-Nov-13 & 1 & 300 \\
\hline 18-Nov-13 & 2 & 600 \\
\hline 19-Nov-13 & 3 & 900 \\
\hline 20-Nov-13 & 1 & 300 \\
\hline 21-Nov-13 & 0 & 0 \\
\hline 22-Nov-13 & 0 & 0 \\
\hline 23-Nov-13 & 3 & 900 \\
\hline 24-Nov-13 & 1 & 300 \\
\hline 25-Nov-13 & 0 & 0 \\
\hline $26-N o v-13$ & 1 & 300 \\
\hline 27-Nov-13 & 0 & 0 \\
\hline 28-Nov-13 & 1 & 300 \\
\hline 29-Nov-13 & 2 & 600 \\
\hline 30-Nov-13 & 1 & 300 \\
\hline \multicolumn{2}{|c|}{ Total for November } & 11400 \\
\hline
\end{tabular}




\begin{tabular}{|c|c|c|}
\hline Date & $\begin{array}{l}\text { Number of } \\
\text { Customers/ } \\
\text { Phones } \\
\text { Charged }\end{array}$ & $\begin{array}{l}\text { Income } \\
\text { Earned }\end{array}$ \\
\hline 01-Dec-13 & 1 & 300 \\
\hline 02-Dec-13 & 2 & 600 \\
\hline 03-Dec-13 & 1 & 300 \\
\hline 04-Dec-13 & 0 & 0 \\
\hline 05-Dec-13 & 0 & 0 \\
\hline 06-Dec-13 & 1 & 300 \\
\hline 07-Dec-13 & 2 & 600 \\
\hline 08-Dec-13 & 1 & 300 \\
\hline 09-Dec-13 & 2 & 600 \\
\hline 10-Dec-13 & 3 & 900 \\
\hline 11-Dec-13 & 4 & 1200 \\
\hline 12-Dec-13 & 1 & 300 \\
\hline 13-Dec-13 & 0 & 0 \\
\hline 14-Dec-13 & 0 & 0 \\
\hline 15-Dec-13 & 0 & 0 \\
\hline 16-Dec-13 & 2 & 600 \\
\hline 17-Dec-13 & 1 & 300 \\
\hline 18-Dec-13 & 2 & 600 \\
\hline 19-Dec-13 & 1 & 300 \\
\hline 20-Dec-13 & 0 & 0 \\
\hline 21-Dec-13 & 0 & 0 \\
\hline 22-Dec-13 & 2 & 600 \\
\hline 23-Dec-13 & 2 & 600 \\
\hline 24-Dec-13 & 4 & 1200 \\
\hline 25-Dec-13 & 4 & 1200 \\
\hline 26-Dec-13 & 3 & 900 \\
\hline 27-Dec-13 & 2 & 600 \\
\hline 28-Dec-13 & 1 & 300 \\
\hline 29-Dec-13 & 2 & 600 \\
\hline 30-Dec-13 & 1 & 300 \\
\hline 31-Dec-13 & 2 & 600 \\
\hline \multicolumn{2}{|c|}{ Total for December } & 14100 \\
\hline \multicolumn{3}{|c|}{ *Note: Repairing my tricycle } \\
\hline
\end{tabular}

\begin{tabular}{|l|l|l|}
\hline Date & $\begin{array}{l}\text { Number of } \\
\text { Customers/ } \\
\text { Phones } \\
\text { Charged }\end{array}$ & $\begin{array}{l}\text { Income } \\
\text { Earned }\end{array}$ \\
\hline 01-Jan-14 & 1 & 300 \\
\hline 02-Jan-14 & 2 & 600 \\
\hline 03-Jan-14 & 0 & 0 \\
\hline 04-Jan-14 & 0 & 0 \\
\hline 05-Jan-14 & 2 & 600 \\
\hline 06-Jan-14 & 1 & 300 \\
\hline 07-Jan-14 & 2 & 600 \\
\hline 08-Jan-14 & 0 & 0 \\
\hline 09-Jan-14 & 0 & 0 \\
\hline 10-Jan-14 & 1 & 300 \\
\hline 11-Jan-14 & 2 & 600 \\
\hline 12-Jan-14 & 0 & 0 \\
\hline 13-Jan-14 & 0 & 0 \\
\hline 14-Jan-14 & 0 & 0 \\
\hline 15-Jan-14 & 3 & 900 \\
\hline 16-Jan-14 & 1 & 300 \\
\hline 17-Jan-14 & 0 & 0 \\
\hline 18-Jan-14 & 4 & 1200 \\
\hline 19-Jan-14 & 0 & 0 \\
\hline 20-Jan-14 & 1 & 300 \\
\hline 21-Jan-14 & 2 & 600 \\
\hline 22-Jan-14 & 1 & 300 \\
\hline 23-Jan-14 & 2 & 600 \\
\hline 24-Jan-14 & 1 & 300 \\
\hline 25-Jan-14 & 0 & 0 \\
\hline 26-Jan-14 & 0 & 0 \\
\hline 27-Jan-14 & 1 & 300 \\
\hline 28-Jan-14 & 0 & 0 \\
\hline 29-Jan-14 & 0 & 000 \\
\hline 30-Jan-14 & 4 & 1 \\
\hline 31-Jan-14 & 1 & 0 \\
\hline Total for January & 0 \\
\hline
\end{tabular}




\begin{tabular}{|l|l|l|}
\hline Date & $\begin{array}{l}\text { Number of } \\
\text { Customers/ } \\
\text { Phones } \\
\text { Charged }\end{array}$ & $\begin{array}{l}\text { Income } \\
\text { Earned }\end{array}$ \\
\hline 01-Feb-14 & 1 & 300 \\
\hline $02-$ Feb-14 & 2 & 600 \\
\hline 03-Feb-14 & 0 & 0 \\
\hline 04-Feb-14 & 0 & 0 \\
\hline 05-Feb-14 & 1 & 300 \\
\hline $06-F e b-14$ & 1 & 300 \\
\hline $07-F e b-14$ & 2 & 600 \\
\hline $08-F e b-14$ & 1 & 300 \\
\hline $09-F e b-14$ & 0 & 0 \\
\hline $10-F e b-14$ & 0 & 0 \\
\hline $11-F e b-14$ & 1 & 300 \\
\hline $12-F e b-14$ & 2 & 600 \\
\hline $13-F e b-14$ & 1 & 300 \\
\hline $14-F e b-14$ & 1 & 300 \\
\hline $15-F e b-14$ & 0 & 0 \\
\hline $16-F e b-14$ & 0 & 0 \\
\hline $17-F e b-14$ & 1 & 300 \\
\hline $18-F e b-14$ & 2 & 600 \\
\hline & Total for & \\
\hline & February & 4800 \\
\hline (so far) & \\
\hline
\end{tabular}

\begin{tabular}{|l|l|}
\hline Total Earned in Approximately 4.5 months (141 days) in UGX & 54300 \\
\hline Total Earned in Approximately 4.5 months (141 days) in \$CAD & $\mathbf{\$ 2 3 . 3 5}$ \\
\hline Average per Day in UGX & $\mathbf{3 8 5 . 1 1}$ \\
\hline Average per Day in \$CAD & $\mathbf{\$ 0 . 1 7}$ \\
\hline
\end{tabular}

